\title{
Cochrane
}

Library

Cochrane Database of Systematic Reviews

\section{Aromatherapy for treatment of postoperative nausea and vomiting} (Review)

Hines S, Steels E, Chang A, Gibbons K

Hines S, Steels E, Chang A, Gibbons K.

Aromatherapy for treatment of postoperative nausea and vomiting.

Cochrane Database of Systematic Reviews 2018, Issue 3. Art. No.: CD007598.

DOI: 10.1002/14651858.CD007598.pub3.

www.cochranelibrary.com 
TABLE OF CONTENTS

ABSTRACT

PLAIN LANGUAGE SUMMARY

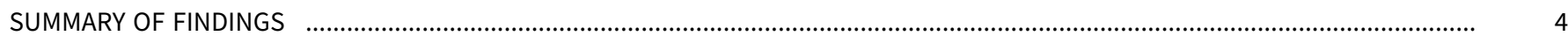

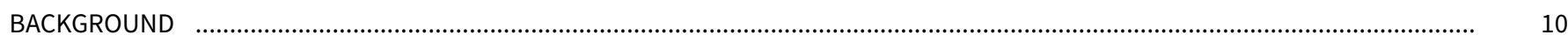

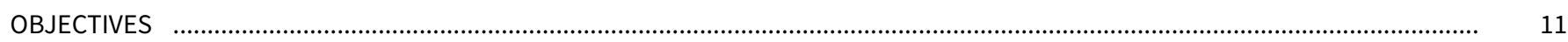

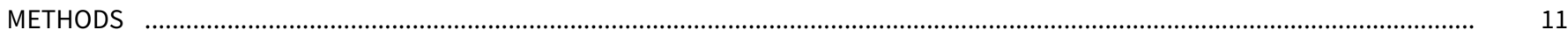

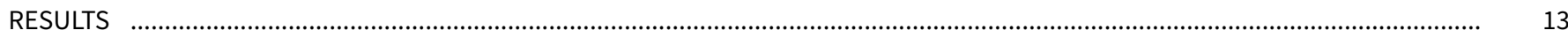

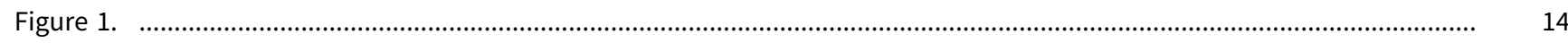

Figure 2.

Figure 3.

DISCUSSION

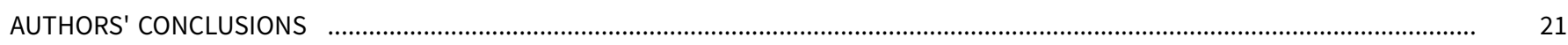

ACKNOWLEDGEMENTS

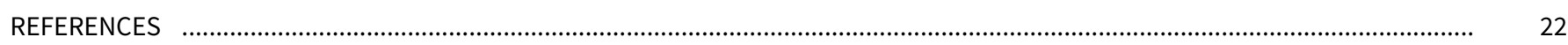

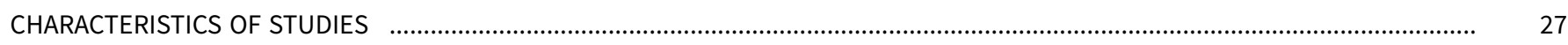

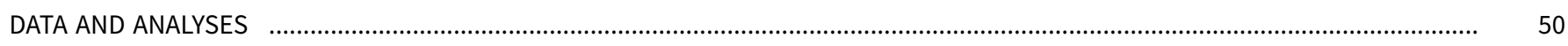

Analysis 1.1. Comparison 1 Aromatherapy versus placebo, Outcome 1 Nausea severity at end of treatment. ........................... 50

Analysis 1.2. Comparison 1 Aromatherapy versus placebo, Outcome 2 Duration of nausea measured as nausea-free at the end 50

of treatment.

Analysis 1.3. Comparison 1 Aromatherapy versus placebo, Outcome 3 Proportion requiring rescue antiemetics. .................... 51

Analysis 2.1. Comparison 2 Peppermint versus placebo, Outcome 1 Nausea severity at 5 minutes post-initial treatment. ........ 51

Analysis 3.1. Comparison 3 Isopropyl alcohol versus standard treatment for PONV, Outcome 1 Time (minutes) to $50 \%$ reduction 52 in nausea score.

Analysis 3.2. Comparison 3 Isopropyl alcohol versus standard treatment for PONV, Outcome 2 Proportion requiring antiemetics.

Analysis 3.3. Comparison 3 Isopropyl alcohol versus standard treatment for PONV, Outcome 3 Patient satisfaction. ................. 52

Analysis 4.1. Comparison 4 Isopropyl alcohol versus saline, Outcome 1 Proportion requiring rescue antiemetics. ................... 53

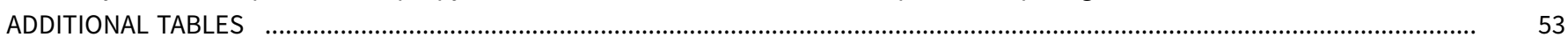

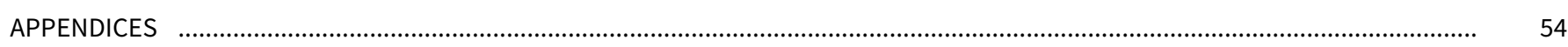

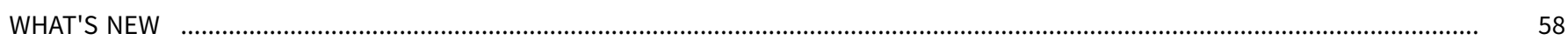

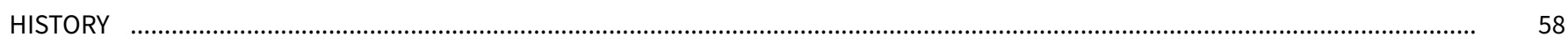

CONTRIBUTIONS OF AUTHORS

DECLARATIONS OF INTEREST

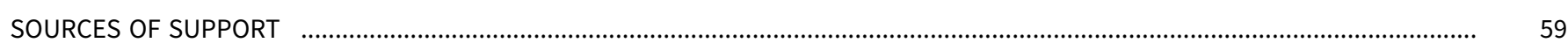

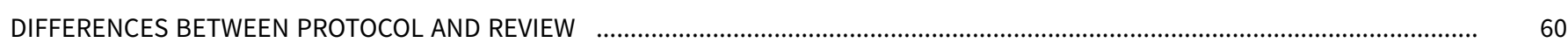

INDEX TERMS 
[Intervention Review]

\section{Aromatherapy for treatment of postoperative nausea and vomiting}

Sonia Hines ${ }^{1}$, Elizabeth Steels ${ }^{2}$, Anne Chang 3 , Kristen Gibbons ${ }^{4}$

1Evidence in Practice Unit, Mater Misericordiae Limited. Queensland Centre for Evidence-Based Nursing \& Midwifery: a Joanna Briggs Centre of Excellence, South Brisbane, Australia. ${ }^{2}$ School of Medical Sciences, The University of Sydney, Medical School, Sydney, Australia. ${ }^{3}$ School of Nursing, Queensland University of Technology, Brisbane, Australia. ${ }^{4}$ Mater Research Institute - The University of Queensland (MRI-UQ), South Brisbane, Australia

Contact: Sonia Hines, Evidence in Practice Unit, Mater Misericordiae Limited. Queensland Centre for Evidence-Based Nursing \& Midwifery: a Joanna Briggs Centre of Excellence, South Brisbane, Australia.sonia.hines@mater.org.au, soniahines@optusnet.com.au.

Editorial group: Cochrane Anaesthesia Group.

Publication status and date: New search for studies and content updated (conclusions changed), published in Issue 3, 2018.

Citation: Hines S, Steels E, Chang A, Gibbons K. Aromatherapy for treatment of postoperative nausea and vomiting. Cochrane Database of Systematic Reviews 2018, Issue 3. Art. No.: CD007598. DOI: 10.1002/14651858.CD007598.pub3.

Copyright () 2018 The Cochrane Collaboration. Published by John Wiley \& Sons, Ltd.

\section{A B S T R A C T}

\section{Background}

Postoperative nausea and vomiting (PONV) is a common, unpleasant phenomenon and current therapies are not always effective for all patients. Aromatherapy has been suggested as an addition to the available treatment strategies. This review was originally published in 2012 and updated in 2017.

\section{Objectives}

The main objective was to establish the efficacy and safety of aromatherapy comparable to standard pharmacological treatments for PONV in adults and children.

\section{Search methods}

We searched CENTRAL; MEDLINE; Embase; CINAHL; CAM on PubMed; Informit; LILACS; and ISI Web of Science as well as grey literature sources and the reference lists of retrieved articles up to March 2017. The original search was performed in August 2011.

\section{Selection criteria}

We included all randomized controlled trials (RCTs) and controlled clinical trials (CCTs) where aromatherapy was used to treat PONV. Interventions were all types of aromatherapy compared to placebo or with standard antiemetics. Primary outcomes were severity and duration of PONV. Secondary outcomes were adverse reactions, use of rescue antiemetics and patient satisfaction.

\section{Data collection and analysis}

Two review authors independently assessed risk of bias in the included studies and extracted data. For dichotomous outcome variables, we used a random-effects model and calculated risk ratio (RR) with associated $95 \%$ confidence interval ( $95 \% \mathrm{Cl}$ ). For continuous outcome variables, we used a random-effects model and calculated standardized mean difference (SMD) with associated 95\% $\mathrm{Cl}$. We used the GRADE software to compile 'Summary of findings' tables.

\section{Main results}

We included seven new studies with 663 participants in the 2017 update; five RCTs and two CCTs. These were added to the nine previously included studies (six RCTs and three CCTs with a total of 373 participants) for a total of 16 included studies and 1036 participants in this updated review. The mean age and range data for all participants were not reported for all studies. We identified two registered trials that met the inclusion criteria for this review; however there are no results for these studies yet. 
Overall, the GRADE assessment of evidence quality ranged from moderate to very low. The method of randomization in 11 of the 12 included RCTs was explicitly stated and adequate. Incomplete or methodologically diverse reporting of data affected the completeness of the analysis. Data on additional aromatherapies were added in the 2017 update (blended aromatherapy products, and peppermint products). Heterogeneity of outcome measures and time points between studies affected the completeness of the analysis.

In the summary of the findings of six studies, we did not find aromatherapy to be effective in reducing nausea severity in comparison to placebo (SMD $-0.22,95 \% \mathrm{Cl}-0.63$ to $0.18, \mathrm{P}$ value $=0.28,241$ participants, level of evidence: low). Those participants receiving aromatherapy were no more likely to be free of nausea at the end of the treatment period than those receiving placebo ( $\mathrm{RR} 3.25,95 \% \mathrm{Cl} 0.31$ to $34.33, \mathrm{P}$ value $=0.33$, 4 trials, 193 participants, evidence level: very low), however they were less likely to require rescue antiemetics (RR 0.60, 95\% $\mathrm{Cl} 0.37$ to 0.97 , $\mathrm{P}$ value $=0.04,7$ trials, 609 participants, evidence level: low). There were no data reported on adverse events or patient satisfaction for this comparison.

A specific comparison of peppermint aromatherapy to placebo did not show evidence of an effect on nausea severity at five minutes posttreatment in the pooled results (SMD $-0.18,95 \% \mathrm{Cl}-0.86$ to $0.49, \mathrm{P}$ value $=0.59,4$ trials, 115 participants, evidence level: low). There were no data reported on nausea duration, use of rescue antiemetics, adverse events or patient satisfaction for this comparison.

When we pooled studies comparing isopropyl alcohol to standard antiemetic treatment in a GRADE summary of findings, in terms of nausea duration, there was a significant effect on the time in minutes to a $50 \%$ reduction in nausea scores (SMD $-1.10,95 \% \mathrm{Cl}-1.43$ to -0.78 , $P$ value $<0.00001,3$ trials, 176 participants, evidence level: moderate). Fewer participants who received isopropyl alcohol required rescue antiemetics (RR $0.67,95 \% \mathrm{Cl} 0.46$ to 0.98 , $\mathrm{P}$ value $=0.04,215$ participants, 4 trials, evidence level: moderate). Two studies with 172 participants measured patient satisfaction; there were high levels of satisfaction across both aromatherapy and standard treatment groups and no differences found (evidence level: low). There were no data reported on nausea severity or adverse events for this comparison.

There was no difference in effectiveness between isopropyl alcohol vapour inhalation and placebo for reducing the proportion of participants requiring rescue antiemetics ( $\mathrm{RR} 0.39,95 \% \mathrm{Cl} 0.12$ to 1.24 , $\mathrm{P}$ value $=0.11,291$ participants, 4 trials, evidence level: very low). There were no data reported on nausea severity, nausea duration, adverse events or patient satisfaction for this comparison.

\section{Authors' conclusions}

Overall, for nausea severity at the end of treatment, aromatherapy may have similar effectiveness to placebo and similar numbers of participants were nausea-free. However, this finding is based on low-quality evidence and therefore very uncertain. Low-quality evidence also suggests that participants who received aromatherapy may need fewer antiemetic medications, but again, this is uncertain. Participants receiving either aromatherapy or antiemetic medications may report similar levels of satisfaction with their treatment, according to low-quality evidence.

\section{PLAIN LANGUAGE SUMMARY}

\section{Aromatherapy for treating postoperative nausea and vomiting}

\section{Review question}

This review sought to evaluate the effect of aromatherapy on the severity and duration of nausea and vomiting experienced by some people immediately after having surgery.

\section{Background}

Postoperative nausea and vomiting (PONV) is a common side effect following surgery, with up to a third of all patients suffering moderate to severe nausea and vomiting following general anaesthesia using inhaled anaesthetics. Nausea is an abdominal discomfort or queasiness that may be accompanied by vomiting. Current pharmaceutical treatments do not always work effectively for people or they may have unpleasant adverse effects. Aromatherapy involves inhalation of the vapour of essential oils or other substances to treat or alleviate physical and emotional symptoms. Aromatherapy is sometimes recommended for treating nausea and vomiting, although currently there is not sufficient evidence to show it is effective. This review is an update of a review previously published in 2012.

\section{Study characteristics}

We examined a total of 16 controlled clinical studies using aromatherapy for PONV with a total of 1036 participants (seven new studies from the March 2017 searches were added to nine studies from the original review). The participants were adults except for two studies in children. The studies applied aromatherapy at the first complaint of nausea in the immediate period after surgery and measured nausea for up to two days. Aromatherapy substances used were isopropyl alcohol (rubbing alcohol), peppermint oil, ginger, or mixtures that included ginger, spearmint, peppermint and cardamom; or lavender, peppermint, ginger, and spearmint oils.

The studies compared aromatherapy to saline or water placebo, controlled breathing, other aromatherapy substances, anti-nausea medications, or a combination of these, with some studies having up to four groups.

\section{Key results}


Overall, aromatherapy was not effective in reducing nausea severity at greater than three minutes after treatment in comparison to saline, water or controlled breathing placebo ( 6 studies with 241 participants) but more participants who received aromatherapy were nausea-free at the end of treatment (4 studies, 193 participants) and fewer participants who received aromatherapy required anti-nausea medications (7 studies with 609 participants).

Peppermint oil did not show an effect on nausea severity at five minutes after treatment (4 studies, 115 participants).

We could not pool data for a comparison of isopropyl alcohol to standard anti-nausea medications for nausea severity. In terms of nausea duration, the time to $50 \%$ relief of symptoms was faster with isopropyl alcohol vapour than with standard antiemetics (ondansetron and promethazine) (3 studies, 176 participants). Aromatherapy using isopropyl alcohol vapour inhalation provided rapid, short-term relief of nausea and reduced the need for rescue anti-nausea drugs (4 studies, 215 participants). Patient satisfaction with aromatherapy appeared high in the four studies that measured this outcome.

Fewer participants who received isopropyl alcohol aromatherapy required rescue anti-nausea drugs compared with those who received saline (4 studies, 291 participants). The participants receiving aromatherapy were not more likely to be free of nausea at the end of the treatment period however they were less likely to require rescue anti-nausea drugs.

All participants in these studies (treatment and comparison groups) reported high levels of satisfaction, possibly indicating that increased attention to the care of postoperative nausea and vomiting improved satisfaction with their care. Aromatherapy may provide a useful therapeutic option, particularly when the alternative is no treatment at all.

None of the included studies reported adverse effects from the aromatherapies used.

\section{Quality of the evidence}

Overall the evidence quality ranged from moderate to very low, as assessed by GRADE. There was a high risk of bias due to the design of some studies. The included studies consisted of 12 randomized controlled trials and 4 controlled clinical trials where participants were not randomly assigned to a treatment group. In most studies, participants and researchers were aware of group allocation and this may have had an influence on the results. The strong odours involved meant that aromatherapy was a difficult intervention to conceal from participants, research staff and those assessing outcomes. The different comparisons, time points and measurement scales limited the data that could be pooled. Some data were expressed as standardized scales and measures, which enabled pooling of results in metaanalyses. The data were incomplete for effects longer than 60 minutes. 
SUMMARY OF FINDINGS

\section{Summary of findings for the main comparison. Aromatherapy compared to placebo for treatment of postoperative nausea and vomiting}

Aromatherapy compared to placebo for treatment of postoperative nausea and vomiting

Patient or population: adults and children having any type of surgical procedure under general anaesthesia, regional anaesthesia or sedation, either as hospital inpatients or outpatients, with existing PONV

Setting: hospital post-anaesthesia care unit or same-day surgery unit in USA and Iran

Intervention: aromatherapy

Comparison: placebo

\begin{tabular}{|c|c|c|c|c|c|c|}
\hline \multirow[t]{2}{*}{ Outcomes } & \multicolumn{2}{|c|}{$\begin{array}{l}\text { Anticipated absolute effects }{ }^{*} \\
(95 \% \mathrm{Cl})\end{array}$} & \multirow[t]{2}{*}{$\begin{array}{l}\text { Relative effect } \\
(95 \% \mathrm{Cl})\end{array}$} & \multirow[t]{2}{*}{$\begin{array}{l}\text { № of partici- } \\
\text { pants } \\
\text { (studies) }\end{array}$} & \multirow[t]{2}{*}{$\begin{array}{l}\text { Quality of the } \\
\text { evidence } \\
\text { (GRADE) }\end{array}$} & \multirow[t]{2}{*}{ Comments } \\
\hline & $\begin{array}{l}\text { Risk with } \\
\text { placebo }\end{array}$ & $\begin{array}{l}\text { Risk with aro- } \\
\text { matherapy }\end{array}$ & & & & \\
\hline $\begin{array}{l}\text { Nausea severity } \\
\text { Assessed with VAS at end of treatment } \\
\text { Scale from } 0 \text { to } 10 \text { (higher indicates worse nausea) } \\
\text { Follow-up: range } 5 \text { minutes to participant discharge }\end{array}$ & $\begin{array}{l}\text { The mean nau- } \\
\text { sea severity was } \\
2.8(S D=10.39)\end{array}$ & $\begin{array}{l}\text { SMD } 0.22 \text { SD } \\
\text { lower } \\
\text { ( } 0.63 \text { lower to } \\
0.18 \text { higher) }\end{array}$ & - & $\begin{array}{l}241 \\
(6 \mathrm{RCTs})\end{array}$ & $\begin{array}{l}\oplus \oplus \oplus \ominus \\
\text { Low }^{1,2}\end{array}$ & $\begin{array}{l}\text { Risk in placebo } \\
\text { group based on } \\
\text { control group in } \\
\text { Anderson } 2004\end{array}$ \\
\hline \multirow{2}{*}{$\begin{array}{l}\text { Nausea duration (nausea-free at end of treatment) } \\
\text { Assessed by numbers of participants } \\
\text { Follow-up: range } 5 \text { minutes to participant discharge } \\
\text { Measured by participant self-report or medical or } \\
\text { nursing observation }\end{array}$} & \multicolumn{2}{|l|}{ Study population } & \multirow[t]{2}{*}{$\begin{array}{l}\text { RR } 3.25 \\
(0.31 \text { to } 34.33)\end{array}$} & \multirow[t]{2}{*}{$\begin{array}{l}193 \\
\text { (4 RCTs) }\end{array}$} & \multirow[t]{2}{*}{$\begin{array}{l}\oplus \ominus \Theta \Theta \\
\text { Very low } 3,4,5\end{array}$} & \\
\hline & 30 per 100 & $\begin{array}{l}96 \text { per } 100 \\
(9 \text { to } 100)\end{array}$ & & & & \\
\hline \multirow{2}{*}{$\begin{array}{l}\text { Proportion requiring rescue antiemetics } \\
\text { Assessed by numbers of participants } \\
\text { Follow up: range } 5 \text { minutes to participant discharge }\end{array}$} & \multicolumn{2}{|l|}{ Study population } & \multirow[t]{2}{*}{$\begin{array}{l}\text { RR } 0.60 \\
\text { (0.37 to } 0.97)\end{array}$} & \multirow{2}{*}{$\begin{array}{l}609 \\
(7 \mathrm{RCTs})\end{array}$} & \multirow[t]{2}{*}{$\begin{array}{l}\oplus \oplus \odot \Theta \\
\text { Low }^{1,2}\end{array}$} & \\
\hline & 68 per 100 & $\begin{array}{l}41 \text { per } 100 \\
\text { ( } 25 \text { to } 66)\end{array}$ & & & & \\
\hline $\begin{array}{l}\text { Adverse events } \\
\text { (common reactions to aromatherapy include skin } \\
\text { rashes, dyspnoea, headache, cardiac arrhythmias, hy- } \\
\text { potension, hypertension or dizziness) }\end{array}$ & See comment & & - & - & - & $\begin{array}{l}\text { The studies re- } \\
\text { porting this com- } \\
\text { parison did not } \\
\text { report this out- } \\
\text { come. }\end{array}$ \\
\hline $\begin{array}{l}\text { Patient satisfaction with treatment } \\
\text { Measured by a validated scale }\end{array}$ & \multicolumn{2}{|l|}{ See comment } & - & - & - & $\begin{array}{l}\text { The studies re- } \\
\text { porting this com- } \\
\text { parison did not }\end{array}$ \\
\hline
\end{tabular}




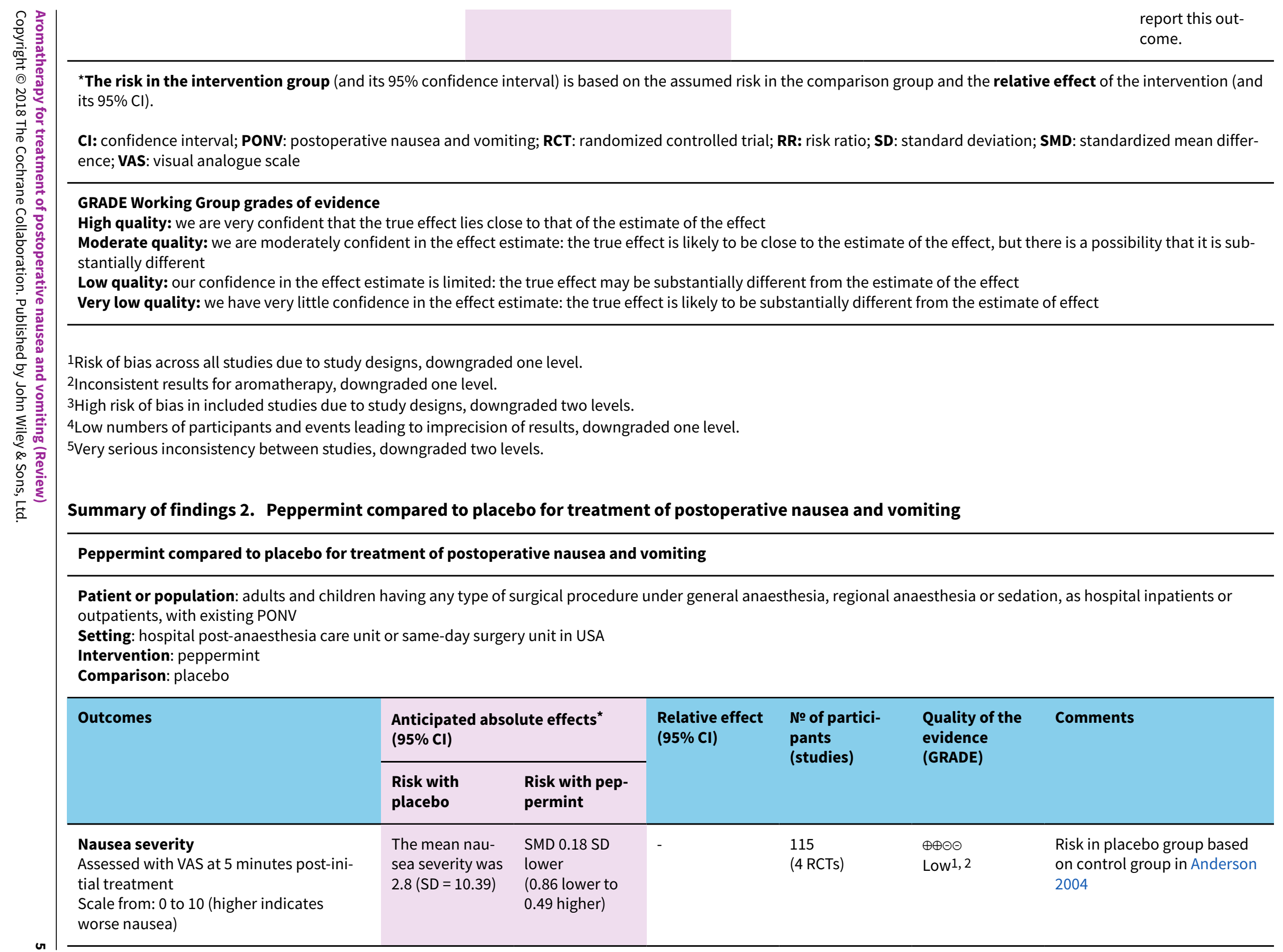

1 Risk of bias across all studies due to study designs, downgraded one level.

2 Inconsistent results for aromatherapy, downgraded one level.

${ }^{3} \mathrm{High}$ risk of bias in included studies due to study designs, downgraded two levels.

4Low numbers of participants and events leading to imprecision of results, downgraded one level.

Summary of findings 2. Peppermint compared to placebo for treatment of postoperative nausea and vomiting

outpatients, with existing PONV

Intervention: peppermint

Comparison: placebo 


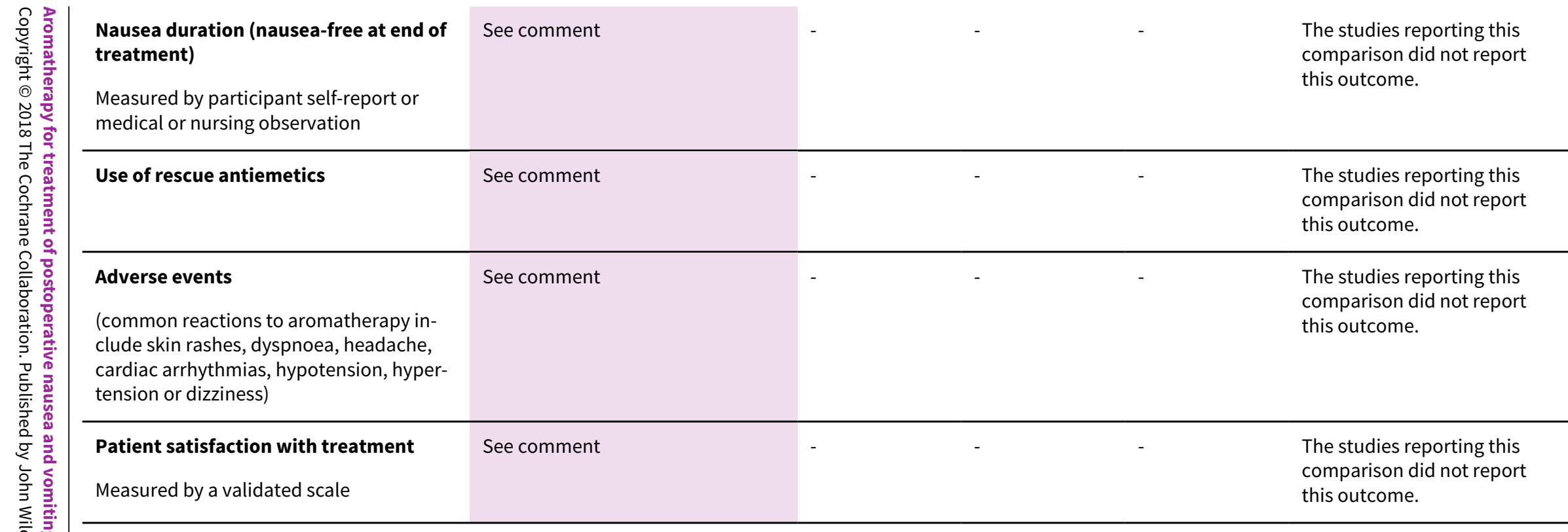

${ }^{*}$ The risk in the intervention group (and its 95\% confidence interval) is based on the assumed risk in the comparison group and the relative effect of the intervention (and its $95 \% \mathrm{Cl})$.

Cl: confidence interval; PONV: postoperative nausea and vomiting; RCT: randomized controlled trial; SD: standard deviation; SMD: standardized mean difference; VAS: visual analogue scale

\section{GRADE Working Group grades of evidence}

High quality: we are very confident that the true effect lies close to that of the estimate of the effect

Moderate quality: we are moderately confident in the effect estimate: the true effect is likely to be close to the estimate of the effect, but there is a possibility that it is substantially different

Low quality: our confidence in the effect estimate is limited: the true effect may be substantially different from the estimate of the effect

Very low quality: we have very little confidence in the effect estimate: the true effect is likely to be substantially different from the estimate of effect

1Risk of bias in included studies due to study designs, downgraded one level.

2Significant inconsistency between studies, downgraded one level.

\section{Summary of findings 3. Isopropyl alcohol compared to standard treatment for postoperative nausea and vomiting}

\section{Isopropyl alcohol compared to standard treatment for postoperative nausea and vomiting}

Patient or population: adults and children having any type of surgical procedure under general anaesthesia, regional anaesthesia or sedation, as hospital inpatients or outpatients, with existing PONV

Setting: hospital post-anaesthesia care unit or same-day surgery unit in USA 


\begin{tabular}{|c|c|c|c|c|c|c|}
\hline $\begin{array}{l}\text { Intervention: isopropyl alcohol } \\
\text { Comparison: standard treatment for PONV }\end{array}$ & & & & & & \\
\hline \multirow[t]{2}{*}{ Outcomes } & \multicolumn{2}{|c|}{$\begin{array}{l}\text { Anticipated absolute effects* } \\
(95 \% \mathrm{Cl})\end{array}$} & \multirow[t]{2}{*}{$\begin{array}{l}\text { Relative effect } \\
(95 \% \mathrm{CI})\end{array}$} & \multirow{2}{*}{$\begin{array}{l}\text { № of partici- } \\
\text { pants } \\
\text { (studies) }\end{array}$} & \multirow{2}{*}{$\begin{array}{l}\text { Quality of the } \\
\text { evidence } \\
\text { (GRADE) }\end{array}$} & \multirow[t]{2}{*}{ Comments } \\
\hline & $\begin{array}{l}\text { Risk with stan- } \\
\text { dard treat- } \\
\text { ment for PONV }\end{array}$ & $\begin{array}{l}\text { Risk with iso- } \\
\text { propyl alcohol }\end{array}$ & & & & \\
\hline $\begin{array}{l}\text { Nausea severity } \\
\text { Measured by a validated scale or medical or nursing } \\
\text { observation }\end{array}$ & See comment & & - & - & - & $\begin{array}{l}\text { The studies re- } \\
\text { porting this com- } \\
\text { parison did not } \\
\text { report this out- } \\
\text { come. }\end{array}$ \\
\hline $\begin{array}{l}\text { Nausea duration (measured as nausea-free at end } \\
\text { of treatment) } \\
\text { Assessed by time (minutes) to } 50 \% \text { reduction in nau- } \\
\text { sea score } \\
\text { Scale from: } 0 \text { to } 120 \\
\text { Follow-up: range } 5 \text { minutes to participant discharge } \\
\text { Measured by participant self-report or medical or } \\
\text { nursing observation }\end{array}$ & $\begin{array}{l}\text { The mean time } \\
\text { to } 50 \% \text { reduc- } \\
\text { tion in nausea } \\
\text { score was } 20.5 \\
\text { minutes }\end{array}$ & $\begin{array}{l}\text { SMD } 1.10 \text { SD } \\
\text { lower } \\
\text { (1.43 lower to } \\
0.78 \text { lower) }\end{array}$ & - & $\begin{array}{l}176 \\
\text { (3 RCTs) }\end{array}$ & $\begin{array}{l}\oplus \oplus \oplus \ominus \\
\text { Moderate } 1\end{array}$ & $\begin{array}{l}\text { Risk in placebo } \\
\text { group based } \\
\text { on Pellegrini } 2009\end{array}$ \\
\hline \multirow{2}{*}{$\begin{array}{l}\text { Use of rescue antiemetics } \\
\text { Assessed by proportion requiring antiemetics } \\
\text { Follow-up: range } 5 \text { minutes to participant discharge }\end{array}$} & \multicolumn{2}{|l|}{ Study population } & \multirow{2}{*}{$\begin{array}{l}\text { RR } 0.67 \\
(0.46 \text { to } 0.98)\end{array}$} & \multirow{2}{*}{$\begin{array}{l}215 \\
\text { (4 RCTs) }\end{array}$} & \multirow{2}{*}{$\begin{array}{l}\oplus \oplus \oplus \ominus \\
\text { Moderate } 2\end{array}$} & \\
\hline & 39 per 100 & $\begin{array}{l}26 \text { per } 100 \\
\text { (18 to } 38)\end{array}$ & & & & \\
\hline Patient satisfaction with treatment & \multicolumn{2}{|l|}{ Study population } & \multirow{2}{*}{$\begin{array}{l}\text { RR } 1.12 \\
\text { (0.62 to } 2.03 \text { ) }\end{array}$} & \multirow{2}{*}{$\begin{array}{l}172 \\
\text { (2 RCTs) }\end{array}$} & \multirow{2}{*}{$\begin{array}{l}\oplus \ominus \ominus \ominus \\
\text { Very low } 1,3,4\end{array}$} & \\
\hline & 76 per 100 & $\begin{array}{l}85 \text { per } 100 \\
(47 \text { to } 100)\end{array}$ & & & & \\
\hline $\begin{array}{l}\text { Adverse events } \\
\text { (common reactions to aromatherapy include skin } \\
\text { rashes, dyspnoea, headache, cardiac arrhythmias, hy- } \\
\text { potension, hypertension or dizziness) }\end{array}$ & See comment & & - & - & - & $\begin{array}{l}\text { The studies re- } \\
\text { porting this com- } \\
\text { parison did not } \\
\text { report this out- } \\
\text { come. }\end{array}$ \\
\hline
\end{tabular}

${ }^{\star}$ The risk in the intervention group (and its $95 \%$ confidence interval) is based on the assumed risk in the comparison group and the relative effect of the intervention (and its $95 \% \mathrm{Cl})$. 
Cl: confidence interval; PONV: postoperative nausea and vomiting; RCT: randomized controlled trial; RR: risk ratio; SD: standard deviation; SMD: standardized mean difference

\section{GRADE Working Group grades of evidence}

High quality: we are very confident that the true effect lies close to that of the estimate of the effect

Moderate quality: we are moderately confident in the effect estimate: the true effect is likely to be close to the estimate of the effect, but there is a possibility that it is substantially different

Low quality: our confidence in the effect estimate is limited: the true effect may be substantially different from the estimate of the effect

Very low quality: we have very little confidence in the effect estimate: the true effect is likely to be substantially different from the estimate of effect

${ }^{1}$ No or unclear blinding in all included studies, downgraded one level.

${ }^{2}$ No or unclear blinding in three of the four included studies, downgraded one level.

3High heterogeneity between studies, downgraded one level.

${ }^{4}$ High imprecision due to wide confidence intervals and small numbers of participants, downgraded one level.

\section{Summary of findings 4. Isopropyl alcohol compared to saline for treatment of postoperative nausea and vomiting}

Isopropyl alcohol compared to saline for treatment of postoperative nausea and vomiting

Patient or population: adults and children having any type of surgical procedure under general anaesthesia, regional anaesthesia or sedation, as hospital inpatients or outpatients, with existing PONV

Setting: hospital post-anaesthesia care unit or same-day surgery unit in USA and Iran

Intervention: isopropyl alcohol

Comparison: saline

\begin{tabular}{|c|c|c|c|c|c|c|}
\hline \multirow[t]{2}{*}{ Outcomes } & \multicolumn{2}{|c|}{$\begin{array}{l}\text { Anticipated absolute effects }{ }^{\star} \\
(95 \% \mathrm{Cl})\end{array}$} & \multirow[t]{2}{*}{$\begin{array}{l}\text { Relative effect } \\
(95 \% \mathrm{Cl})\end{array}$} & \multirow{2}{*}{$\begin{array}{l}\text { № of partici- } \\
\text { pants } \\
\text { (studies) }\end{array}$} & \multirow{2}{*}{$\begin{array}{l}\text { Quality of the } \\
\text { evidence } \\
\text { (GRADE) }\end{array}$} & \multirow[t]{2}{*}{ Comments } \\
\hline & $\begin{array}{l}\text { Risk with } \\
\text { saline }\end{array}$ & $\begin{array}{l}\text { Risk with iso- } \\
\text { propyl alcohol }\end{array}$ & & & & \\
\hline $\begin{array}{l}\text { Nausea severity } \\
\text { Measured by a validated scale or medical or } \\
\text { nursing observation }\end{array}$ & \multicolumn{2}{|c|}{ See comment } & - & - & - & $\begin{array}{l}\text { The studies reporting this } \\
\text { comparison did not report } \\
\text { this outcome. }\end{array}$ \\
\hline $\begin{array}{l}\text { Nausea duration (nausea-free at end of } \\
\text { treatment) } \\
\text { Measured by participant self-report or med- } \\
\text { ical or nursing observation }\end{array}$ & \multicolumn{2}{|c|}{ See comment } & - & - & - & $\begin{array}{l}\text { The studies reporting this } \\
\text { comparison did not report } \\
\text { this outcome. }\end{array}$ \\
\hline Use of rescue antiemetics & \multicolumn{2}{|c|}{ Study population } & $\begin{array}{l}\text { RR } 0.39 \\
(0.12 \text { to } 1.24)\end{array}$ & $\begin{array}{l}291 \\
(4 \mathrm{RCTs})\end{array}$ & $\begin{array}{l}\oplus \ominus \ominus \odot \\
\text { Very low } 1,2,3\end{array}$ & \\
\hline
\end{tabular}


Assessed by proportion requiring rescue antiemetics

90 per $100 \quad 35$ per 100

Follow-up: range 5 minutes to participant

discharge

\section{Adverse events}

(common reactions to aromatherapy include

skin rashes, dyspnoea, headache, cardiac

arrhythmias, hypotension, hypertension or dizziness)

\begin{tabular}{|c|c|c|c|}
\hline $\begin{array}{l}\text { Patient satisfaction with treatment } \\
\text { Measured by a validated scale }\end{array}$ & See comment & 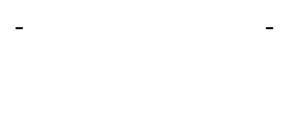 & $\begin{array}{l}\text { The studies reporting this } \\
\text { comparison did not report } \\
\text { this outcome. }\end{array}$ \\
\hline
\end{tabular}

${ }^{*}$ The risk in the intervention group (and its 95\% confidence interval) is based on the assumed risk in the comparison group and the relative effect of the intervention (and its $95 \% \mathrm{Cl})$.

Cl: confidence interval; PONV: postoperative nausea and vomiting; RCT: randomized controlled trial; RR: risk ratio

\section{GRADE Working Group grades of evidence}

High quality: we are very confident that the true effect lies close to that of the estimate of the effect

Moderate quality: we are moderately confident in the effect estimate: the true effect is likely to be close to the estimate of the effect, but there is a possibility that it is substantially different

Low quality: our confidence in the effect estimate is limited: the true effect may be substantially different from the estimate of the effect

Very low quality: we have very little confidence in the effect estimate: the true effect is likely to be substantially different from the estimate of effect

1Poor reporting in Kamalipour 2002 and Langevin 1997 affect confidence in results, downgraded one level.

2Wide confidence interval for pooled results, downgraded one level.

3 Very high heterogeneity between studies, downgraded two levels. 


\section{B A C K G R O U N D}

Aromatherapy has been recommended for the treatment of postoperative nausea and vomiting (PONV) (Huntley 2014; Lindquist 2013). It is known that this therapy is inexpensive, non-invasive and generally has low levels of adverse effects (Lua 2012), particularly in comparison to standard pharmacological treatments. What is not known is whether the clinical effectiveness justifies its use.

\section{Description of the condition}

Nausea is an abdominal discomfort or queasiness that may be accompanied by vomiting. Postoperative nausea and vomiting (PONV) is one of the most common adverse reactions to surgery and all types of anaesthesia, with $30 \%$ to $50 \%$ of all patients suffering moderate to severe nausea and vomiting following general anaesthesia using volatile agents (Gan 2014).

Aside from the distressing nature of PONV itself, patients may experience such adverse effects as wound dehiscence, dehydration, electrolyte imbalances or aspiration pneumonia as a result of PONV (Apfel 2010). Other adverse effects may include increased patient bed days, and unplanned readmissions (particularly in the case of day surgery) (Gan 2014). Certain patients are more pre-disposed than others to suffering from PONV and risk factors include being female, a non-smoker, and having a history of PONV or perioperative opioid exposure (Gan 2014). Along with postoperative pain, PONV is one of the main concerns of people facing surgery and one of the main causes of patient dissatisfaction (Myles 2000).

Current treatment involves either the prophylactic or symptomatic administration of antiemetic drugs such as droperidol, metoclopramide or 5-HT3 receptor antagonists such as ondansetron (Gan 2014). Multi-modal treatment using a range of drugs is now recognized as more effective (Gan 2014; Jokinen 2012). Despite a wide range of available treatments, some patients will still experience PONV in varying levels of severity (Jokinen 2012). Clinically, the severity of PONV is generally measured by means of a visual analogue scale (VAS), which provides a visual representation of the patient's condition over a numerical range (for example 0 to 5), or verbal descriptive scales (for example no nausea, some nausea, very nauseated, retching, vomiting) (Boogaerts 2000).

\section{Description of the intervention}

The use of aromatherapy oils has been recommended as a treatment for nausea (Lindquist 2013; Mamaril 2006; Safajou 2014). Aromatherapy uses the application of essential oils or other substances to any part of the body for the purpose of inhalation of the vapours or absorption of the oil into the skin to treat or alleviate physical and emotional symptoms (Lindquist 2013). Essential oils can be absorbed through the skin and may exert a physiological effect on cellular and organ function, although this is not clinically understood (Ernst 2001). Aromatherapy is well accepted by many health consumers; a meta-analysis of survey data from the UK shows it to be one of the most commonly used complementary therapies (Posadzki 2013). A significant number of health consumers already self-prescribe and administer aromatherapy products for various common conditions, or consult qualified or unqualified aromatherapy practitioners for health advice (Eisenberg 1998).
In particular, ginger, fennel and peppermint, as either a topical application (massage or a compress) or via inhalation, are wellknown treatments (Lindquist 2013). The effectiveness of the oils may be due to analgesic and antiemetic properties (with peppermint oil and ginger oil) or anti-spasmodic properties (peppermint oil and fennel oil). Peppermint oil is well recognized for its role in digestion disorders, due principally to the presence of menthols (see Appendix 1 for details). There have been a number of studies conducted using ginger oil, with conflicting results (Arfeen 1995; Bone 1990; Meyer 1995; Phillips 1993). Isopropyl alcohol is said to be a traditional nausea remedy from South America (Anderson 2004; Mamaril 2006; Spencer 2004), however none of the papers citing this provided a primary source for this information. Isopropyl alcohol, also known as rubbing alcohol and commonly found in the type of 'prep-pad' used to clean skin prior to injection, does appear to be widely used in some postanaesthesia care units to treat PONV (Cotton 2007; Hunt 2013; Merritt 2002; Pellegrini 2009; Spencer 2004; Wang 1999; Winston 2003).

\section{How the intervention might work}

The mechanism of action for aromatherapy is not well understood. Essential oils are reported to have effects at the psychological, physiological and cellular level (Dobetsberger 2011) but there are currently no human studies to show that any ingredient from the inhaled vapours of essential oils are present in the blood or plasma (Herz 2009). Herz's critique of the current state of aromatherapy science highlights many of the poorly supported claims that are made about these substances and suggests that rather than there being a pharmacological action for aromatherapy, it is more likely that aromatherapy's effects are psychologically or culturally based (Ferdenzi 2011; Herz 2009). The theory that the action of aromatherapy is pharmacological, Herz suggests, may be disproved by the immediacy of its effect, as pharmacological substances require time for absorption within the body (usually a minimum of 20 minutes) (Herz 2009). This position does not take into account the more rapid absorption of inhaled drugs; for example, drugs commonly used to treat asthma begin to take effect as early as five minutes postadministration (Balint 2010) and it may be possible that the vapours of essential oils act with similar rapidity. Essential oils can be absorbed through the skin and some may exert a physiological effect on cellular and organ function (Ernst 2001), but this type of absorption is different to the olfactory mechanism of action disputed by Herz 2009.

One proposed mechanism of action that seems more likely is that the scent activates the olfactory system, which in turn triggers the limbic system (Lis-Balchin 2006). This in turn may produce emotional responses and may enhance the retrieval of learnt memories (Lis-Balchin 1997). Brain activation associated with emotional response in connection to odour exposure has been recorded on functional MRI imaging, although this was a brief report of a small study with incomplete detailing of its methods and the findings should be taken with due scepticism (Lowe 2010). It is known that olfactory pathways reach into the hypothalamus, which may be the route for emotional responses to aromas (Linck 2010).

\section{Why it is important to do this review}

The effectiveness of the various drugs for PONV has already been the subject of a Cochrane Review (Carlisle 2006), however, prior to the original review in 2012, no existing review had examined the effectiveness of aromatherapy to treat this condition for a broad 
range of surgical patients. It was important to update this review as several new studies have been published since our original review (Hines 2012).

\section{OB JECTIVES}

The main objective was to establish the efficacy and safety of aromatherapy comparable to standard pharmacological treatments for PONV in adults and children.

In particular, we wanted to establish:

- what effect the use of aromatherapy has on the severity of established PONV;

- what effect the use of aromatherapy has on the duration of established PONV;

- whether aromatherapy can be used with safety and clinical effectiveness comparable to standard pharmacological treatments to treat established PONV.

\section{METHODS}

\section{Criteria for considering studies for this review \\ Types of studies}

We considered any randomized controlled trials (RCTs) or controlled clinical trials (CCTs) that evaluated the effect of aromatherapy on established PONV. In order to obtain the widest range of studies we set no date of publication or language limits.

\section{Types of participants}

We considered all studies that included participants (both adult and paediatric, paediatric being children aged less than 18 years of age) having any type of surgical procedure under general anaesthesia, regional anaesthesia or sedation, either as hospital inpatients or in day or ambulatory facilities, who were given aromatherapy treatments for management of existing PONV. For the purposes of this review we considered postoperative to be the period from day of surgery to discharge from hospital or, in the case of day hospital patients, up to the fifth postdischarge day.

We excluded studies of non-surgical participants (medical, oncology). We also excluded studies in which aromatherapy was used solely to prevent postoperative nausea and vomiting.

\section{Types of interventions}

Interventions of interest were those where aromatherapy products were used by any delivery method (for example direct inhalation, diffusion, massage or compress) to treat symptoms of established postoperative nausea and vomiting, compared to a placebo or with standard antiemetic treatments. Aromatherapy was defined as the inhalation of the vapours of any substance for the purposes of a therapeutic benefit.

\section{Types of outcome measures}

\section{Primary outcomes}

- Severity of nausea or vomiting, or both, post-initiation of treatment as measured by a validated scale or medical or nursing observation
- Duration of nausea or vomiting, or both, post-initiation of treatment as measured by patient report or medical or nursing observation

\section{Secondary outcomes}

- Use of pharmacological antiemetics

- Any adverse reactions or events (common reactions to aromatherapy include skin rashes, dyspnoea, headache, cardiac arrhythmias, hypotension, hypertension or dizziness (Price 2007))

- Patient satisfaction with treatment as measured by a validated scale

\section{Search methods for identification of studies}

\section{Electronic searches}

For the initial review we searched the Cochrane Central Register of Controlled Trials (CENTRAL, 2011, Issue 3); MEDLINE (via Ovid) (1966 to 2 August 2011); Embase (1966 to 2 August 2011); CINAHL (EBSCOhost) (1982 to 2 August 2011); CAM on PubMed (1966 to 2 August 2011); Meditext (1995 to 2 August 2011); LILACS (1982 to 2 August 2011); and ISI Web of Science (1985 to 2 August 2011) (Hines 2012).

We conducted searches for this update on all the previous databases in March 2017 for the period 1 January 2011 to 2 March 2017.

We developed a specific strategy for each database. We based each search strategy on that developed for MEDLINE (see Appendix 2 for details). We combined the MEDLINE search strategy with the Cochrane Highly Sensitive Search Strategy, phases one and two, as contained in the Cochrane Handbook for Systematic Reviews of Interventions (Lefebvre 2011).

\section{Searching other resources}

We checked the reference lists of relevant articles and attempted to contact relevant trial authors to identify any additional or ongoing studies.

We also searched for relevant trials on specific sites:

- Clinical Trial Results at www.clinicaltrialresults.org/ (March, 2017);

- Open Grey at www.opengrey.eu/ (grey literature) (March, 2017);

- Grey Literature Report at www.greylit.org/ (grey literature) (March, 2017);

- Australian Clinical Trials Registry www.anzctr.org.au/ Default.aspx (March, 2017);

- Science.gov at www.science.gov/ (grey literature) (March, 2017);

- World Health Organization (WHO) International Clinical Trials Registry Platform (ICTRP) apps.who.int/trialsearch/Default.aspx

We did not apply language restrictions.

\section{Data collection and analysis}

\section{Selection of studies}

Two review authors (SH and ES) independently scanned the titles and abstracts of reports identified by the described variety of search strategies. We retrieved and evaluated potentially relevant 
studies, chosen by at least one author, in full-text versions. We retrieved and translated any articles that appeared relevant but were not published in full in English. Three authors ( $\mathrm{SH}, \mathrm{AC}$ and ES) independently assessed the congruence of trials with the review's inclusion criteria using a checklist that was designed in advance for that purpose (Appendix 3).

\section{Data extraction and management}

Two review authors (SH and ES) independently extracted data using a tool developed and piloted by the authors (Appendix 4). We used Plot Digitizer software version 2.6.6 (Huwalt 2014) to extract some data that had been reported graphically in the included studies. Where necessary we contacted study authors to request missing data or details of methods. We dealt with trials with more than two arms either by combining intervention or placebo groups where appropriate, or excluding groups if appropriate to the specific comparison being performed.

\section{Assessment of risk of bias in included studies}

We assessed the risk of bias using the Cochrane tool provided in the Review Manager 5 (RevMan 5) software (RevMan 2014), described in the Cochrane Handbook for Systematic Reviews of Interventions (Higgins 2011). Any disagreements were adjudicated by the third author (AC). We used the following five criteria to assess risk of bias for each individual study: random sequence generation, allocation concealment, blinding, incomplete outcome data, and selective reporting.

\section{Measures of treatment effect}

Because of the subjective nature of nausea, measures of treatment effect were largely limited to patient-reported effects, measured by various scales including visual analogue scales (VAS), verbal numerical rating scales (VRNS) and descriptive ordinal scales (DOS). We included other measures of effect, such as number of vomiting episodes or retching, and the use of pharmacological 'rescue' antiemetics. We used risk ratio (RR) with 95\% confidence interval $(95 \% \mathrm{Cl})$ to measure treatment effect for dichotomous outcome measures and standardized mean differences (SMDs) with $95 \% \mathrm{Cl}$ for continuous outcomes.

\section{Unit of analysis issues}

For cross-over trials, had sufficient data been available we planned to use a paired t-test to analyse participant data. Had we included any cluster-randomized trials, we would have meta-analysed effect estimates and standard errors using the generic inverse-variance method in RevMan 5. For studies using scales that could be standardized (e.g. converting $100 \mathrm{~mm}$ scale to $10 \mathrm{~cm}$ scale) to enable data pooling, standardization was done.

\section{Dealing with missing data}

Where necessary, we contacted authors of included studies regarding missing study information. We were able to contact some study authors to retrieve missing data, such as details about randomization, statistical detail and standard deviations (SDs), however others did not reply or were not contactable. Where we found that data were missing and the study authors were not contactable, where possible we calculated missing statistics (such as SDs) from other quoted statistics (such as frequencies, standard errors or Cls) (Altman 2005). If missing data remained, we performed an available case analysis, excluding data where outcome information was unavailable.

\section{Assessment of heterogeneity}

We assessed statistical heterogeneity through the use of the $\mathrm{Chi}_{2}$ test, as well as by reviewing the $l_{2}$ statistic (Higgins 2003). If either the $\mathrm{Ch}_{2}$ test resulted in a $\mathrm{P}$ value less than 0.10 or the $\mathrm{I}_{2}$ statistic was greater than $40 \%$, we further investigated the reasons for heterogeneity (Deeks 2011). Wherever appropriate we analysed studies with diverse interventions separately.

\section{Assessment of reporting biases}

Due to the small number of studies included in the meta-analyses, we considered it inappropriate to generate funnel plots to assess reporting biases for all meta-analyses (Egger 1997). We did consider studies from a wide range of locations, languages and publications, as well as unpublished work, which we believe has reduced the likelihood of reporting biases affecting our findings (Sterne 2011).

\section{Data synthesis}

We entered all trials included in the systematic review into RevMan 5 (RevMan 2014) and combined data quantitatively, where possible, although there was significant diversity of outcome measurement scales and time points, which limited the amount of data that could be pooled. We calculated pooled estimates using the randomeffects model with the Mantel-Haenszel method as we observed small numbers of events (Borenstein 2010). We determined the levels of heterogeneity by the $\mathrm{I}_{2}$ statistic (Deeks 2011; Higgins 2003).

\section{Subgroup analysis and investigation of heterogeneity}

We planned to conduct subgroup analyses where data were available, as described by Deeks and colleagues (Deeks 2001) and as recommended in Section 8.8 of the Cochrane Handbook for Systematic Reviews of Interventions (Higgins 2011). We planned to compare:

- adults and children;

- different types of surgery (e.g. orthopaedic and gynaecologic surgery);

- types of aromatherapy delivery methods (e.g. inhalation, massage, ingestion);

- trial quality (e.g. RCT, CCT).

Due to the limited data available, we were unable to perform any subgroup analyses.

\section{Sensitivity analysis}

In the 2012 review we had concerns about the risk of bias due to confounding in Merritt 2002 and we performed a sensitivity analysis and reported findings both with and without the results of this study (Hines 2012). On further consideration of this study and considering that while aggressive antiemetic prophylaxis may have had an effect on the overall study results in reducing the severity of nausea in the whole study population, that effect was likely to be similar between the groups and therefore not likely to have caused a difference between the intervention and control groups, and so we have deleted the sensitivity analysis in the 2017 update. 


\section{Summary of findings}

We used the GRADE approach to summarize and interpret our findings (Langendam 2013). We used GRADEPro GDT software (GRADEpro GDT 2015) to import data from RevMan 5 (RevMan 2014) and create 'Summary of findings' tables. 'Summary of findings' tables display the key results of the review by outcome, adjusted for the quality of the evidence. We downgraded the evidence from the included studies by one grade for serious, and two grades for very serious threats to study validity in terms of high risk of bias, indirect evidence from outcome reporting in the studies, serious inconsistency between the pooled studies, imprecision of effect estimates or detected publication bias. We synthesized the following outcomes in the 'Summary of findings' tables: severity of nausea at the end of treatment (primary outcome) duration of nausea (primary outcome), and use of rescue antiemetics (secondary outcome), adverse events and patient satisfaction.

\section{RES ULT S}

\section{Description of studies}

The studies were randomized controlled trials (RCTs) or controlled clinical trials (CCTs) conducted on postoperative adult and paediatric patients in postanaesthesia care units (PACU) and sameday surgery units (SDSU). The intervention groups were given aromatherapy treatments to treat complaints of PONV. The control groups were treated with either a saline, sham aromatherapy, or controlled breathing control condition, or standard antiemetic drugs. The time points at which data were collected by each study varied from 2 minutes, 5 minutes, 15 minutes, 30 minutes and various combinations of these for total periods of 5 minutes to discharge from PACU or SDSU.

\section{Results of the search}

We conducted searches in a wide range of databases and sources: CENTRAL; MEDLINE; Embase; CINAHL; CAM on PubMed; Meditext; LILACS; Web of Science; Current Controlled Trials (2012); Clinical Study Results (2012); SIGLE (2012); New York Library of Medicine Grey Literature Report (2012); National Institute of Clinical Studies (2012); Google Scholar (English, German, Spanish) (2012); Conference Proceedings of the National Association for Holistic Aromatherapy; Clinical Trial Results at www.clinicaltrialresults.org/ (March, 2017); Open Grey at www.opengrey.eu/ (grey literature) (March, 2017); Grey Literature Report at www.greylit.org/ (grey literature) (March, 2017); Australian Clinical Trials Registry www.anzctr.org.au/Default.aspx (March, 2017); Science.gov at www.science.gov/ (grey literature) (March, 2017); World Health Organization (WHO) International Clinical Trials Registry Platform (ICTRP) apps.who.int/trialsearch/Default.aspx (March, 2017) and reference lists.

In 2012, of the 1386 articles we identified, we deemed 44 relevant enough to be retrieved for further evaluation. After appraisal of the full version of each study, we found nine studies that met the criteria for inclusion in the review (Hines 2012).

In 2017, we identified 612 potentially relevant studies for the period 2011 to 2017 and retrieved 16 full-text articles, nine of which met the criteria for inclusion in the review, although two are ongoing studies without results, so we included seven completed studies in the analysis. For further details see Figure 1. 
Figure 1. Study flow diagram

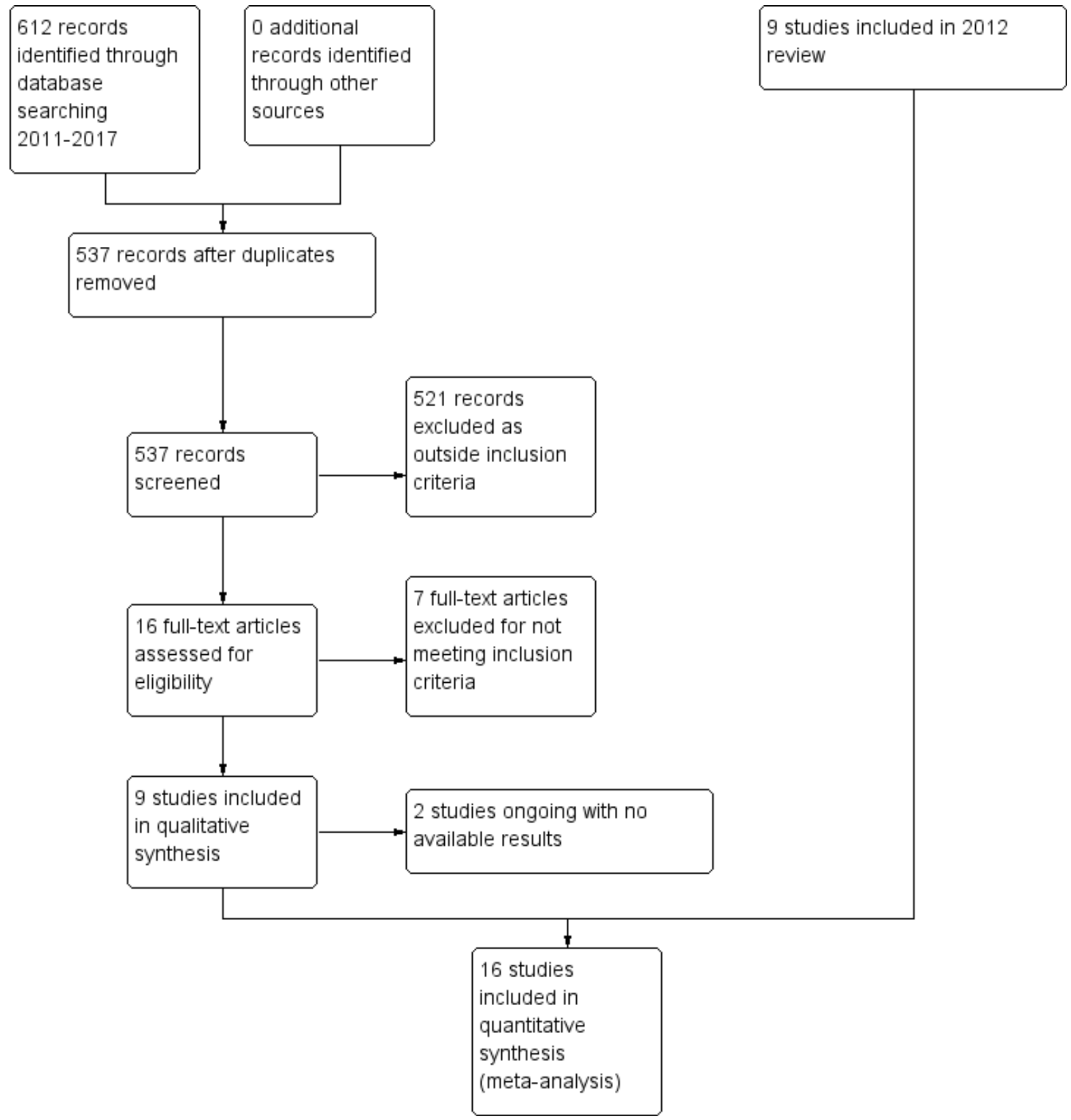

\section{Included studies}

We included 16 studies, seven identified in the 2017 update and nine from the original 2012 review (Hines 2012), comprised of 11 RCTs (Anderson 2004; Cotton 2007; Hodge 2014; Hunt 2013; Kamalipour 2002; Kiberd 2016; Lane 2012; Pellegrini 2009; Sites 2014; Wang 1999; Winston 2003) and five CCTs (Cronin 2015; Ferruggiari 2012; Langevin 1997; Merritt 2002; Tate 1997) with a total of 1036 participants. The mean age and range data for all participants were not available for all studies. See Characteristics of included studies for further details.

\section{Excluded studies}

The 2012 review excluded 35 studies for not meeting the inclusion criteria, either by study design (not RCT or CCT) or by treatment objectives (prevention of PONV not treatment) (Hines 2012). See Characteristics of excluded studies for details.

In the 2017 update we retrieved 16 studies and excluded seven for not meeting the inclusion criteria, either by study design (not RCT/ $\mathrm{CCT}$ ) or by study outcomes (prevention of PONV not treatment). Therefore the total number of excluded studies in the updated review is 42 . 


\section{Studies awaiting classification}

There are no studies awaiting classification.

\section{Ongoing studies}

We identified two registered trials that met the inclusion criteria for this review; however there are no results for these studies yet (NCT02189980; NCT02732379).

\section{Risk of bias in included studies}

We assessed the risk of bias in terms of allocation sequence generation, blinding, incomplete reporting of outcome data, and selective reporting. Risk of bias was variable across all included studies with a range of risks from low to high. For details of the risk of bias assessment, see Figure 2 and Figure 3.

Figure 2. Methodological quality graph: review authors' judgements about each methodological quality item presented as percentages across all included studies

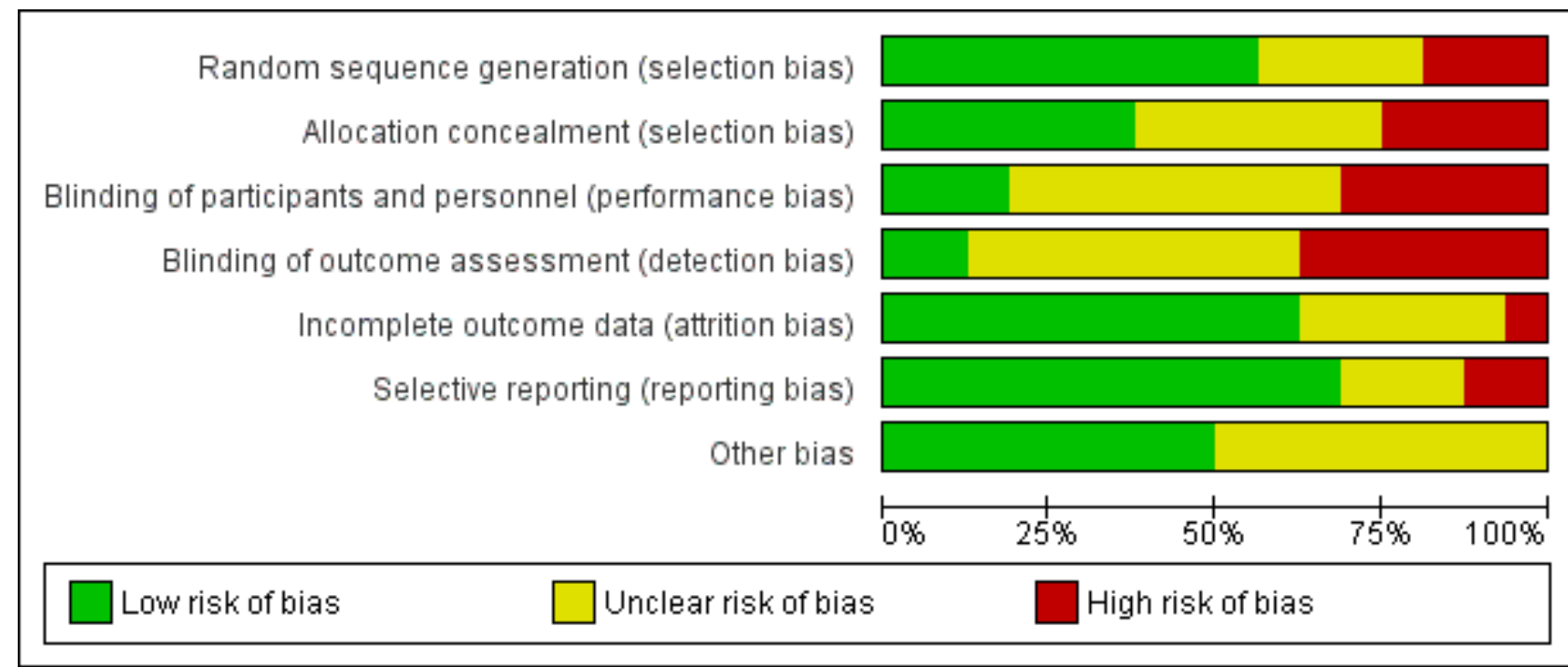


Figure 3. Methodological quality summary: review authors' judgements about each methodological quality item for each included study

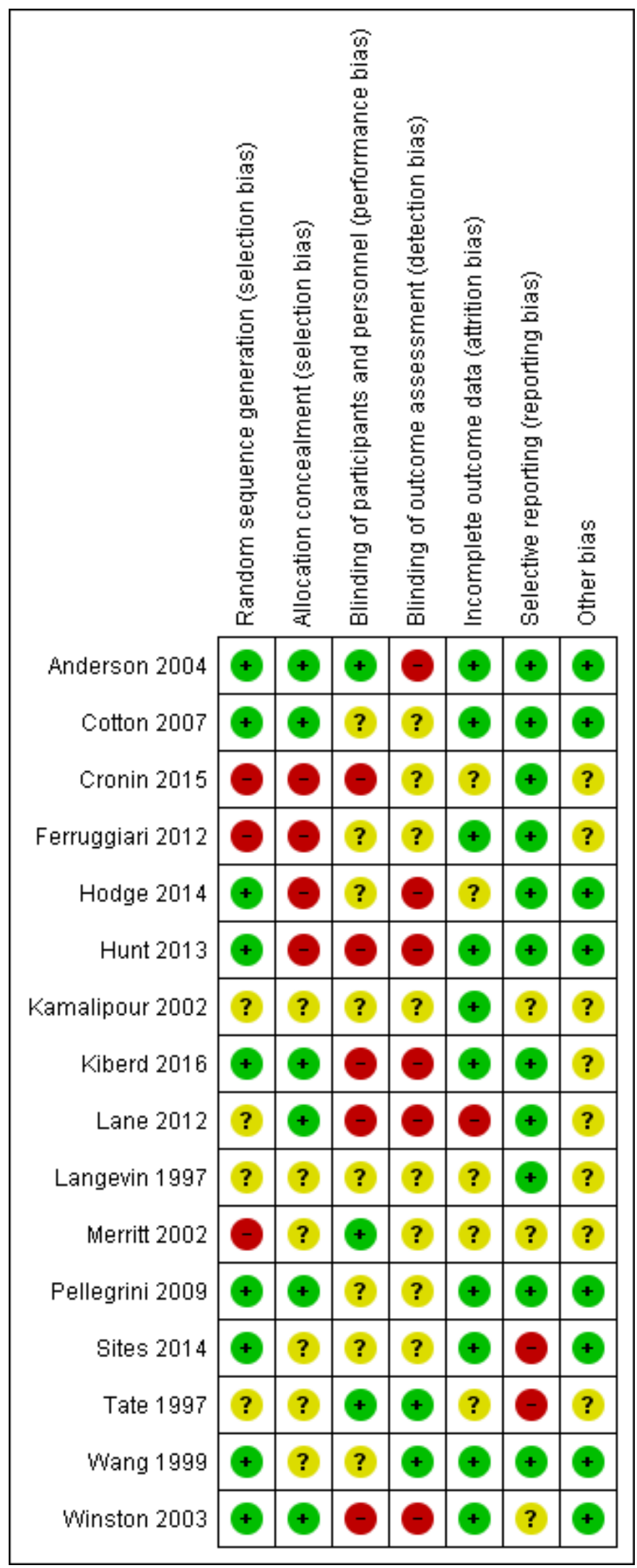




\section{Allocation}

Methods of allocation varied across the included studies. Nine studies explicitly stated the method of randomization: Wang 1999 utilized a 'random number table'; Cotton 2007, Pellegrini 2009; Sites 2014; and Winston 2003 utilized a 'computer generated random numbers table'; Hodge 2014, and Hunt 2013 used 'computer generated random number sequences'; Lane 2012 used "blocked systematic random assignment" and Anderson 2004 used a "random number generator". For Kamalipour 2002 the treatment and control groups were "randomly selected" but the authors did not state what method of randomization was used. In Langevin 1997, which used a cross-over clinical trial design, the test agents were administered in a "random sequence" but again the method of randomization was not stated. In Kiberd 2016 randomization was done using a "block 6" method, which is not further described. The studies by Merritt 2002; Ferruggiari 2012 and Cronin 2015 were not adequately randomized (only Merritt 2002 being explicitly described as a CCT by its authors): in Merritt 2002 assignment to the treatment and control groups was alternated by day; in Ferruggiari 2012 research staff "randomly selected" the treatment from a box; while allocation in Cronin 2015 was based on the calendar month of admission with assignment to the experimental group in evennumbered months and to the control in odd-numbered months. The participants in Tate 1997 were "randomly allocated" to wards that had been assigned to the separate treatments, the control and placebo arms of the study, with no details provided about the randomization method.

Allocation concealment appeared to have been undertaken for six studies (Anderson 2004; Cotton 2007; Kiberd 2016; Lane 2012; Pellegrini 2009; Winston 2003) generally by the use of an independent or external allocator. The remaining ten studies did not report data on whether allocation was concealed.

\section{Blinding}

Blinding was explicitly done in Merritt 2002; Tate 1997; and Wang 1999. Three included studies (Anderson 2004; Langevin 1997; Wang 1999) also blinded assessors. While several other studies attempted to blind participants or assessors, or both, to the treatment allocation, the nature of the intervention and the difficulty of concealing strong odours meant that unblinding may have occurred. Kiberd 2016 reported that nursing staff and research assistants became unblinded to intervention allocation due to leakage of the treatment aroma. In seven studies (Anderson 2004; Cotton 2007; Hodge 2014; Kamalipour 2002; Langevin 1997; Pellegrini 2009; Sites 2014) the completeness of blinding was unclear. In six studies, blinding was clearly not done (Cronin 2015; Ferruggiari 2012; Hunt 2013; Kiberd 2016; Lane 2012; Winston 2003).

\section{Incomplete outcome data}

Data appeared to have been reported for all participants and outcomes in 10 studies (Anderson 2004; Cotton 2007; Ferruggiari 2012; Hunt 2013; Kamalipour 2002; Kiberd 2016; Pellegrini 2009; Sites 2014; Wang 1999; Winston 2003), however it was unclear whether this had occurred in five studies (Cronin 2015; Hodge 2014; Langevin 1997; Merritt 2002; Tate 1997). There appeared to be a large amount of missing data affecting the results in one study (Lane 2012).

\section{Selective reporting}

Most studies (Anderson 2004; Cotton 2007; Cronin 2015; Ferruggiari 2012; Hodge 2014; Hunt 2013; Kiberd 2016; Lane 2012; Langevin 1997; Pellegrini 2009; Wang 1999) were at low risk of selective reporting, but for three studies the risk was unclear (Kamalipour 2002; Merritt 2002; Winston 2003). We assessed two included studies as being at high risk of selective reporting (Sites 2014; Tate 1997).

\section{Other potential sources of bias}

Other potential sources of bias were evident in two studies. Due to the design of the study by Tate 1997, it was possible there was some demand characteristic effect (an effect where participants interpret the purpose of the study and modify their behaviour or reporting accordingly (Orne 1962)) on patient self-reporting of results. The authors of Merritt 2002 reported that their study was probably confounded by the aggressive preoperative antiemetic prophylaxis given to 104 out of the 111 participants enrolled into the study, although it seems unlikely this would have had an effect on the direction of the results in favour of the intervention given that almost all participants in both groups received prophylaxis. Four studies appeared free of other potential sources of bias (Cotton 2007; Pellegrini 2009; Wang 1999; Winston 2003). It was unclear from the minimal data reported in Langevin 1997 and Kamalipour 2002 whether there were any other potential sources of bias. The aromatherapy inhalers used in Kiberd 2016 were supplied by the manufacturer, however the study authors state that the manufacturer had no other input into the study.

\section{Effects of interventions}

See: Summary of findings for the main comparison Aromatherapy compared to placebo for treatment of postoperative nausea and vomiting; Summary of findings 2 Peppermint compared to placebo for treatment of postoperative nausea and vomiting; Summary of findings $\mathbf{3}$ Isopropyl alcohol compared to standard treatment for postoperative nausea and vomiting; Summary of findings $\mathbf{4}$ Isopropyl alcohol compared to saline for treatment of postoperative nausea and vomiting

There were a variety of comparisons used by the included studies. Isopropyl alcohol vapour inhalation was the most commonly used experimental substance with 10 studies evaluating its effectiveness. Several studies used multiple comparisons, for example: peppermint oil versus isopropyl alcohol versus saline, or ginger versus an essential oil mix versus isopropyl alcohol versus saline placebo. Where studies used multiple comparison groups, only one intervention and one comparison group from those studies are used in any single meta-analysis to avoid double-counting of participants. Two studies evaluated controlled breathing to treat PONV. All included studies measured nausea as a chief outcome. Seven studies also reported data on the number of participants requiring rescue antiemetics for unresolved nausea. The diversity of comparisons, time points and measurement scales limited the data that could be pooled. We converted some data to standardized scales and measures to enable meta-analyses.

\section{Comparison: aromatherapy versus placebo}

\section{Primary outcome: severity of nausea}

Eight studies overall reported data on the severity of nausea, but the variety of measurement scales and time points used 
limited the advisability of conducting meta-analyses; however after standardization of scale data some pooling was possible. Six studies (Anderson 2004 (peppermint and saline groups only); Ferruggiari 2012 (peppermint and saline groups only); Hodge 2014; Lane 2012 (peppermint and water groups only); Merritt 2002; Sites 2014) with 241 participants compared aromatherapy to placebo (saline, water or controlled breathing) and measured nausea severity at greater than three minutes posttreatment. Aromatherapies used were peppermint (Anderson 2004; Ferruggiari 2012; Lane 2012), an essential oil blend of lavender, peppermint, ginger and spearmint (Hodge 2014), and isopropyl alcohol (Merritt 2002). The GRADE assessment of study quality was low. No difference was found between the groups receiving aromatherapy and those receiving an inert placebo (SMD - $0.22,95 \%$ $\mathrm{Cl}-0.63$ to $0.18, \mathrm{P}$ value $=0.28$ ). These studies were moderately methodologically heterogeneous $\left(I_{2}\right.$ statistic $\left.=52 \%\right)$. (Analysis 1.1$)$ (Summary of findings for the main comparison).

Hunt 2013 conducted a four-group comparison of ginger oil, saline, isopropyl alcohol and an essential oil blend of ginger, spearmint, peppermint and cardamom with 301 participants. While nausea severity was measured, it was reported as odds of greater improvement in nausea relief. Across the study arms, three of the four comparisons showed evidence of an effect: the essential oil blend was more effective than saline (OR 2.70, 95\% Cl 1.78, 4.56, P value $<0.001$ ), or isopropyl alcohol (OR $2.13,95 \% \mathrm{Cl} 1.50$ to $3.17, \mathrm{P}$ value $<0.001)$ and ginger was more effective than saline (OR 1.86 , $95 \% \mathrm{Cl} 1.22$ to $3.00, \mathrm{P}$ value $=0.002$ )

Kiberd 2016 compared QueaseEase ${ }^{\mathrm{T} M}$ aromatherapy blend to placebo in 39 children having elective outpatient surgery and found only small, non-significant effects on nausea and no difference in vomiting.

\section{Primary outcome: duration of nausea}

An overall comparison of aromatherapy to placebo for the number of participants free of nausea at the end of the treatment period included four studies with 193 participants (Kamalipour 2002; Langevin 1997; Sites 2014; Wang 1999) and found little or no effect for aromatherapy (RR $3.25,95 \% \mathrm{Cl} 0.31$ to 34.33 , $\mathrm{P}$ value $=0.33$, very low-quality evidence) with a high degree of heterogeneity between the studies $\left(I_{2}\right.$ statistic $\left.=97 \%\right)$ and subgroup analyses were not possible due to the small number of studies (Analysis 1.2).

\section{Secondary outcome: use of rescue antiemetics}

Ten studies with 695 participants trialled aromatherapy interventions and reported on the use of rescue antiemetics (Anderson 2004; Cotton 2007; Cronin 2015; Hunt 2013; Kamalipour 2002; Kiberd 2016; Langevin 1997; Merritt 2002; Sites 2014; Winston 2003). Studies used peppermint (Anderson 2004; Sites 2014), essential oil blend or ginger (Hunt 2013); essential oil blend (Kiberd 2016) and isopropyl alcohol (Anderson 2004; Cotton 2007; Cronin 2015; Hunt 2013; Kamalipour 2002; Langevin 1997; Merritt 2002; Winston 2003) as the active interventions. Of these studies, seven studies with 609 participants compared aromatherapy interventions with placebo and reported data suitable for metaanalysis (Anderson 2004; Cronin 2015; Hunt 2013; Kamalipour 2002; Kiberd 2016; Langevin 1997; Sites 2014). Fewer instances of rescue antiemetics were required by participants who received aromatherapy ( $\mathrm{RR} 0.60,95 \% \mathrm{Cl} 0.37$ to $0.97, \mathrm{P}$ value $=0.04$ ) although heterogeneity was high $(79 \%)$, likely due to the variety of substances trialled, and the GRADE assessment of study quality was low Analysis 1.3.

Kiberd 2016 (39 participants) found no difference between the QueaseEase $^{\mathrm{TM}}$ aromatherapy and standard treatment groups in terms of use of rescue antiemetics ( $P$ value $=0.75$, Eta 0.08).

\section{Secondary outcome: adverse reactions}

No data on adverse reactions to the experimental substances were reported by any of the included studies. No studies added in the 2017 update reported adverse reactions.

\section{Secondary outcome: patient satisfaction with treatment}

Two studies with 127 participants measured patient satisfaction with treatment.

Anderson 2004 measured patient satisfaction on a VAS $(0 \mathrm{~mm}$ extremely dissatisfied, $100 \mathrm{~mm}$ fully satisfied). Participants $(\mathrm{n}=33)$ across all three groups reported high levels of satisfaction with their treatment: isopropyl alcohol 90.3 (SD 14.9); peppermint oil 86.3 (SD 32.3); saline 83.7 (SD 25.6). Hodge 2014 (94 participants) also measured satisfaction on a scale of $0-10$ and reported a mean satisfaction of 6.9 in the group receiving essential oil blend aromatherapy, and 7.1 in the water placebo group (no further data reported).

The results from all studies reporting on this outcome are collated in Table 1.

\section{Comparison: peppermint versus placebo}

\section{Primary outcome: severity of nausea}

Four studies (Anderson 2004; Ferruggiari 2012; Lane 2012; Sites 2014) with 115 participants compared peppermint aromatherapy to placebo (saline, water or controlled breathing) and measured nausea severity at five minutes post initial treatment. Moderately high heterogeneity $\left(I_{2}\right.$ statistic $\left.=66 \%\right)$ was probably due to clinical and methodological differences between the studies. The use of peppermint may lead to little or no difference in the severity of nausea (SMD $-0.18,95 \% \mathrm{Cl}-0.86$ to $0.49, \mathrm{P}$ value $=0.59$ ) (Analysis 2.1). Tate 1997 compared peppermint oil to a peppermint essence placebo and a standard treatment control group but only reported average daily nausea scores on a 0 to 4 descriptive ordinal scale, which we were not able to include in the meta-analysis. On the operative day the standard treatment group's mean daily nausea score was 0.97 , the peppermint essence placebo group's was 1.61 , and the peppermint oil group's was 0.5 (no SD reported), which the study authors report as a significant difference between the groups ( $P$ value $=0.02)$. The GRADE assessment of study quality was low (Summary of findings 2).

\section{Primary outcome: duration of nausea}

No studies reported data on this outcome for this comparison.

\section{Secondary outcome: use of rescue antiemetics}

No studies reported data on this outcome for this comparison.

\section{Secondary outcome: adverse reactions}

No data on adverse reactions to the experimental substances were reported by any of the included studies. No studies added in the 2017 update reported adverse reactions. 


\section{Comparison: isopropyl alcohol versus standard treatment}

\section{Primary outcome: severity of nausea}

Merritt 2002 compared isopropyl alcohol and standard antiemetic drugs in 39 adult participants, measuring nausea on a 0 to 10 descriptive ordinal scale (DOS) and found $52.4 \%(n=11)$ of the experimental group had their nausea relieved after the first treatment, compared to $72.2 \%(n=13)$ in the standard treatment group. There was no significant difference between the groups at post-test (isopropyl alcohol mean 2.7 (SD 3.02), standard treatment mean 1.94 (SD 2.48).

\section{Primary outcome: duration of nausea}

Three studies with 176 participants (Cotton 2007; Pellegrini 2009 (PACU subgroup); Winston 2003) compared isopropyl alcohol to standard antiemetics and reported time in minutes to a $50 \%$ reduction in nausea scores. Heterogeneity between these studies was very low $\left(I_{2}\right.$ statistic $\left.=0 \%\right)$ and the pooled result was significant (SMD - 1.10 minutes, $95 \% \mathrm{Cl}-1.43$ to -0.78 , $\mathrm{P}$ value $<0.001$ ) indicating that aromatherapy using isopropyl alcohol has a significantly faster effect than the comparison drugs, ondansetron and promethazine (Analysis 3.1) (Summary of findings 3). According to the GRADE analysis, if 1000 patients with PONV were given a placebo, 297 would be nausea-free by the end of the treatment period, whereas if 1000 patients with PONV received aromatherapy, 695 would be nausea-free at the end of the treatment period. The GRADE level of evidence was moderate.

\section{Secondary outcome: use of rescue antiemetics}

Four studies with a total of 215 participants compared isopropyl alcohol to standard treatment and reported the number of participants in each group who required rescue antiemetics (Cotton 2007; Merritt 2002; Pellegrini 2009; Winston 2003), which showed an effect when pooled (RR $0.67,95 \% \mathrm{Cl} 0.46$ to 0.98 , $\mathrm{P}$ value $=0.04$ ) (Analysis 3.2) (Summary of findings 3).

\section{Secondary outcome: adverse reactions}

No data on adverse reactions to the experimental substances were reported by any of the included studies. No studies added in the 2017 update reported adverse reactions.

\section{Secondary outcome: patient satisfaction with treatment}

Four studies measured patient satisfaction with treatment. No new studies added in 2017 measured patient satisfaction.

Cotton 2007 (72 participants, comparing isopropyl alcohol to ondansetron) used a four-point ordinal scale on which the participants were asked to rate their postoperative experience as poor, fair, good or excellent; participants in both the treatment and control groups reported their experience as good or excellent, resulting in no difference between the groups ( $P$ value $>0.05)$.

Winston 2003 (41 participants) also measured patient satisfaction using a four-point ordinal scale $(0=$ poor; $1=$ fair $; 2=$ good and $3=$ excellent). For the ondansetron group: $0=1$ participant (3\%); $1=2$ participants (6\%); $2=17$ participants $(52 \%)$; and $3=13$ participants (39\%). For the isopropyl alcohol group, the satisfaction numbers were: $0=0$ participants; $1=0$ participants; $2=18$ participants $(47 \%)$, and $3=20$ participants $(53 \%)$. The study authors stated that, although these findings were not statistically significant, they nonetheless regarded them as clinically significant (unreported data supplied via email). We collapsed results from Cotton 2007 and Winston 2003 into dichotomous data (good or excellent interpreted as satisfied) and combined them in Analysis 3.3 (Summary of findings 3 ).

Participants also reported high levels of satisfaction with their treatment regardless of allocation in Pellegrini 2009 (63 participants), with a median score of 4 on a 5-point ordinal scale (1, totally dissatisfied; 2 , somewhat dissatisfied; 3 , somewhat satisfied; 4 , satisfied; 5 , totally satisfied).

\section{Comparison: isopropyl alcohol versus placebo}

\section{Primary outcome: severity of nausea}

Two studies (Anderson 2004; Cronin 2015) used isopropyl alcohol as an intervention and compared it to either controlled breathing or saline placebo (Anderson 2004 used a three-group design comparing isopropyl alcohol, peppermint and saline) and reported data on nausea severity. We were unable to carry out any metaanalyses for these studies due to differing measures and data reporting. Anderson 2004 compared isopropyl alcohol and saline and reported means and SDs for baseline, two and five minutes, reporting an overall decrease in nausea scores, which, while significant in comparison to baseline, did not differ between the groups at five minutes. Cronin 2015 trialled isopropyl alcohol with and without controlled breathing and reported means without SDs and reported similarly that while the nausea severity decreased significantly for all groups between baseline and five minutes, there was no significant difference between the control and intervention groups at five minutes.

\section{Primary outcome: duration of nausea}

Wang 1999 compared isopropyl alcohol and saline in a population of 39 children having elective outpatient surgery under general anaesthesia. Wang 1999 found that while isopropyl alcohol may have an effect on postoperative nausea at 20 minutes posttreatment ( $P$ value $=0.05)$, this effect could not be sustained at 60 minutes (RR $2.85,95 \% \mathrm{Cl} 0.32$ to $25.07, \mathrm{P}$ value $=0.35$ ). No effect on postoperative vomiting was demonstrated at 20 minutes or 60 minutes (RR 1.27, 95\% Cl 0.33 to 4.93 ).

\section{Secondary outcome: use of rescue antiemetics}

Four studies of adult patients (Anderson 2004; Hunt 2013; Kamalipour 2002; Langevin 1997), with a total of 291 participants, compared isopropyl alcohol and saline and measured the number of participants who required rescue antiemetics. We combined these studies. Meta-analysis showed no evidence of an effect (RR $0.39,95 \% \mathrm{Cl} 0.12$ to $1.24, \mathrm{P}$ value $=0.11$, very low-quality evidence) although heterogeneity was again very high ( $I_{2}$ statistic $\left.=92 \%\right)$ (Analysis 4.1). Subgroup analyses were not possible due to the small number of studies (Summary of findings 4).

One study of 39 paediatric patients having day surgical procedures (Wang 1999) also compared isopropyl alcohol and saline and measured the number of participants requiring rescue antiemetics. For participants with nausea only, $60 \%$ of those in the placebo (saline) group required rescue antiemetics compared to $9 \%$ of those in the isopropyl alcohol group (RR $0.15,95 \% \mathrm{Cl} 0.02$ to 1.05 ). For participants with vomiting, $89 \%$ of the saline group required rescue antiemetics compared to $67 \%$ of the isopropyl alcohol group (RR $0.75,95 \% \mathrm{Cl} 0.23$ to 1.12 ). 


\section{Secondary outcome: adverse reactions}

No data on adverse reactions to the experimental substances were reported by any of the included studies. No studies added in the 2017 update reported adverse reactions.

\section{Secondary outcome: patient satisfaction with treatment}

No studies reported data on this outcome for this comparison.

\section{DISCUSSION}

\section{Summary of main results}

This review was able to include studies of isopropyl alcohol, peppermint oil, ginger oil, essential oil blends of peppermint, spearmint, ginger and cardamom, or peppermint, spearmint, ginger and lavender aromatherapy interventions compared to water, saline or controlled breathing placebo, ondansetron, promethazine, or other unspecified 'standard antiemetic' treatments. All aromatherapy was delivered via direct inhalation of vapours. There were 979 adult and 39 paediatric participants in the 16 included studies. The majority of participants were women. Studies were conducted in both inpatient and day surgery settings. Outcomes of interest to this review measured by the included studies were severity of nausea, duration of nausea reported as time to reduction in nausea, the use of 'rescue' antiemetics, and patient satisfaction. No studies reported data on adverse effects. Study quality was moderate to very low.

Sixteen studies (Anderson 2004; Cotton 2007; Cronin 2015; Ferruggiari 2012; Hodge 2014; Hunt 2013; Kamalipour 2002; Kiberd 2016; Lane 2012; Langevin 1997; Merritt 2002; Pellegrini 2009; Sites 2014; Tate 1997; Wang 1999; Winston 2003) compared aromatherapies of various types to placebo and reported data on the severity and duration of nausea, use of rescue antiemetics and patient satisfaction. While there was little or no difference between the groups in terms of nausea severity, there were more participants who were nausea-free at the end of treatment, and fewer participants who received aromatherapy required antiemetics to treat nausea.

Isopropyl alcohol was tested in several studies, both against standard pharmacological treatments and against other aromatherapies and placebo, in both adults and children. In comparison to saline placebo, isopropyl alcohol appears effective in reducing the number of patients requiring rescue antiemetics (Anderson 2004; Hunt 2013; Kamalipour 2002; Langevin 1997) and in providing short-term relief of symptoms in children (Wang 1999). In three studies (Cotton 2007; Pellegrini 2009, Winston 2003), isopropyl alcohol provided a significantly faster time to $50 \%$ relief of symptoms than ondansetron and promethazine. When compared to standard antiemetic drugs, participants receiving isopropyl alcohol to treat their nausea required fewer instances of rescue antiemetics (Cotton 2007; Merritt 2002; Pellegrini 2009; Winston 2003). There were no data suitable to be pooled for a comparison of isopropyl alcohol to standard treatment for the outcome of nausea severity.

The updated 2017 searches introduced a greater variety of treatment substances into the review. Five included studies trialled peppermint aromatherapy as a treatment for PONV (Anderson 2004; Ferruggiari 2012; Lane 2012; Sites 2014; Tate 1997). Three included studies (Hodge 2014; Hunt 2013; Kiberd 2016) used blends of four essential oils as treatments for nausea: peppermint, spearmint, ginger and lavender in Hodge 2014 and Kiberd 2016 and peppermint, spearmint, ginger and cardamom in Hunt 2013. Peppermint, when compared to placebo, may lead to little or no difference in nausea severity.

Patient satisfaction with aromatherapy treatment appeared high in studies that measured this outcome (Anderson 2004; Cotton 2007; Pellegrini 2009; Winston 2003), with participants reporting high levels of satisfaction with their experience. However it should be noted that all participants in these studies (treatment and comparison groups) reported high levels of satisfaction, possibly indicating that increased attention to the care of PONV improved patient satisfaction with their care.

The findings are further summarized in 'Summary of findings' tables for aromatherapy versus placebo (Summary of findings for the main comparison; Summary of findings 2; Summary of findings 3; Summary of findings 4).

\section{Overall completeness and applicability of evidence}

It seems likely that further studies of all aromatherapy products to treat PONV could provide different results from those described here if greater rigour was applied in the study methods. Due to the strong odours involved, aromatherapy is inherently a difficult intervention to conceal from participants, research staff and those assessing outcomes; however several included studies attempted no blinding at all. Unlike the previous iteration of this review, some larger, well-conducted studies of peppermint oil or other aromatherapies have now been included, which has changed the evidence significantly. The evidence base for aromatherapy to treat PONV is still incomplete, with only two studies of children meeting the inclusion criteria and many aromatherapy treatments incompletely investigated or tested. While there appears to be no evidence of adverse reactions from the use of the included interventions, it is unclear from the included studies whether data were collected on any possible adverse reactions experienced by participants. In the context of current postoperative practice, there is a place for adjunct therapies to treat PONV and while aromatherapy is a simple and inexpensive treatment that seems to be more effective than placebo in terms of some outcomes, there is currently no evidence to suggest that it can replace pharmacological antiemetics.

Of additional concern are the early time points utilized by all included studies except Tate 1997, which did measure PONV at 24 and 48 hours but only reported average daily scores for each group. Apfel 2002 recommends that study authors measure PONV for early (up to two hours) and late (to 24 hours) outcomes. The data that we were able to include in this review remain incomplete for effects longer than 60 minutes.

Due to the many risk factors for and influences on PONV, such as type of anaesthesia, narcotic medication intake, sex, and type of surgery, it was a concern that there were differences between groups that might account for some of the effect. Examination of the demographic and procedural data, however, shows that control and experimental groups were very similar and that confounding due to risk factors was unlikely. 
It should be remembered that we have not included any evidence of effectiveness for aromatherapy in the prevention of PONV and that all results apply only to treatment of an existing complaint.

\section{Quality of the evidence}

The included studies were comprised of 12 RCTs and four CCTs, with total of 1036 participants. The overall quality of the retrieved evidence was low, with incomplete reporting and unavailable data hampering pooling on some important outcomes. Due to the age of some studies or non-contactability of the study authors, further data were not available in some cases. The 16 included studies measured the effectiveness of a range of commonly used aromatherapy interventions for this condition in settings appropriate to its use, that is, post-anaesthesia care units and same-day surgery units. Additionally, the high level of inconsistency in some of the pooled results reduces the level of confidence in those results. Imprecision, as a result of wide confidence intervals and small numbers of participants in some included studies also reduces the quality of the evidence, however indirectness and publication bias were less of a concern.

\section{Potential biases in the review process}

It is possible there are studies that were not identified in the searches or reference list checks done for this review, but it seems unlikely as search alerts running since the first version of this review was conducted identified no studies not also found with the search strategies. We have reported all the relevant data on the outcomes of interest to this review and attempted to contact five study authors for the newly added studies to obtain clarifications on methods or data not reported in the publication. Four of the five author groups contacted supplied the requested information. The new searches did not identify any non-English-language studies, unlike the initial searches in 2010, and this may indicate a flaw in the search strategies or simply a lack of new research. The inclusion of meta-analyses with high heterogeneity, such as those in Analysis $1.2\left(1^{2}=97 \%\right)$ and Analysis $4.1(12=97 \%)$, may increase the risk of bias, however these analyses combine the results of multiple aromatherapy types and research designs, which are likely the source of heterogeneity.

\section{Agreements and disagreements with other studies or reviews}

A systematic review of the effectiveness of noninvasive complementary therapies for reducing PONV in women having abdominal laparoscopic hysterectomy (Hewitt 2009) found, similarly to this review, that there was no strong evidence to support the use of aromatherapy for PONV. We have been unable to find any other systematic reviews of aromatherapy for treating PONV.

\section{AUTHORS' CONCLUSIONS}

\section{Implications for practice}

From the evidence of this review, which is very low to moderate quality, it is unknown whether isopropyl alcohol vapour inhalation as an adjunct therapy for postoperative nausea and vomiting (PONV) is associated with adverse effects, as it is unclear from the included studies whether adverse effect data were not reported by participants, or not collected by study authors. Isopropyl alcohol may provide rapid, short-term relief of nausea for some adult patients and reduce the need for rescue antiemetics, but the evidence level is generally low. It may provide a useful therapeutic option, particularly when the alternative is no treatment at all. As an inexpensive, readily available therapy (in the form of injection site 'prep-pads'), isopropyl alcohol vapour inhalation could be considered for use in situations where standard pharmacological antiemetics are unavailable, refused by patients, or contraindicated.

Included studies that examined this intervention used one preppad or isopropyl alcohol-soaked cotton ball or gauze pad per treatment and most asked the patient to take two or three deep breaths while the pad was held close to their nose without touching. Treatments were repeated up to three times without any adverse effects being reported.

There is no evidence of an effect for peppermint aromatherapy in reducing nausea severity. There is incomplete evidence for the use of aromatherapy blends and ginger, however individual studies do report evidence of an effect.

\section{Implications for research}

It is important that future trials fully report their methodology, demography and findings. Full descriptions of the results of interventions would enable clinicians to make more informed decisions about the uptake of these therapies in their clinical setting. Improved reporting would also benefit future updates of this review. While blinding is difficult with this intervention due to the aroma, future research should explore the use of sham therapies such as those employed by some studies included here to conceal the therapeutic allocation. There are only a few large, wellreported trials in this area. Further studies in paediatric populations are needed. Future trials should include measures for longer time intervals (two to 24 hours) and report discrete data on both postoperative nausea and postoperative vomiting.

\section{ACK N OWLEDGEMENTS}

We thank Mathew Zacharias, Jung T Kim, NL Pace, Peter Kranke and Anne Lyddiatt for their help and advice during the preparation of the 2012 systematic review (Hines 2012), and Janet Wale, Winnie Schats, Jacqueline Dienemann, Fakher Rahim, Janet Roseman, Jing Xie and Anna Lee for their advice on the 2017 update.

We also thank Mathew Zacharias, Katrina Farber, Milli Reddy, Jung T Kim and Janet Wale for their help and editorial advice during the preparation of the protocol (Hines 2009), for the systematic review.

The authors wish to acknowledge Kathy Hibberd (Librarian, University of Queensland Medical Library) for her invaluable assistance in preparing and conducting the searches for the 2012 review, and Leandra Blake for her comments on the protocol and 2012 review. We also thank Kate Kynoch and Lisa Brown for assisting with the testing of the data extraction tool.

Thanks to Marie Kristensson for the Swedish translations, Abbas Breesem for the Farsi translation, and Laurie Bay at the Institute of Modern Languages at the University of Queensland for the French translation. 


\section{RE F E R E N C E S}

\section{References to studies included in this review}

Anderson 2004 \{published and unpublished data\}

Andersen L, Gross J. Aromatherapy with peppermint, isopropyl alcohol or placebo is equally effective in reducing postoperative nausea. Journal of Perianesthesia Nursing 2004;19(1):29-35. [PUBMED: 14770380 ]

\section{Cotton 2007 \{published and unpublished data\}}

Cotton JW, Rowell LR, Hood RR, Pellegrini JE. A comparative analysis of isopropyl alcohol and ondansetron in the treatment of postoperative nausea and vomiting from the hospital setting to the home. American Association of Nurse Anesthetists Journal 2007;75(1):21. [PUBMED: 17304779]

\section{Cronin 2015 \{published and unpublished data\}}

Cronin S, Odom-Forren J, Roberts H, Thomas M, Williams S, Wright $\mathrm{M}$. Examining the effectiveness of controlled breathing, with or without aromatherapy, in the treatment of postoperative nausea in female patients undergoing outpatient laparoscopic procedures. Journal of Perianesthesia Nursing 2015;30(5):389-97. [DOI: 10.1016/j.jopan.2015.03.010]

\section{Ferruggiari 2012 \{published and unpublished data\}}

Ferruggiari L, Ragione B, Rich E, Lock K. The effect of aromatherapy on postoperative nausea in women undergoing surgical procedures. Journal of Perianesthesia Nursing 2012;27(4):246-51.

\section{Hodge 2014 \{published and unpublished data\}}

Hodge N, McCarthy M, Pierce R. A prospective randomized study of the effectiveness of aromatherapy for relief of postoperative nausea and vomiting. Journal of Perianesthesia Nursing 2014;29(1):5-11.

Hunt 2013 \{published data only (unpublished sought but not used)\} Hunt R, Dienemann J, Norton HJ, Hartley W, Hudgens A, Stern T, et al. Aromatherapy as treatment for postoperative nausea: a randomized trial. Anesthesia and Analgesia 2013;117(3):597-604.

Kamalipour 2002 \{published data only (unpublished sought but not used)\}

Kamalipour H, Parviz Kazemi A. The effect of isopropyl alcohol sniffing on the treatment of post-operative nausea and vomiting. Journal of Medical Research (JMR) 2002;1(1):15-9.

\section{Kiberd 2016 \{published data only\}}

Kiberd M, Clarke S, Chorney J, d'Eon B, Wright S. Aromatherapy for the treatment of PONV in children: a pilot RCT. BMC Complementary and Alternative Medicine 2016;16(450):2-6. [DOI: 10.1186/s12906-016-1441-1; PUBMED: 27829428]

\section{Lane 2012 \{published data only\}}

Lane B, Cannella K, Bowen C, Copelan D, Nteff G, Barnes K, et al. Examination of the effectiveness of peppermint aromatherapy on nausea in women post c-section. Journal of Holistic Nursing 2012;30(2):90-104. [DOI: 10.1177/0898010111423419]
Langevin 1997 \{published data only (unpublished sought but not used)\}

Langevin P, Brown M. A simple, innocuous, and inexpensive treatment for postoperative nausea and vomiting. Anesthesiology 1997;84 Suppl:971. [ISSN: 0003-3022]

\section{Merritt 2002 \{published data only\}}

Merritt BA, Okyere CP, Jasinski DM. Isopropyl alcohol inhalation: alternative treatment of postoperative nausea and vomiting. Nursing Research 2002;51(2):125. [PUBMED: 11984383]

Pellegrini 2009 \{published and unpublished data\}

Pellegrini J, DeLoge J, Bennett J, Kelly J. Comparison of inhalation of isopropyl alcohol vs promethazine in the treatment of postoperative nausea and vomiting (PONV) in patients identified as at high risk for developing PONV. American Association of Nurse Anesthetists Journal 2009;77(4):293-9. [PUBMED: 19731848]

\section{Sites 2014 \{published and unpublished data\}}

Sites D, Johnson N, Miller J, Torbush P, Hardin J, Knowles S, et al. Controlled breathing with or without peppermint aromatherapy for postoperative nausea and/or vomiting symptom relief: a randomized controlled trial. Journal of Perianesthesia Nursing 2014;29(1):12-9. [DOI: 10.1016/ j.jopan.2013.09.008]

Tate 1997 \{published and unpublished data\}

Tate S. Peppermint oil: a treatment for postoperative nausea. Journal of Advanced Nursing 1997;26(3):543-9. [PUBMED: 9378876]

Wang 1999 \{published data only (unpublished sought but not used)\}

Wang SM, Hofstadter MB, Kain ZN. An alternative method to alleviate postoperative nausea and vomiting in children. Journal of Clinical Anesthesia 1999;11(3):231-4. [PUBMED: 10434220]

\section{Winston 2003 \{published and unpublished data\}}

Winston AW, Rinehart RS, Riley GP, Vacchiano CA, Pellegrini JE. Comparison of inhaled isopropyl alcohol and intravenous ondansetron for treatment of postoperative nausea. American Association of Nurse Anesthetists Journal 2003;71(2):127-32. [PUBMED: 12776641]

\section{References to studies excluded from this review}

Adib-Hajbaghery, 2015 \{published data only\}

Adib-Hajbaghery M, Hosseini F. Investigating the effects of inhaling ginger essence on post-nephrectomy nausea and vomiting. Complementary Therapies in Medicine 2015;23:827-31.

\section{Apariman 2006 \{published data only\}}

Apariman S, Ratchanon S, Wiriyasirivej B. Effectiveness of ginger for prevention of nausea and vomiting after gynecological laparoscopy. Journal of the Medical Association of Thailand 2006;89(12):2003-9. [PUBMED: 17214049] 
Apfel 2001 \{published data only\}

Apfel C, Kranke P, Greim C, Roewer N. What can be expected from risk scores for predicting postoperative nausea and vomiting?. British Journal of Anaesthesia 2001;86(6):822-7. [PUBMED: 11573590]

\section{Arfeen 1995 \{published data only\}}

Arfeen Z, Owen H, Plummer J, Ilsley A, Sorby-Adams R, Doecke $C$. A double blind randomized controlled trial of ginger for the prevention of postoperative nausea and vomiting. Anaesthesia and Intensive Care 1995;23:449-52. [PUBMED: 7485935

\section{Betz 2005 \{published data only\}}

Betz $\mathrm{O}$, Kranke $\mathrm{P}$, Geldner $\mathrm{G}$, Wulf $\mathrm{H}$, Eberhart L. Is ginger a clinically relevant antiemetic? A systematic review of randomised controlled studies [Ist ingwer ein klinisch relevantes antiemetikum? Eine systematische übersicht randomisierter kontrollierter studien]. Logo 2005;12(1):14-23. [DOI: 10.1159/000082536]

\section{Bone 1990 \{published data only\}}

Bone M, Wilkinson D, Young J, McNeil J, Charlton S. Ginger root; a new antiemetic. The effect of ginger root on postoperative nausea and vomiting after major gynaecological surgery. Anaesthesia 1990;45(8):669-71. [PUBMED: 2205121]

\section{Briggs, 2016 \{published data only\}}

Briggs P, Hawrylack H, Mooney R. Inhaled peppermint oil for postop nausea in patients undergoing cardiac surgery. Nursing 2016;46(7):61-7.

\section{Buckle 1999 \{published data only\}}

Buckle J. Aromatherapy in perianesthesia nursing. Journal of Perianesthesia Nursing 1999;14(6):336-44. [PUBMED: 10839071]

\section{Chaiyakunapruk 2006 \{published data only\}}

Chaiyakunapruk N, Kitikannakorn N, Nathisuwan S, Leeprakobboon $\mathrm{K}$, Leelasettagool C. The efficacy of ginger for the prevention of postoperative nausea and vomiting: a meta-analysis. American Journal of Obstetrics and Gynecology 2006;194(1):95-9. [PUBMED: 16389016]

\section{Chiravalle 2005 \{published data only\}}

Chiravalle P, McCaffrey R. Alternative therapy applications for postoperative nausea and vomiting. Holistic Nursing Practice 2005;19(5):207-10. [PUBMED: 16145329]

\section{Chrubasik 2005 \{published data only\}}

Chrubasik S, Pittler MH, Roufogalis BD. Zingiberis rhizoma: a comprehensive review on the ginger effect and efficacy profiles. Phytomedicine 2005;12(9):684-701. [PUBMED: 16194058]

\section{Couture 2006 \{published data only\}}

Couture D, Maye J, O'Brien D, Beldia Smith A. Therapeutic modalities for the prophylactic management of postoperative nausea and vomiting. Journal of Perianesthesia Nursing 2006;21(6):398-403. [PUBMED: 17169749]
Dabaghzadeh, 2014 \{published data only\}

Dabaghzadeh F, Khalili H, Dashti-Khavidaki S. Ginger for prevention or treatment of drug-induced nausea and vomiting. Current Clinical Pharmacology 2014;9(4):387-94. [PUBMED: 24218997]

\section{de Pradier 2006 \{published data only\}}

de Pradier E. A trial of a mixture of three essential oils in the treatment of postoperative nausea and vomiting [Essai d'un melange de trois huiles essentielles dans le traitement des nausees et vomissements postoperatoires]. International Journal of Aromatherapy 2006;16(1):15-20. [INIST-CNRS, Cote INIST : 27514, 35400013920567.0030]

Eberhart 2003 \{published data only\}

Eberhart L, Mayer R, Betz O, Tsolakidis S, Hilpert W, Morin A, et al. Ginger does not prevent postoperative nausea and vomiting after laparoscopic surgery. Anesthesia and Analgesia 2003;96:995-8. [PUBMED: 12651648]

\section{Eberhart 2006 \{published data only\}}

Eberhart L, Frank S, Lange H, Morin A, Scherag A, Wulf H, et al. Systematic review on the recurrence of postoperative nausea and vomiting after a first episode in the recovery room - implications for the treatment of PONV and related clinical trials. BMC Anesthesiology 2006;6(1):14. [PUBMED: 17166262]

\section{Ekenberg 2007 \{published data only\}}

Ekenberg M, Larsson A. The non-pharmacological care of nausea and vomiting [Sjuksköterskans ickefarmakologiska omvårdnadsåtgärder vid illamående och kräkningar]. unpublished dissertation 2007. [http:// hdl.handle.net/2077/4746]

\section{Ernst 2000 \{published data only\}}

Ernst E, Pittler M. Efficacy of ginger for nausea and vomiting: a systematic review of randomized clinical trials. British Journal of Anaesthesia 2000;84(3):367-71. [PUBMED: 10793599]

Fujii 2008 \{published data only\}

Fujii Y. Current prevention and treatment of postoperative nausea and vomiting after gynecological laparoscopic surgery. Current Drug Therapy 2008;3(1):14-25. [DOI: $10.2174 / 157488508783331180]$

\section{Geiger 2005 \{published data only\}}

Geiger JL. The essential oil of ginger, zingiber officinale, and anaesthesia. International Journal of Aromatherapy 2005;15(1):7-14. [DOI: 10.1016/j.ijat.2004.12.002]

\section{Golembiewski 2005 \{published data only\}}

Golembiewski J, Chernin E, Chopra T. Prevention and treatment of postoperative nausea and vomiting. American Journal of Health-System Pharmacy 2005;62(12):1247. [PUBMED: 15947124]

\section{Hosseini, 2015 \{published data only\}}

Hosseini F, Adib-Hajbaghery M. Ginger essence effect on nausea and vomiting after open and laparoscopic nephrectomies. Nursing and Midwifery Studies 2015;4(2):1-6. [DOI: 10.17795/ nmsjournal28625; PUBMED: 26339671] 
Keifer 2007 \{published data only\}

Keifer D, Ulbricht C, Abrams T, Basch E, Giese N, Giles M, et al. Peppermint (mentha piperita): an evidence-based systematic review by the natural standard research collaboration. Journal of Herbal Pharmacotherapy 2007;7(2):91-143. [PUBMED: 18285310]

\section{Kim 2006 \{published data only\}}

Kim JT, Wajda M, Cuff G, Serota D, Schlame M, Axelrod DM, et al. Evaluation of aromatherapy in treating postoperative pain: pilot study. Pain Practice 2006;6(4):273-7. [PUBMED: 17129308]

\section{Kim 2007 \{published data only\}}

Kim JT, Ren CJ, Fielding GA, Pitti A, Kasumi T, Wajda M, et al. Treatment with lavender aromatherapy in the post-anesthesia care unit reduces opioid requirements of morbidly obese patients undergoing laparoscopic adjustable gastric banding. Obesity Surgery 2007;17(7):920-5. [PUBMED: 17894152]

\section{King 2009 \{published and unpublished data\}}

King L, Reagan S, Thomason H, Clements F, Botchuck J, Hardin S. Quease Ease aromatherapy for treatment of PONV. 2009 National Teaching Institute Research Abstracts. American Journal of Critical Care. 2009; Vol. 18:e1-e17. [http:// ajcc.aacnjournals.org/cgi/reprint/18/3/e1]

\section{Koretz 2004 \{published data only\}}

Koretz RL, Rotblatt M. Complementary and alternative medicine in gastroenterology: the good, the bad, and the ugly. Clinical Gastroenterology and Hepatology 2004;2(11):957-67. [PUBMED: 15551247]

\section{Lee, 2016 \{published data only\}}

Lee YR, Shin HS. Effectiveness of ginger essential oil on postoperative nausea and vomiting in abdominal surgery patients. The Journal of Alternative and Complementary Medicine 2016 [Epub ahead of print]:1-5. [DOI: 10.1089/ acm.2015.0328; PUBMED: 27841938]

\section{Mamaril 2006 \{published data only\}}

Mamaril ME, Windle PE, Burkard JF. Prevention and management of postoperative nausea and vomiting: a look at complementary techniques. Journal of Perianesthesia Nursing 2006;21(6):404-10. [PUBMED: 17169750]

\section{Mcilvoy, 2015 \{published data only\}}

Mcilvoy L, Richmer L, Kramer D, Jackson R, Shaffer L, Lawrence J, et al. The efficacy of aromatherapy in the treatment of postdischarge nausea in patients undergoing outpatient abdominal surgery. Journal of Perianesthesia Nursing 2015;30(5):383-88. [DOI: 10.1016/j.jopan.2014.10.004; PUBMED: 26408512]

\section{Morin 2004 \{published data only\}}

Morin A, Betz O, Kranke P, Geldner G, Wulf H, Eberhart L. Is ginger a relevant antiemetic for postoperative nausea and vomiting? [Ist ingwer ein sinnvolles antiemetikum für die postoperative phase?]. Anasthesiologie, Intensivmedizin, Notfallmedizin, Schmerztherapie: Ains 2004;39(5):281-5. [PUBMED: 15156419]

\section{Nale 2007 \{published data only\}}

Nale R, Bhave S, Divekar DS. A comparative study of ginger and other routinely used antiemetics for prevention of post operative nausea and vomiting. Journal of Anaesthesiology, Clinical Pharmacology 2007;23(4):405-10. [http:// www.joacp.org/index.php?option=com_journal\&task=check_ subscription\&id=642]

\section{Nanthakomon 2006 \{published data only\}}

Nanthakomon T, Pongrojpaw D. The efficacy of ginger in prevention of postoperative nausea and vomiting after major gynecologic surgery. Journal of the Medical Association of Thailand 2006;89(4):S130-6. [PUBMED: 17725149]

Phillips 1993 \{published data only\}

Phillips S, Ruggier R, Hutchinson SE. Zingiber officinale (ginger) - an antiemetic for day case surgery. Anaesthesia 1993;48(8):715-7. [PUBMED: 8214465]

\section{Pompeo 2007 \{published data only\}}

Pompeo DA, Nicolussi AC, Galvão CM, Sawada N. Nursing interventions for the prevention and relief of nausea and vomiting during the immediate postoperative period [Intervenciones de enfermeria para nausea y vomito en el periodo postoperativo immediato]. Acta Paulista de Enfermagem 2007;20:191-8. [LILACS: 457066]

\section{Pongrojpaw 2003 \{published data only\}}

Pongrojpaw D, Chiamchanya C. The efficacy of ginger in prevention of post-operative nausea and vomiting after outpatient gynecological laparoscopy. Journal of the Medical Association of Thailand 2003;86(3):244-50. [PUBMED: 12757064]

\section{Rosén 2006 \{published data only\}}

Rosén E, Jackson K. Nursing interventions to prevent and/or relieve postoperative nausea and vomiting [Förebyggande och/eller lindrande omvårdnadsåtgärder vid illamående och kräkning efter operativa ingrepp]. Unpublished Thesis 2006. [http://urn.kb.se/resolve?urn=urn:nbn:se:oru:diva-700]

\section{Spencer 2004 \{published data only\}}

Spencer KW. Isopropyl alcohol inhalation as treatment for nausea and vomiting. Plastic Surgical Nursing 2004;24(4):149. [PUBMED: 15632723]

\section{Tavlan 2006 \{published data only\}}

Tavlan A, Tuncer S, Erol A, Reisli R, Aysolmaz G, Otelcioglu S. Prevention of postoperative nausea and vomiting after thyroidectomy: combined antiemetic treatment with dexamethasone and ginger versus dexamethasone alone. Clinical Drug Investigation 2006;26(4):209. [PUBMED: 17163253]

\section{Tramer 2001 \{published data only\}}

Tramer MR. A rational approach to the control of postoperative nausea and vomiting: evidence from systematic reviews. Part 1. Efficacy and harm of antiemetic interventions, and methodological issues. Acta Anaesthesiologica Scandinavica 2001;45(1):4-13. [PUBMED: 11152031] 
Visaylaputra 1998 \{published data only\}

Visalyaputra S, Petchpaisit N, Somcharoen K, Choavaratana R. The efficacy of ginger root in the prevention of postoperative nausea and vomiting after outpatient gynaecological laparoscopy. Anaesthesia 1998;53(5):506-10. [PUBMED: 9659029]

\section{Zeraati, 2016 \{published data only\}}

Zeraati H, Shahinfar J, Hesari S, Masrorniya M, Nasimi F. The effect of ginger extract on the incidence and severity of nausea and vomiting after cesarean section under spinal anesthesia. Anesthesiology and Pain Medicine 2016;6(5):1-7. [DOI: 10.5812] aapm.38943]

\section{References to ongoing studies}

NCT02189980 \{published data only\}

NCT02189980. Aromatherapy using a nasal clip after surgery. clinicaltrials.gov/ct2/show/NCT02189980 2016.

\section{NCT02732379 \{published data only\}}

NCT02732379. Effect of aromatherapy on postoperative nausea, vomiting and quality of recovery. clinicaltrials.gov/ct2/show/ NCT02732379 2017.

\section{Additional references}

\section{Altman 2005}

Altman DG, Bland JM. Standard deviations and standard errors. BMJ 2005;331(7521):903. [PUBMED: PMC1255808]

\section{Apfel 2002}

Apfel C, Roewer N, Korttila K. How to study postoperative nausea and vomiting. Acta Anaesthesiologica Scandinavica 2002;46(8):921-8. [PUBMED: 12190791]

\section{Apfel 2010}

Apfel CC. Postoperative nausea and vomiting. In: Miller RD editor(s). Miller's anesthesia. 7th Edition. Philadelphia: Churchill Livingstone, 2010:2729-55.

\section{Balint 2010}

Balint B, Watz H, Amos C, Owen R, Higgins M, Kramer B. Onset of action of indacaterol in patients with COPD: comparison with salbutamol and salmeterol-fluticasone. International Journal of Chronic Obstructive Pulmonary Disease 2010;5:311-8. [PUBMED: 20856830]

\section{Boogaerts 2000}

Boogaerts JG, Vanacker E, Seidel L, Albert A, Bardiau FM. Assessment of postoperative nausea using a visual analogue scale. Acta Anaesthesiologica Scandinavica 2000;44(4):470-4. [PUBMED: 10757584 ]

\section{Borenstein 2010}

Borenstein M, Hedges LV, Higgins J, Rothstein HR. A basic introduction to fixed-effect and random-effects models for meta-analysis. Research Synthesis Methods 2010;1(2):97-111. [DOI: 10.1002/jrsm.12]

\section{Carlisle 2006}

Carlisle JB, Stevenson CA. Drugs for preventing postoperative nausea and vomiting. Cochrane Database of Systematic Reviews 2006, Issue 3. [DOI: 10.1002/14651858.CD004125.pub2]

\section{Dalvi 1991}

Dalvi SS, Nadkarni PM, Pardesi R, Gupta KC. Effect of peppermint oil on gastric emptying in man: a preliminary study using a radiolabelled solid test meal. Indian Journal of Physiology and Pharmacology 1991;35(3):212-4. [PUBMED: 1791066]

\section{Deeks 2001}

Deeks JJ, Altman DG, Bradburn MJ. Egger M, Davey Smith G, Altman DG, editor(s). Systematic Reviews in Health Care: Meta-Analysis in Context. Statistical methods for examining heterogeneity and combining results from several studies in meta-analysis. 2nd Edition. London: BMJ Publication Group, 2001.

\section{Deeks 2011}

Deeks JJ, Higgins JPT, Altman DG (editors). Chapter 9: Analysing data and undertaking meta-analyses. In: Higgins JPT, Green $S$ (editors). Cochrane Handbook for Systematic Reviews of Interventions Version 5.1.0 (updated March 2011). The Cochrane Collaboration, 2011. Available from handbook.cochrane.org.

\section{Dobetsberger 2011}

Dobetsberger C, Buchbauer G. Actions of essential oils on the central nervous system: an updated review. Flavour and Fragrance Journal 2011;26:300-16. [DOI: 10.1002/ffj.2045]

\section{Egger 1997}

Egger M, Davey Smith G, Schneider M, Minder C. Bias in meta-analysis detected by a simple, graphical test. $B M J$ 1997;315(7109):629-34. [PUBMED: 9310563]

\section{Eisenberg 1998}

Eisenberg DM, Davis R, Ettner S, Appel S, Wilkey S, Von Rompay M, et al. Trends in alternative medicine use in the United States, 1990-1997: results of a follow-up national survey. JAMA 1998;280(18):1569-75. [PUBMED: 9820257 ]

\section{Ernst 2001}

Ernst E (editor). Aromatherapy. The Desktop Guide to Complementary and Alternative Medicine: An Evidence-Based Approach. Edinburgh, United Kingdom: Harcourt Publishers Limited, 2001:33-5. [ISBN: 0-723-43383-6]

\section{Ferdenzi 2011}

Ferdenzi C, Schirmer A, Roberts SC, Delplanque S, Porcherot C, Cayeux I, et al. Affective dimensions of odor perception: a comparison between Swiss, British, and Singaporean populations. Emotion 2011;11(5):1168. [PUBMED: 21534667]

\section{Gan 2014}

Gan TJ, Diemunsch P, Habib AS, Kovac A, Kranke P, Meyer TA, et al. Consensus guidelines for the management of postoperative nausea and vomiting. Anesthesia and Analgesia 2014;118(1):85-113. [DOI: 10.1213/ANE.0000000000000002] 


\section{GRADEpro GDT 2015 [Computer program]}

McMaster University (developed by Evidence Prime). GRADEpro GDT. Version assessed 6 August 2016. Hamilton (ON): McMaster University (developed by Evidence Prime), 2015.

\section{Herz 2009}

Herz RS. Aromatherapy facts and fictions: a scientific analysis of olfactory effects on mood, physiology and behavior. International Journal of Neuroscience 2009;119(2):263-90. [DOI: 10.1080/00207450802333953]

\section{Hewitt 2009}

Hewitt V, Watts R. The effectiveness of non-invasive complementary therapies in reducing postoperative nausea and vomiting following abdominal laparoscopic surgery in women: a systematic review. The JBI Library of Systematic Reviews 2009;7(19):850-907. [http://wacebnm.curtin.edu.au/ reviews/SR_81_revised_WA.pdf]

\section{Higgins 2003}

Higgins JPT, Thompson SG, Deeks JJ, Altman DG. Measuring inconsistency in meta-analyses. BMJ 2003;327:557-60.

\section{Higgins 2011}

Higgins JPT, Altman DG, Sterne JAC (editors). Chapter 8: Assessing risk of bias in included studies. In: Higgins JPT, Green $S$ (editors). Cochrane Handbook for Systematic Reviews of Interventions Version 5.1.0 (updated March 2011). The Cochrane Collaboration, 2011. Available from handbook.cochrane.org.

\section{Hills 1991}

Hills JM, Aaronson PI. The mechanism of action of peppermint oil on gastrointestinal smooth muscle. An analysis using patch clamp electrophysiology and isolated tissue pharmacology in rabbit and guinea pig. Gastroenterology 1991;101(1):55-65. [PUBMED: 1646142]

\section{Huntley 2014}

Huntley A, Hunt R. Some patients experience relief from postoperative nausea with aromatherapy. Focus on Alternative and Complementary Therapies 2014;19(2):114-5. [DOI: 10.1111/ fct.12116]

\section{Huwalt 2014 [Computer program]}

Huwalt J, Steinhorst S. Plot Digitizer. Version 2.6.6. Huwalt J, Steinhorst S, 2014

\section{Jokinen 2012}

Jokinen J, Smith AF, Roewer N, Eberhart LH, Kranke P. Management of postoperative nausea and vomiting: how to deal with refractory PONV. Anesthesiology Clinics 2012;30(3):481-93. [10.1016/j.anclin.2012.07.003]

\section{Langendam 2013}

Langendam MW, Akl EA, Dahm P, Glasziou P, Guyatt G, Schunemann HJ. Assessing and presenting summaries of evidence in Cochrane Reviews. Systematic Reviews 2013;2(81):1-9. [DOI: 10.1186/2046-4053-2-81]

\section{Lefebvre 2011}

Lefebvre C, Manheimer E, Glanville J. Chapter 6: Searching for studies. In: Higgins JPT, Green S (editors). Cochrane Handbook for Systematic Reviews of Interventions Version 5.1.0 (updated March 2011). The Cochrane Collaboration, 2011. Available from handbook.cochrane.org.

\section{Leicester 1982}

Leicester RJ, Hunt RH. Peppermint oil to reduce colonic spasm during endoscopy. Lancet 1982;2(8305):989. [PUBMED: 6127488]

\section{Linck 2010}

Linck V, da Silva A, Figueiró M, Caramão EB, Moreno PR, Elisabetsky E. Effects of inhaled linalool in anxiety, social interaction and aggressive behavior in mice. Phytomedicine 2010;17(8-9):679-83. [PUBMED: 19962290]

\section{Lindquist 2013}

Lindquist R, Snyder M, Tracy MF. Complementary \& Alternative Therapies in Nursing. New York: Springer Publishing Company, LLC, 2013. [ISBN: 0-8261-9612-8, 978-0-8261-9612-5]

\section{Lis-Balchin 1997}

Lis-Balchin M. Essential oils and aromatherapy: their modern role in healing. The Journal of the Royal Society for the Promotion of Health 1997;117(5):324. [PUBMED: 9519666]

\section{Lis-Balchin 2006}

Lis-Balchin M. Aromatherapy Science. London: Pharmaceutical Press, 2006. [ISBN: 85369578 4]

\section{Lowe 2010}

Lowe AE, FitzGerald L. Aromatherapy and mood changes in females with functional abdominal pain. Communicating Nursing Research 2010;43:283.

\section{Lua 2012}

Lua PL, Zakaria NS. A brief review of current scientific evidence involving aromatherapy use for nausea and vomiting. The Journal of Alternative and Complementary Medicine 2012;18(6):534-40. [DOI: 10.1089/acm.2010.0862]

\section{May 1996}

May B, Kuntz HD, Kieser M, KoÈhler S. Efficacy of a fixed peppermint oil/caraway oil combination in nonulcer dyspepsia. Arzneimittel-Forschung/Drug Research 1996;46:1149-53. [PUBMED: 9006790]

\section{Meyer 1995}

Meyer K, Schwartz J, Crater D, Keyes B. Zingiber officinale (ginger) used to prevent 8-Mop associated nausea. Dermatology Nursing 1995;7(4):242-4. [PUBMED: 7646942]

\section{Myles 2000}

Myles P, Williams D, Hendrata M, Anderson H, Weeks A. Patient satisfaction after anaesthesia and surgery: results of a prospective survey of 10,811 patients. British Journal of Anaesthesia 2000;84(1):6-10. [PUBMED: 10740539] 


\section{Orne 1962}

Orne MT. On the social psychology of the psychological experiment: with particular reference to demand characteristics and their implications. American Psychologist 1962;17(11):776-83. [DOI: 10.1037/h0043424]

\section{Posadzki 2013}

Posadzki P, Watson LK, Alotaibi A, Ernst E. Prevalence of use of complementary and alternative medicine (CAM) by patients/ consumers in the UK: systematic review of surveys. Clinical Medicine 2013;13(2):126-31. [PUBMED: 23681857]

\section{Price 2007}

Price S, Price L (editors). Aromatherapy for Health Professionals. 3rd Edition. Edinburgh: Churchill Livingstone, 2007. [ISBN: 0-443-06210-2

\section{RevMan 2014 [Computer program]}

Nordic Cochrane Centre, The Cochrane Collaboration. Review Manager 5 (RevMan 5). Version 5.3. Copenhagen: Nordic Cochrane Centre, The Cochrane Collaboration, 2014.

\section{Rogers 1988}

Rogers J, Tay H, Misiewicz J. Peppermint oil. Lancet 1988;332(8602):98-9. [PUBMED: 2898713 ]

\section{Safajou 2014}

Safajou F, Shahnazi M, Nazemiyeh H. The effect of lemon inhalation aromatherapy on nausea and vomiting of pregnancy: a double-blinded, randomized, controlled clinical trial. Iranian Red Crescent Medical Journal 2014;16(3):1-6. [DOI: 10.5812/ ircmj.14360]

\section{CHARACTERISTICS OF STUDIES}

Characteristics of included studies [ordered by study ID]

\section{Sigmund 1969}

Sigmund CJ, McNally EF. The action of a carminative on the lower esophageal sphincter. Gastroenterology 1969;56(1):13-8. [PUBMED: 5765428]

\section{Sterne 2011}

Sterne JAC, Egger M, Moher D (editors). Chapter 10: Addressing reporting biases. In: Higgins JPT, Green S (editors). Cochrane Handbook for Systematic Reviews of Interventions. Version 5.1.0 (updated March 2011). The Cochrane Collaboration, 2011. Available from handbook.cochrane.org.

\section{Westphal 1996}

Westphal J, Hörning M, Leonhardt K. Phytotherapy in functional abdominal complaints: results of a clinical study with a preparation of several plants. Phytomedicine 1996;2:285-91. [CENTRAL: CN-00254483]

\section{References to other published versions of this review \\ Hines 2009}

Hines S, Steels E, Chang A, Gilshenan K. Aromatherapy for treatment of postoperative nausea and vomiting. Cochrane Database of Systematic Reviews 2009, Issue 1. [DOI: 10.1002/14651858.CD007598]

\section{Hines 2012}

Hines S, Steels E, Chang A, Gibbons K. Aromatherapy for treatment of postoperative nausea and vomiting. Cochrane Database of Systematic Reviews 2012, Issue 4. [DOI: 10.1002/14651858.CD007598.pub2]

Anderson 2004

\begin{tabular}{|c|c|}
\hline Methods & $\begin{array}{l}\text { RCT of peppermint oil, IPA or normal saline aromatherapy to treat PONV } \\
\text { Setting: PACU acute hospital, USA }\end{array}$ \\
\hline Participants & $\begin{array}{l}33 \text { patients aged } 18 \text { years + having surgery under general or regional anaesthesia, or deep IV sedation, } \\
\text { who reported nausea in PACU. Treatment groups did not differ in the percentage having general anaes- } \\
\text { thesia, the type of surgery, age or gender distribution. } \\
\text { Exclusions: patients who were unable to give informed consent; patients who did not require anaesthe- } \\
\text { sia services }\end{array}$ \\
\hline Interventions & $\begin{array}{l}\text { On the participant's spontaneous report of PON, they were instructed to take three slow deep breaths } \\
\text { to inhale the vapours from a pre-prepared gauze pad soaked with either peppermint oil }(n=10), \text { IPA ( } n \\
=11) \text {, or normal saline placebo }(n=12) \text { held directly under their nostrils. After } 2 \text { min the participant was } \\
\text { asked to rate their nausea by VAS and given the choice to continue aromatherapy or have standard IV } \\
\text { antiemetics. At } 5 \text { min post the initial treatment, the participant was again asked to rate their nausea } \\
\text { and if they would like to continue aromatherapy or have standard IV antiemetics. }\end{array}$ \\
\hline
\end{tabular}

Outcomes

- Severity of nausea as measured on $100 \mathrm{~mm}$ VAS at 2 min and 5 min after treatment. VAS from 'no nausea' to 'worst possible nausea'.

- Choosing to use 'rescue' antiemetics 
- Satisfaction with management of nausea, as measured by $100 \mathrm{~mm}$ VAS with range from $0=$ extremely dissatisfied to $100=$ fully satisfied

Notes

Possible lack of accuracy with some participants self-recording data in PACU if they had poor or blurred vision. Authors Lynn Anderson and Dr Jeffrey Gross emailed to request further information on group sizes, which was supplied by Dr Gross. Supported by the Department of Anesthesiology, University of Connecticut School of Medicine.

\section{Risk of bias}

\begin{tabular}{lll}
\hline Bias & Authors' judgement & Support for judgement \\
\hline $\begin{array}{l}\text { Random sequence genera- } \\
\text { tion (selection bias) }\end{array}$ & Low risk & "...group assignments were made in a randomised, double-blind fashion" \\
& $\begin{array}{l}\text { Comment: probably done. Nurses administering treatment were unaware of } \\
\text { contents of each package of treatment materials. Patients who had consented } \\
\text { to participate entered study when they spontaneously reported nausea. }\end{array}$
\end{tabular}

\begin{tabular}{|c|c|c|}
\hline \multirow[t]{3}{*}{$\begin{array}{l}\text { Allocation concealment } \\
\text { (selection bias) }\end{array}$} & Low risk & $\begin{array}{l}\text { "A random number generator determined the contents of each serially num- } \\
\text { bered bag." "...prepared by an individual not otherwise involved in the study..." }\end{array}$ \\
\hline & & Data "analysed by investigator unaware of treatment allocation". \\
\hline & & Comment: probably done \\
\hline
\end{tabular}

\begin{tabular}{|c|c|c|}
\hline $\begin{array}{l}\text { Blinding of participants } \\
\text { and personnel (perfor- }\end{array}$ & Low risk & $\begin{array}{l}\text { Staff administering treatment blinded by use of "lightly scented" surgical } \\
\text { masks. }\end{array}$ \\
\hline All outcomes & & Comment: probably done \\
\hline
\end{tabular}

\begin{tabular}{lll}
\hline $\begin{array}{l}\text { Blinding of outcome as- } \\
\text { sessment (detection bias) }\end{array}$ & High risk & $\begin{array}{l}\text { Participants were self-reporting subjective assessment of nausea and were not } \\
\text { blinded. }\end{array}$ \\
$\begin{array}{l}\text { All outcomes } \\
\text { Comment: due to the strong aroma of the peppermint oil, it would be impos- } \\
\text { sible to blind the participant receiving this to their allocation once treatment } \\
\text { commenced. Probably not done }\end{array}$
\end{tabular}

\begin{tabular}{lll}
\hline $\begin{array}{l}\text { Incomplete outcome data } \\
\text { (attrition bias) } \\
\text { All outcomes }\end{array}$ & Low risk & Comment: outcomes reported for all participants \\
\hline $\begin{array}{l}\text { Selective reporting (re- } \\
\text { porting bias) }\end{array}$ & Low risk & Comment: results reported for all stated outcomes \\
\hline Other bias & Low risk & Comment: study appears to be free of other sources of bias \\
\hline
\end{tabular}

Cotton 2007

\begin{tabular}{ll} 
Methods & $\begin{array}{l}\text { Prospective randomized study of IPA inhalation as compared to IV ondansetron for PONV. Replication } \\
\text { of study: Winston } 2003 .\end{array}$ \\
& Setting: PACU/same day surgery unit, USA \\
\hline Participants & $\begin{array}{l}21 \text { women aged } 18-65 \text { who were scheduled for laparoscopic same-day surgery (ASA physical status I, II } \\
\text { or III), } \mathrm{n}=10 \text { treatment, } \mathrm{n}=11 \text { control }\end{array}$ \\
& $\begin{array}{l}\text { Exclusions: patients who had recent upper respiratory tract infections, inability or impaired ability to } \\
\text { breathe through the nose, or history of hypersensitivity to IPA, 5- } \mathrm{HT}_{3} \text { receptor antagonists, promet- }\end{array}$
\end{tabular}


Cotton 2007 (Continued)

hazine or any other anaesthesia protocol medication, had used an antiemetic within 24 hours of surgery, were pregnant or breastfeeding, had history of inner ear pathology, motion sickness or migraine headaches or were taking disulfiram, cefoperazone, or metronidazole

Interventions

Comparison of inhaled IPA to intravenous ondansetron for treatment of PONV

Ondansetron (control) group: nausea treated with ondansetron $4 \mathrm{mg}$ IV every $15 \mathrm{~min}$ to a maximum 8 $\mathrm{mg}$ dose. Time, dose and VNRS score recorded

IPA (experimental) group: nausea treated by holding a folded alcohol pad approximately $1 / 2$ inch (approximately $1.3 \mathrm{~cm}$ ) from the participant's nares and instructing them to take 3 deep breaths in and out through the nose. Treatments given every 5 min up to a total of 3 administrations

Breakthrough PONV was treated with promethazine suppositories for both groups.

Participants were also given supplies of IPA and promethazine to use as needed at home after discharge and asked to record any occurrences of PONV with a data collection tool provided by the researchers.

Outcomes $\begin{aligned} & \text { Time to reduction in nausea score as measured by VRNS (range 0-10 where } 0=\text { no nausea and } 10= \\ & \text { worst imaginable nausea). Collected for baseline at pre op, then immediately postop in PACU and at } \\ & \text { any time the participant complained of nausea. Additionally, participants who complained of nausea } \\ & \text { were assessed every } 5 \text { min following treatment for } 30 \text { min and then every } 15 \text { min until discharge from } \\ & \text { PACU. } \\ & \text { Participants also reported data on PONV for the } 24 \text { h post-discharge as well rating their anaesthesia ex- } \\ & \text { perience overall. }\end{aligned}$
$\begin{aligned} & \text { Author, Joseph Pellegrini contacted for further data. Some was provided however due to data corrup- } \\ & \text { tion problems not all requested data were available. Support was received from the US Navy Clinical, } \\ & \text { Investigation Department. }\end{aligned}$

\section{Risk of bias}

\begin{tabular}{|c|c|c|}
\hline Bias & Authors' judgement & Support for judgement \\
\hline \multirow[t]{2}{*}{$\begin{array}{l}\text { Random sequence genera- } \\
\text { tion (selection bias) }\end{array}$} & Low risk & $\begin{array}{l}\text { "patient was randomly assigned to the control group or the experimental } \\
\text { group by using a computer-generated random numbers program." }\end{array}$ \\
\hline & & Comment: done \\
\hline \multirow[t]{2}{*}{$\begin{array}{l}\text { Allocation concealment } \\
\text { (selection bias) }\end{array}$} & Low risk & $\begin{array}{l}\text { "Block randomisation was used for all of the studies using a computer gener- } \\
\text { ated randomisation program done by an independent party (myself) who was } \\
\text { not involved in the data collection" (emailed author response) }\end{array}$ \\
\hline & & Comment: done \\
\hline
\end{tabular}

\begin{tabular}{|c|c|c|}
\hline $\begin{array}{l}\text { Blinding of participants } \\
\text { and personnel (perfor- }\end{array}$ & Unclear risk & $\begin{array}{l}\text { Comment: no information given regarding blinding. Does not appear to have } \\
\text { been done }\end{array}$ \\
\hline
\end{tabular}

mance bias)

All outcomes

\begin{tabular}{lll}
\hline $\begin{array}{l}\text { Blinding of outcome as- } \\
\text { sessment (detection bias) } \\
\text { All outcomes }\end{array}$ & Unclear risk & $\begin{array}{l}\text { Comment: no information given regarding blinding. Does not appear to have } \\
\text { been done }\end{array}$ \\
\hline $\begin{array}{l}\text { Incomplete outcome data } \\
\begin{array}{l}\text { (attrition bias) } \\
\text { All outcomes }\end{array}\end{array}$ & Low risk & $\begin{array}{l}28 \text { participants "disenrolled due to protocol violations": } 12 \text { from control group } \\
\text { who were given IPA postoperatively; } 6 \text { from experimental group given other } \\
\text { antiemetics in PACU before IPA; and } 10 \text { who lost their IPA or promethazine fol- } \\
\text { lowing discharge to home. }\end{array}$
\end{tabular}


Cotton 2007 (Continued)

Comment: probably done

Selective reporting (re- Low risk Comment: results reported for all stated outcomes
porting bias)

Other bias Low risk Comment: study appears to be free of other sources of bias

\section{Cronin 2015}

Methods

2-group CCT comparing controlled breathing to controlled breathing with IPA aromatherapy. Experimental group $(n=41)$ received controlled breathing exercise ( 3 deep breaths in and out, guided by PACU nurse) and an IPA pad held under their nose at the same time. Control group $(n=41)$ received controlled breathing exercise only

Setting: day surgery unit, USA

Participants women having laparoscopic surgery. Age range: 18-59 years, (mean = 40.5 (SD = 11.35)) No signifi-
cant differences between experimental and control in history of PONV, or type of procedure. No signifi-
cant difference in time spent in surgery and recovery, or total amount of fluids received. Mean ages sig-
nificantly different between groups: experimental group (mean $=43.2)$ versus control (mean $=37.8)$. Al-
so there were significantly fewer smokers in the experimental group (5\%) than the control group (20\%).

Interventions

Controlled breathing with and without IPA aromatherapy. IPA aromatherapy: standard 'prep-pad' held under participant's nose while breathing deeply

Outcomes

Nausea severity as measured on a VRS (0-10, $0=$ no nausea, $10=$ worst possible) at initial complaint, 2 $\mathrm{min}$ and $5 \mathrm{~min}$, use of rescue medications

Notes Conference abstract: further information received from study authors. No information on funding sources

\section{Risk of bias}

\section{Bias Authors' judgement Support for judgement}

Random sequence genera- High risk
tion (selection bias)

\author{
"This study used a prospective randomized two-group experimental design." \\ "Randomization was based on the calendar month, with the experimental \\ treatment group assigned in even months and the control group assigned dur- \\ ing odd months." \\ Comment: study is CCT
}

\begin{tabular}{|c|c|c|}
\hline $\begin{array}{l}\text { Allocation concealment } \\
\text { (selection bias) }\end{array}$ & High risk & $\begin{array}{l}\text { "...experimental treatment group assigned in even months and the control } \\
\text { group assigned during odd months." }\end{array}$ \\
\hline
\end{tabular}

Comment: probably not concealed

\begin{tabular}{|c|c|c|}
\hline $\begin{array}{l}\text { Blinding of participants } \\
\text { and personnel (perfor- } \\
\text { mance bias) }\end{array}$ & High risk & $\begin{array}{l}\text { "For those in the experimental group, in addition to the CB coaching, an IPA } \\
\text { pad was placed directly under the nostrils of the patient, so that aromatherapy } \\
\text { was received during inhalation." }\end{array}$ \\
\hline All outcomes & & Comment: likely no blinding of participants or staff administering intervention \\
\hline
\end{tabular}

Blinding of outcome as- Unclear risk sessment (detection bias)

All outcomes
Comment: the publication does not state who measured the treatment outcomes. 
Cronin 2015 (Continued)

Incomplete outcome data Unclear risk $\quad$ "...RNs verbalized that the actual PON score was difficult to obtain when a pa(attrition bias) tient was severely nauseated. We excluded these patients which decreased

All outcomes our sample size to $82 . "$

Comment: exclusion of severely nauseated participants a potential source of bias, but it is unclear from reported results to which group these participants were allocated

Selective reporting (re- Low risk Comment: stated outcomes reported
porting bias)

Other bias Unclear risk Comment: no other sources of bias apparent

\section{Ferruggiari 2012}

\begin{tabular}{ll}
\hline Methods & 3-group non-RCT comparing peppermint vapour, saline vapour and ondansetron to treat PON \\
\hline Participants & $\begin{array}{l}70 \text { non-pregnant female surgical patients (23 peppermint/22 saline/25 ondansetron) > 18 years under- } \\
\text { going a surgical procedure at a suburban community hospital. Exclusionary criteria were olfactory sen- } \\
\text { sory loss, allergy to peppermint, asthma, chronic obstructive pulmonary disease, or chronic respiratory } \\
\text { conditions }\end{array}$ \\
& Setting: community hospital, USA \\
\hline Interventions & $\begin{array}{l}\text { Peppermint oil or normal saline placed on identical size gauze squares and sealed in zip-lock plastic } \\
\text { bags. Treatment administered on initial complaint of nausea in PACU. Aromatherapy group partici- } \\
\text { pants instructed to take one inhalation from opened bag. Ondansetron group received } 4 \text { mg IV. A VAS } \\
\text { was used to rate nausea at the first complaint; at } 5 \text { min after intervention; and, if nausea persisted, at } \\
10 \text { min after intervention }\end{array}$ \\
\hline Outcomes & $\begin{array}{l}\text { Nausea severity at } 3 \text { and } 5 \text { min (and, if nausea persisted, at } 10 \text { min after intervention) as measured by } \\
200 \text { mm VAS (0 = no nausea, } 200=\text { worst possible nausea) }\end{array}$ \\
\hline Notes & $\begin{array}{l}\text { Confirmation received from study authors that while a 200 mm VAS was used to measure nausea, the } \\
\text { results were converted to centimetres (i.e. } 20 \text { cm scale, 0-20) in the published report. No information on } \\
\text { funding sources }\end{array}$ \\
\hline
\end{tabular}

\section{Risk of bias}

\begin{tabular}{lll}
\hline Bias & Authors' judgement & Support for judgement \\
\hline $\begin{array}{ll}\text { Random sequence genera- } \\
\text { tion (selection bias) }\end{array}$ & High risk & $\begin{array}{l}\text { "For those receiving inhalation, the investigators randomly selected a sealed } \\
\text { zip lock bag from a box containing bags of both peppermint and saline aro- } \\
\text { mas." } \\
\text { Comment: not done: study is CCT }\end{array}$ \\
\end{tabular}

\begin{tabular}{lll}
\hline $\begin{array}{l}\text { Allocation concealment } \\
\text { (selection bias) }\end{array}$ & High risk & Comment: not done: study is CCT \\
\hline $\begin{array}{l}\text { Blinding of participants } \\
\begin{array}{l}\text { and personnel (perfor- } \\
\text { mance bias) }\end{array}\end{array}$ & Unclear risk & $\begin{array}{l}\text { Comment: probably not done: no statement addressing blinding, although } \\
\text { peppermint and saline treatments appeared identical \& stored in same box, in- } \\
\text { vestigators would have been unblinded to treatment when bag opened due to } \\
\text { odour }\end{array}$ \\
\hline $\begin{array}{l}\text { Blinding of outcome as- } \\
\text { sessment (detection bias) }\end{array}$ & Unclear risk & $\begin{array}{l}\text { Comment: no blinding of assessors described. Study investigators appear to } \\
\text { have assessed outcomes }\end{array}$ \\
\hline
\end{tabular}


Ferruggiari 2012 (Continued)

All outcomes

Incomplete outcome data Low risk Comment: no attrition described. Results of all participants reported
(attrition bias)

All outcomes

\begin{tabular}{lll}
\hline $\begin{array}{l}\text { Selective reporting (re- } \\
\text { porting bias) }\end{array}$ & Low risk & Comment: all outcomes stated in the paper also have data reported \\
\hline Other bias & Unclear risk & Comment: no other sources of bias apparent \\
\hline
\end{tabular}

Hodge 2014

\begin{tabular}{|c|c|}
\hline Methods & 2-group RCT comparing commercial aromatherapy preparation to placebo \\
\hline \multirow[t]{3}{*}{ Participants } & $\begin{array}{l}94 \text { adult surgical patients ( } 54 \text { treatment/ } 40 \text { control) patients with planned admission. Patients with an } \\
\text { allergy to lavender, peppermint, spearmint, or ginger excluded. }\end{array}$ \\
\hline & Mean Age $=41.25$ years. $S D=14.2$. Range $=18-86$ \\
\hline & Setting: military medical centre, USA \\
\hline Interventions & $\begin{array}{l}\text { Treatment: patient-administered inhalations from 'QueaseEase }{ }^{\mathrm{TM} 1} \text { commercial aromatherapy inhaler } \\
\text { containing peppermint, spearmint, lavender and ginger oils. Control: unscented placebo inhaler. On } \\
\text { first complaint of nausea, "the patient is instructed to remove the cap, hold the container under the } \\
\text { nose, and take a few deep breaths." }\end{array}$ \\
\hline Outcomes & $\begin{array}{l}\text { Nausea severity at initial report and } 3 \text { min as measured on a } 10 \text {-point Likert scale ( } 0=\text { no nausea, } 10= \\
\text { worst possible nausea). Patient satisfaction as measured by a questionnaire. }\end{array}$ \\
\hline Notes & $\begin{array}{l}27 \text { patients eligible for the study did not receive the allocated treatment. Additional information re- } \\
\text { quested \& supplied. QueaseEase }{ }^{T M} \text { devices and placebo devices were provided free of charge by the } \\
\text { manufacturer. }\end{array}$ \\
\hline
\end{tabular}

\section{Risk of bias}

\begin{tabular}{lll}
\hline Bias & Authors' judgement & Support for judgement \\
\hline $\begin{array}{l}\text { Random sequence genera- } \\
\text { tion (selection bias) }\end{array}$ & Low risk & $\begin{array}{l}\text { Probably done: further information received from study author, Nancy Hodge, } \\
\text { states that a computer-generated random number sequence was used. }\end{array}$ \\
\hline
\end{tabular}

\begin{tabular}{|c|c|c|}
\hline $\begin{array}{l}\text { Allocation concealment } \\
\text { (selection bias) }\end{array}$ & High risk & $\begin{array}{l}\text { Comment: probably not done. No concealment described in published paper } \\
\text { or extra information provided by study author }\end{array}$ \\
\hline
\end{tabular}

\begin{tabular}{|c|c|c|}
\hline $\begin{array}{l}\text { Blinding of participants } \\
\text { and personnel (perfor- } \\
\text { mance bias) } \\
\text { All outcomes }\end{array}$ & Unclear risk & $\begin{array}{l}\text { Probably done: further information from study author, Nancy Hodge, states: } \\
\text { "The perceived nausea VAS forms and interview questions forms were placed } \\
\text { in a sealed packet along with either an aromatherapy inhaler or a placebo } \\
\text { inhaler. Each packet was numbered and randomly assigned an inhaler. The } \\
\text { sealed packets were placed on the nursing unit and when a post-op patient } \\
\text { complained of nausea the nurse took the next numbered packet to the bed- } \\
\text { side." }\end{array}$ \\
\hline & & $\begin{array}{l}\text { Comment: despite these measures, unblinding of participants would have oc- } \\
\text { curred on opening the packets due to the scent of the aromatherapy product }\end{array}$ \\
\hline $\begin{array}{l}\text { Blinding of outcome as- } \\
\text { sessment (detection bias) }\end{array}$ & High risk & $\begin{array}{l}\text { Comment: despite the above measures, unblinding of nursing staff would have } \\
\text { occurred on opening the packets due to the scent of the aromatherapy prod- }\end{array}$ \\
\hline
\end{tabular}


Hodge 2014 (Continued)

All outcomes uct. The nursing staff who administered the intervention also measured the outcomes.

\begin{tabular}{lll}
\hline $\begin{array}{l}\text { Incomplete outcome data } \\
\text { (attrition bias) } \\
\text { All outcomes }\end{array}$ & Unclear risk & $\begin{array}{l}\text { Comment: the 27 patients whose outcomes were not included did not receive } \\
\text { any of the study treatments }\end{array}$ \\
\hline $\begin{array}{l}\text { Selective reporting (re- } \\
\text { porting bias) }\end{array}$ & Low risk & Comment: no evidence of selective reporting. All stated outcomes reported \\
\hline Other bias & Low risk & Comment: no other sources of bias apparent \\
\hline
\end{tabular}

Hunt 2013

\begin{tabular}{|c|c|}
\hline Methods & $\begin{array}{l}\text { 4-group RCT comparing an aromatherapy blend }(n=74) \text {, ginger aromatherapy }(n=76) \text {, and IPA }(n=78) \text {, } \\
\text { with a saline placebo }(n=73)\end{array}$ \\
\hline \multirow[t]{2}{*}{ Participants } & $\begin{array}{l}301 \text { adult patients having surgical procedures. Inclusion criteria: "age } 18 \text { years or older, being cogni- } \\
\text { tively able to give informed consent, having surgery that day, not receiving warfarin (Coumadin), he- } \\
\text { parin, full dose } 325 \mathrm{mg} \text { aspirin, or clopidogrel (Plavix), and not having a history or diagnosis of bleeding } \\
\text { diatheses or any known allergies to ginger, spearmint, peppermint, or cardamom. The exclusion of pa- } \\
\text { tients with clotting disorders was based on studies finding antiplatelet and cyclooxygenase- } 1 \text { enzymes } \\
\text { inhibitors from constitutions of ginger." }\end{array}$ \\
\hline & Setting: ambulatory surgical centre, USA \\
\hline Interventions & $\begin{array}{l}\text { Comparison of normal saline, } 70 \% \text { IPA, essential oil of ginger, and a blend of the essential oils of gin- } \\
\text { ger, spearmint, peppermint, and cardamom. "Each aromatherapy was stored in a plain white bottle la- } \\
\text { belled } 1 \text { to } 4 \text { and kept in a locked cart labelled "For Research Purposes Only." "One millilitre of the ran- } \\
\text { domly selected, designated aromatherapy was placed on a } 2 \text {-inch by } 2 \text {-inch [ } 5 \mathrm{~cm} \times 5 \mathrm{~cm} \text { ] impermeable, } \\
\text { backed gauze pad. On complaint of nausea, participants were instructed to inhale the scent through } \\
\text { the nose } 3 \text { times." }\end{array}$ \\
\hline
\end{tabular}

Outcomes Nausea severity at first complaint and 5 min as measured on a 4-point Likert scale $(0=$ no nausea, $3=$
severe) reported as percentage improvement in nausea scores, percentage requiring rescue antiemetics

Notes Additional information requested and promised but not yet supplied. No funding received

\section{Risk of bias}

\begin{tabular}{lll}
\hline Bias & Authors' judgement & Support for judgement \\
\hline $\begin{array}{l}\text { Random sequence genera- } \\
\text { tion (selection bias) }\end{array}$ & Low risk & $\begin{array}{l}\text { "Participants who responded with a [nausea] score of } 1 \text { to } 3 \text { were randomly as- } \\
\text { signed to } 1 \text { of the } 4 \text { treatment groups using a computerized listing for random } \\
\text { assignments generated by Assumption College." } \\
\text { Comment: likely done }\end{array}$ \\
\hline $\begin{array}{l}\text { Allocation concealment } \\
\text { (selection bias) }\end{array}$ & High risk & $\begin{array}{l}\text { "The research nurse checked off the study number of the participant and aro- } \\
\text { matherapy on the list and then prepared the gauze pad." }\end{array}$ \\
& $\begin{array}{l}\text { Comment: probably not done. Allocator reported as preparing the interven- } \\
\text { tion treatments }\end{array}$
\end{tabular}


Hunt 2013 (Continued)

Blinding of participants High risk "Despite the lack of any identifying label, the study treatment arms could not and personnel (perforbe blinded because of the specificity of odours."

mance bias)

All outcomes

Comment: probably not done

\section{Blinding of outcome as- High risk} sessment (detection bias)

All outcomes

\section{Incomplete outcome data Low risk} (attrition bias)

All outcomes

\section{"Despite the lack of any identifying label, the study treatment arms could not} be blinded because of the specificity of odours."

Comment: probably not done

"...2 subjects were excluded from the protocol analysis because of what was believed to be a degradation of the blend of the aromatherapy

oils". "The ITT analysis population differed only for the blend group, and the ITT blend comparisons were virtually identical to those for the PP analysis for saline and alcohol ( $P<0.001$ for all 3 outcomes)."

Comment: low attrition

\begin{tabular}{lll}
\hline $\begin{array}{l}\text { Selective reporting (re- } \\
\text { porting bias) }\end{array}$ & Low risk & Comment: small range of outcomes, all reported. No protocol available \\
\hline Other bias & Low risk & Comment: no other sources of bias apparent \\
\hline
\end{tabular}

\section{Kamalipour 2002}

\begin{tabular}{ll}
\hline Methods & RCT of IPA versus normal saline placebo for treatment of PONV \\
& Setting: postoperative care unit, acute hospital, Iran \\
\hline Participants & $\begin{array}{l}82 \text { consecutive patients randomized into experimental }(\mathrm{n}=41) \text { and control ( } \mathrm{n}=41) \text { groups. No age data } \\
\text { or demographic except } 48 \text { female/34 male }\end{array}$ \\
\hline Interventions & $\begin{array}{l}2 \text { sniffs of IPA (treatment) or } 2 \text { sniffs normal saline (control) (on reporting symptoms) and re-treated at } \\
5 \text { min if necessary. Participants who did not respond the } 2 \text { nd time received metoclopramide injection. }\end{array}$ \\
\hline Outcomes & Response to treatment/cessation of symptoms, recurrence of symptoms, use of rescue antiemetics \\
\hline Notes & Attempted to contact study author, Dr H Kamalipour, via email however no response received
\end{tabular}

\section{Risk of bias}

\begin{tabular}{|c|c|c|}
\hline Bias & Authors' judgement & Support for judgement \\
\hline $\begin{array}{l}\text { Random sequence genera- } \\
\text { tion (selection bias) }\end{array}$ & Unclear risk & $\begin{array}{l}\text { "The patients were randomly divided into two groups." } \\
\text { Comment: probably done }\end{array}$ \\
\hline $\begin{array}{l}\text { Allocation concealment } \\
\text { (selection bias) }\end{array}$ & Unclear risk & Comment: no data \\
\hline $\begin{array}{l}\text { Blinding of participants } \\
\text { and personnel (perfor- } \\
\text { mance bias) } \\
\text { All outcomes }\end{array}$ & Unclear risk & Comment: no data \\
\hline $\begin{array}{l}\text { Blinding of outcome as- } \\
\text { sessment (detection bias) }\end{array}$ & Unclear risk & Comment: no data \\
\hline
\end{tabular}


Kamalipour 2002 (Continued)

All outcomes

Incomplete outcome data Low risk Comment: data reported for all stated outcomes
(attrition bias)

(attrition bias)

All outcomes

Selective reporting (re- Unclear risk $\quad$ Comment: brief report with little detail
porting bias)

porting bias)

Other bias Unclear risk Comment: unable to ascertain from details reported

\section{Kiberd 2016}

\begin{tabular}{|c|c|}
\hline Methods & 2-group RCT comparing 'Quease Ease' aromatherapy blend to saline placebo \\
\hline \multirow[t]{3}{*}{ Participants } & $\begin{array}{l}39 \text { children aged } 4-16 \text { years ( } 21 \text { intervention/18 control) admitted for elective day surgery. Anesthesia } \\
\text { Society of America Physical Status I or II (ASA I or II) }\end{array}$ \\
\hline & $\begin{array}{l}\text { Exclusion criteria included the presence of neurodevelopmental disorders, allergy or sensitivity to aro- } \\
\text { matherapy components, or inability to smell }\end{array}$ \\
\hline & Setting: health centre in Canada \\
\hline \multirow[t]{2}{*}{ Interventions } & $\begin{array}{l}\text { Intervention participants received QueaseEase }{ }^{\mathrm{TM}} \text { commercial aromatherapy blend (lavender, } \\
\text { spearmint, ginger and peppermint) contained in a plastic inhaler delivery system on first report of nau- } \\
\text { sea in PACU. }\end{array}$ \\
\hline & $\begin{array}{l}\text { Control participants received saline placebo in identical plastic inhaler delivery system on first report } \\
\text { of nausea in PACU. }\end{array}$ \\
\hline
\end{tabular}

Nausea incidence and severity as measured by the 11-point Baxter Retching Faces $(B A R F)$ scale $(0=$ no
nausea, $10=$ vomiting) every 15 min until discharge.

Notes

Funding of this study was from the Dr Thomas Coonan Studentship through the Dalhousie Medical Research Foundation

\section{Risk of bias}

\begin{tabular}{lll}
\hline Bias & Authors' judgement & Support for judgement \\
\hline $\begin{array}{ll}\text { Random sequence genera- } \\
\text { tion (selection bias) }\end{array}$ & Low risk & $\begin{array}{l}\text { "If the patient reported a BARF scale of } 4 \text { or greater they were randomized } \\
\text { to the intervention aromatherapy or a saline inhaler. Randomization was by } \\
\text { block } 6 \text { design." } \\
\text { Comment: unclear how sequence was generated }\end{array}$ \\
& & \\
\hline
\end{tabular}

\begin{tabular}{|c|c|c|}
\hline $\begin{array}{l}\text { Allocation concealment } \\
\text { (selection bias) }\end{array}$ & Low risk & $\begin{array}{l}\text { "Concealment was maintained by using sequentially numbered opaque en- } \\
\text { velopes containing the identical appearing intervention and control inhalers." } \\
\text { Comment: probably done }\end{array}$ \\
\hline $\begin{array}{l}\text { Blinding of participants } \\
\text { and personnel (perfor- } \\
\text { mance bias) } \\
\text { All outcomes }\end{array}$ & High risk & $\begin{array}{l}\text { Intervention and control devices were identical in appearance. "The control } \\
\text { was with identical housing but contained only saline." } \\
\text { "Despite a delivery system with controlled exposure to the therapy (twist top) } \\
\text { the aroma rapidly penetrated the area around the patient. Researchers and } \\
\text { nurses correctly identified intervention versus control in all cases." }\end{array}$ \\
\hline
\end{tabular}



intervention device

\begin{tabular}{|c|c|c|}
\hline $\begin{array}{l}\text { Blinding of outcome as- } \\
\text { sessment (detection bias) } \\
\text { All outcomes }\end{array}$ & High risk & $\begin{array}{l}\text { "Despite a delivery system with controlled exposure to the therapy (twist top) } \\
\text { the aroma rapidly penetrated the area around the patient. Researchers and } \\
\text { nurses correctly identified intervention versus control in all cases." }\end{array}$ \\
\hline & & $\begin{array}{l}\text { Comment: likely that unblinding to allocation occurred due to the odour of the } \\
\text { intervention device }\end{array}$ \\
\hline
\end{tabular}

\begin{tabular}{ll}
\hline $\begin{array}{l}\text { Incomplete outcome data } \\
\text { (attrition bias) }\end{array}$ & Low risk \\
All outcomes & $\begin{array}{l}\text { "Randomization occurred in } 41 \text { subjects of which } 2 \text { were excluded post ran- } \\
\text { domization (1 subject in each arm [1], for failure to meet exposure criteria and } \\
{[1] \text { for leaving before assessment." }}\end{array}$ \\
& Comment: no concerns
\end{tabular}

\begin{tabular}{|c|c|c|}
\hline $\begin{array}{l}\text { Selective reporting (re- } \\
\text { porting bias) }\end{array}$ & Low risk & $\begin{array}{l}\text { Primary and secondary outcomes planned in study registration are reported in } \\
\text { study }\end{array}$ \\
\hline
\end{tabular}

Other bias Unclear risk

\begin{abstract}
"The aromatherapy sticks and saline control were provided in kind by QueaseEASE ${ }^{\mathrm{TM}}$."

Comment: the study authors state the company was not involved in study methodology.

"Unreliability of the outcome measurement (BARF scale) in the youngest children may also contribute to error. Although the BARF scale has been validated down to 4 years old, there is variability in children's ability to self-report on internal experiences in this age group that may have influenced their use of this scale."

Comment: some risk of outcome measurement error

"Despite randomization there was a difference in the types of surgeries patients in each group received. For example, more patients in the control group had Ophthalmological surgery compared with aromatherapy ( $28 \%$ versus 5 $\%)$. This was likely balanced by a higher portion of aromatherapy patient's having ENT surgery."

Comment: potential for error due to baseline differences between groups
\end{abstract}

Lane 2012

\begin{tabular}{|c|c|}
\hline Methods & 3-group RCT comparing peppermint spirit vapour with inert placebo or standard antiemetics \\
\hline \multirow[t]{4}{*}{ Participants } & $\begin{array}{l}35 \text { women post-cesarean section delivery. ( } 22 \text { peppermint/ } 8 \text { placebo/5 standard antiemetic). Mean age } \\
31.3 \text { years (range } 22-43 \text { ) }\end{array}$ \\
\hline & $\begin{array}{l}\text { Inclusion criteria: "scheduled for a nonemergency C-section, English speaking, at least } 18 \text { years of age, } \\
\text { nonsmoker, and became nauseated post C-section". }\end{array}$ \\
\hline & $\begin{array}{l}\text { Exclusion criteria: allergy to peppermint or food colorings, diagnosed with persistent vomiting such as } \\
\text { hyperemesis, receiving magnesium sulphate therapy or had a condition in which the contraction of ab- } \\
\text { dominal muscles during vomiting would have been contraindicated such as infected wound. }\end{array}$ \\
\hline & Setting: community hospital, USA \\
\hline Interventions & $\begin{array}{l}\text { Zip-lock bag containing either pharmacy-grade peppermint spirits ("Humco Peppermint Spirit USP: } \\
\text { ethyl alcohol 82\%, peppermint oil, purified water, peppermint leaf extract") or green-coloured, sterile } \\
\text { water on cotton balls. Participants in aromatherapy groups instructed to hold opened bag } 2 \text { inches un- }\end{array}$ \\
\hline
\end{tabular}


Lane 2012 (Continued)

der their nose and take 3 deep breaths. Standard antiemetic group received either IV ondansetron or PR promethazine depending on surgeon protocol.

\begin{tabular}{ll}
\hline Outcomes & $\begin{array}{l}\text { Nausea severity at initial complaint, 2, } 5 \text { min, as measured by 6-point ordinal nausea scale }(0=\text { no nau- } \\
\text { sea, } 6=\text { vomiting) measured by 'staff nurse' }\end{array}$ \\
\hline Notes & $\begin{array}{l}\text { Unequal group sizes caused by allocation prior to complaints of nausea/ failure to recruit sufficient par- } \\
\text { ticipants to account for the majority not experiencing nausea/ protocol violations and large amounts } \\
\text { of missing/ accidentally destroyed data. Additional information requested. No information on funding } \\
\text { source }\end{array}$
\end{tabular}

\section{Risk of bias}

\begin{tabular}{|c|c|c|}
\hline Bias & Authors' judgement & Support for judgement \\
\hline $\begin{array}{l}\text { Random sequence genera- } \\
\text { tion (selection bias) }\end{array}$ & Unclear risk & $\begin{array}{l}\text { "...blocked systematic random assignment" method used } \\
\text { Comment: unclear how sequence was generated }\end{array}$ \\
\hline $\begin{array}{l}\text { Allocation concealment } \\
\text { (selection bias) }\end{array}$ & Low risk & $\begin{array}{l}\text { "The AD [admitting department] staff performed random assignment" i.e. allo- } \\
\text { cation to groups done by administrative staff in separate department. } \\
\text { Comment: probably done }\end{array}$ \\
\hline $\begin{array}{l}\text { Blinding of participants } \\
\text { and personnel (perfor- } \\
\text { mance bias) } \\
\text { All outcomes }\end{array}$ & High risk & $\begin{array}{l}\text { Although the intervention and placebo were stored in identical bags and ap- } \\
\text { peared identical, unblinding would have occurred on opening the bags due to } \\
\text { the odour of the peppermint. Nurses became unblinded to the intervention } \\
\text { and chose not to implement if it was the placebo (Quote: "nurses...did not im- } \\
\text { plement the research protocol for participants in the placebo aromatherapy } \\
\text { group.") } \\
\text { Comment: probably not done }\end{array}$ \\
\hline
\end{tabular}

\begin{tabular}{lll}
\hline $\begin{array}{l}\text { Blinding of outcome as- } \\
\text { sessment (detection bias) }\end{array}$ & High risk & $\begin{array}{l}\text { Clinical staff who delivered the intervention also measured the outcomes. Al- } \\
\text { though the intervention and placebo were stored in identical bags and ap- } \\
\text { peared identical, unblinding would have occurred on opening the bags due to } \\
\text { the odour of the peppermint. Nurses became unblinded to the intervention } \\
\text { and chose not to implement if it was the placebo (Quote: "nurses...did not im- } \\
\text { plement the research protocol for participants in the placebo aromatherapy } \\
\text { group.") } \\
\text { Comment: probably not done }\end{array}$
\end{tabular}

Incomplete outcome data High risk

All outcomes (attrition bias)

Large attrition/missing data from study due in part to unblinding of intervention ("nurses...did not implement the research protocol for participants in the placebo aromatherapy group.") Some data destroyed by accident. Incomplete data recorded for several participants.

Comment: likely attrition bias

\begin{tabular}{lll}
\hline $\begin{array}{l}\text { Selective reporting (re- } \\
\text { porting bias) }\end{array}$ & Low risk & $\begin{array}{l}\text { Comment: reporting appears comprehensive, within constraints of large } \\
\text { amounts of lost data }\end{array}$ \\
\hline Other bias & Unclear risk & Comment: unequal group sizes likely to be a problem for statistical inference. \\
\hline
\end{tabular}

Methods Double-blinded cross-over clinical trial/pilot study comparing IPA to saline placebo


Langevin 1997 (Continued)

Setting: acute hospital, USA

15 consecutive patients in PACU who complained of nausea or vomiting after elective surgery.

Interventions

Either $0.5 \mathrm{~mL}$ saline or $0.5 \mathrm{~mL}$ IPA on a cotton ball (according to random sequence) was held under participants' noses and the participant was instructed to sniff twice. If symptoms recurred, the test agents were re-administered in random sequence. When neither test agent was effective, standard antiemetics were given and the PONV assessed every 5 min until participant left PACU

\begin{tabular}{ll}
\hline Outcomes & $\begin{array}{l}\text { Severity of PONV as assessed with VAS. VAS range from } 0=\text { none to } 10=\text { vomiting } \\
\text { Treatment failure attributed to the last agent given. }\end{array}$ \\
\hline Notes & $\begin{array}{l}\text { No demographic data supplied in brief report. Letter sent to study author, Dr Paul Langevin, to ask for } \\
\text { more data, no response received. No funding source information reported }\end{array}$
\end{tabular}

\section{Risk of bias}

\begin{tabular}{lll}
\hline Bias & Authors' judgement & Support for judgement \\
\hline $\begin{array}{l}\text { Random sequence genera- } \\
\text { tion (selection bias) }\end{array}$ & Unclear risk & "the test agents were readministered in the randomised sequence" \\
\hline $\begin{array}{l}\text { Allocation concealment } \\
\text { (selection bias) }\end{array}$ & Unclear risk & Comment: no information on how this sequence was generated \\
\hline
\end{tabular}

\begin{tabular}{|c|c|c|}
\hline $\begin{array}{l}\text { Blinding of participants } \\
\text { and personnel (perfor- } \\
\text { mance bias) } \\
\text { All outcomes }\end{array}$ & Unclear risk & $\begin{array}{l}\text { "We designed a randomised double-blinded study..." "Nurses who adminis- } \\
\text { tered the test therapy were blinded to group assignment by applying an ISO- } \\
\text { soaked Band-Aid under their noses while another person applied the test } \\
\text { agent to a cotton ball, which was attached to a sponge stick." }\end{array}$ \\
\hline & & $\begin{array}{l}\text { Comment: participants would not have been blinded to the treatment due to } \\
\text { the distinctive odour of the IPA. Unclear where the 'double-blinding' occurred }\end{array}$ \\
\hline
\end{tabular}

\begin{tabular}{|c|c|c|}
\hline $\begin{array}{l}\text { Blinding of outcome as- } \\
\text { sessment (detection bias) }\end{array}$ & Unclear risk & $\begin{array}{l}\text { Comment: the published conference abstract does not specify who measured } \\
\text { the treatment outcomes. }\end{array}$ \\
\hline
\end{tabular}

All outcomes

\begin{tabular}{|c|c|c|}
\hline $\begin{array}{l}\text { Incomplete outcome data } \\
\text { (attrition bias) }\end{array}$ & Unclear risk & $\begin{array}{l}\text { Comment: original study protocol not available, no apparent losses to fol- } \\
\text { low-up }\end{array}$ \\
\hline
\end{tabular}

All outcomes

Selective reporting (re- Low risk Comment: data reported for all participants
porting bias)
porting bias)

\begin{tabular}{ll}
\hline Other bias $\quad$ Unclear risk $\quad$ Comment: minimal data reported in this publication \\
\hline
\end{tabular}

\section{Merritt 2002}

\begin{tabular}{ll}
\hline Methods & CCT comparing IPA inhalation to standard antiemetics for treatment of PONV \\
& Setting: acute hospital, USA \\
\hline Participants & $\begin{array}{l}\text { 39 adults having surgery. Age range: } 19-80 \text { years; mean age }=43 . \text { Types of surgery included intra-ab- } \\
\text { dominal }(29.7 \%) \text {, orthopaedic/extremity }(23.4 \%), \text { perineal }(19.8 \%) \text { neuro-skeletal }(10.8 \%), \text { extra-tho- } \\
\text { racic }(6.3 \%) \text { eyes/ears/nose/throat }(6.3 \%), \text { neck }(3.6 \%)\end{array}$
\end{tabular}


Merritt 2002 (Continued)

Of 40 participants evaluated for study, 21 received IPA and 18 were controls. 1 participant entered into the study had their PONV resolve spontaneously.

Inclusion criteria were requirements for general anaesthesia, ability to breathe through nose before and after procedure, minimum of 18 years of age, American Society of Anesthesiologists (ASA) physical status of I, II, or III, and ability to read and write English.

Exclusion criteria were allergy to IPA, alcohol abuse, no recent history of nausea or vomiting within the last $8 \mathrm{~h}$, no recent intake of cefoperazone, Antabuse, or metronidazole, ability to communicate in recovery room, regional anaesthesia, and monitored anaesthesia care

Interventions
propriate antiemetic was given. Experimental participants were given IPA via nasal inhalation using
standard hospital alcohol pads. The participant was instructed to take three deep sniffs with the pad
one inch from the nose. This was repeated every five minutes for three doses or until nausea and vom-
iting was relieved. If nausea and vomiting continued after three doses of IPA, then an intravenous drug
was given."

Outcomes Severity of PONV as measured by a DOS from "0 to 10 , with 0 being no nausea or vomiting and 10 being the worst nausea and vomiting they could imagine."

Cost of treatment in USD

\begin{tabular}{ll}
\hline Notes & $\begin{array}{l}\text { Antiemetic prophylaxis was given to participants in both groups. No information provided on funding } \\
\text { source }\end{array}$ \\
\hline
\end{tabular}

\section{Risk of bias}

\begin{tabular}{|c|c|c|}
\hline Bias & Authors' judgement & Support for judgement \\
\hline \multirow[t]{2}{*}{$\begin{array}{l}\text { Random sequence genera- } \\
\text { tion (selection bias) }\end{array}$} & High risk & $\begin{array}{l}\text { "Group assignment was alternated by day: experimental one day and control } \\
\text { the next." }\end{array}$ \\
\hline & & Comment: study is CCT \\
\hline $\begin{array}{l}\text { Allocation concealment } \\
\text { (selection bias) }\end{array}$ & Unclear risk & $\begin{array}{l}\text { Comment: allocators and caregivers appear to have been aware of the alloca- } \\
\text { tion. }\end{array}$ \\
\hline $\begin{array}{l}\text { Blinding of participants } \\
\text { and personnel (perfor- } \\
\text { mance bias) } \\
\text { All outcomes }\end{array}$ & Low risk & $\begin{array}{l}\text { "Participants were blinded to which treatment they were to receive." } \\
\text { Comment: probably done }\end{array}$ \\
\hline
\end{tabular}

Blinding of outcome as- Unclear risk sessment (detection bias) All outcomes
Comment: the publication does not state who measured the treatment outcomes.

\begin{tabular}{|c|c|c|}
\hline $\begin{array}{l}\text { Incomplete outcome data } \\
\text { (attrition bias) }\end{array}$ & Unclear risk & $\begin{array}{l}\text { Comment: original study protocol unavailable. Stated outcomes were all ad- } \\
\text { dressed in report }\end{array}$ \\
\hline
\end{tabular}

All outcomes dressed in report

Selective reporting (re- Unclear risk $\quad$ Comment: no apparent loss to follow-up
porting bias)

\begin{tabular}{ll}
\hline Other bias & "Only 40 of the 111 participants recruited had PONV. This is explained by ag- \\
& gressive prophylactic treatment at the study facility where only 7 ( $6.3 \%)$ of \\
& 111 participants did not receive prophylactic medication and none of these 7 \\
participants had PONV. Additionally, the researchers speculate that pain may & have been a confounding factor in accurate assessment on the DOS."
\end{tabular}




\section{Pellegrini 2009}

\begin{tabular}{|c|c|}
\hline \multirow[t]{2}{*}{ Methods } & $\begin{array}{l}\text { RCT comparing } 70 \% \text { IPA inhalation to promethazine to treat breakthrough nausea in surgical patients } \\
\text { at high risk of PONV }\end{array}$ \\
\hline & Setting: day hospital, USA \\
\hline \multirow[t]{2}{*}{ Participants } & $\begin{array}{l}85 \text { surgical patients scheduled for general anaesthesia of more than } 60 \text { minutes' duration and having } \\
2 \text { of the } 4 \text { individual risk factors for PONV, (female gender, nonsmoker, history of PONV or motion sick- } \\
\text { ness) (IPA group, 42; promethazine group, 43) }\end{array}$ \\
\hline & $\begin{array}{l}\text { Excluded: recent upper respiratory infection; documented allergy to IPA, ondansetron, promethazine, } \\
\text { or metoclopramide; antiemetic or psychoactive drug use within } 24 \mathrm{~h} \text {; inability to breathe through the } \\
\text { nose; pregnancy; history of inner ear pathology; and/or taking disulfiram, cefoperazone, or metronida- } \\
\text { zole }\end{array}$ \\
\hline
\end{tabular}

Interventions

Control group: $12.5 \mathrm{mg}$ to $25 \mathrm{mg}$ IV promethazine for complaints of PONV in the PACU and SDSU and by promethazine suppository self-administration following discharge to home

Experimental group: administration of inhaled 70\% IPA

Nausea, measured by VNRS $(0-10,0=$ no nausea $10=$ worst imaginable nausea)
Incidence of nausea events in PACU, SDSU or at home (number)
Doses of promethazine required as rescue antiemetic (number)
Promethazine requirements in PACU, SDSU or at home $(\mathrm{mg})$
Time in minutes to $50 \%$ reduction of nausea scores
Participant satisfaction

$\begin{array}{ll}\text { Notes } & \begin{array}{l}\text { All participants received antiemetic prophylaxis prior to surgery. Study author J Pellegrini emailed to } \\ \text { request numeric data for results published in graph form. Data received. Other clarifications requested } \\ \text { and some were received. }\end{array}\end{array}$

\section{Risk of bias}

Bias Authors' judgement Support for judgement

Random sequence genera- Low risk tion (selection bias)

"All subjects were then randomly assigned using a computer-generated random numbers process into a control or an experimental group."

Comment: probably done

Allocation concealment Low risk
(selection bias)

"Block randomisation was used for all of the studies using a computer generated randomisation program done by an independent party (myself) who was not involved in the data collection." (emailed study author response)

Comment: probably done

\begin{tabular}{|c|c|c|}
\hline $\begin{array}{l}\text { Blinding of participants } \\
\text { and personnel (perfor- }\end{array}$ & Unclear risk & $\begin{array}{l}\text { Comment: no data on blinding. It appears that participants were aware of } \\
\text { group allocations during study }\end{array}$ \\
\hline
\end{tabular}

All outcomes 
Pellegrini 2009 (Continued)

Blinding of outcome assessment (detection bias)

Unclear risk All outcomes
Comment: no data on blinding. It appears that assessors were aware of group allocations during study

\section{Incomplete outcome data Low risk (attrition bias)}

All outcomes

\begin{abstract}
"A total of 96 subjects were enrolled, but 11 subjects were withdrawn, leaving a total of 85 subjects (IPA group, 42; promethazine group, 43) whose data would be included in the final analysis. Reasons for withdrawal included 4 subjects who received additional antiemetics intraoperatively ( 2 in each group), 1 subject inadvertently enrolled despite being scheduled for a nasal surgical procedure (IPA group), and 6 subjects who required postoperative inpatient hospitalisation for reasons unrelated to PONV ( 3 in each group)."

Comment: probably done
\end{abstract}

Selective reporting (re- Low risk Comment: all outcomes stated in the article have data reported
porting bias)

Other bias Low risk Comment: no other sources of bias apparent

Sites 2014

\begin{tabular}{ll}
\hline Methods & 2-group RCT comparing peppermint spirit aromatherapy to controlled breathing \\
\hline Participants & 42 adult surgical patients (16 aromatherapy/26 controlled breathing) "18 years and older, male or fe- \\
male, of any ethnic background, ASA status I or II, able to breathe through their nose, capable of verbal- \\
izing occurrences of nausea and/or vomiting, scheduled for laparoscopic, ENT, orthopedic, or urologi- \\
cal day surgery procedures undergoing general anaesthesia with intubation. Exclusion criteria included \\
nausea and/or vomiting within 24 hours of admission, history of alcoholism, allergy to menthol or pep- \\
permint, weekend or emergent surgeries, department of correction clients, pregnant women, patients \\
taking disulfiram (Antabuse) or metronidazole (Flagyl), and minors."
\end{tabular}

Setting: PACU or day surgery unit, rural hospital, USA

\begin{abstract}
Interventions $\quad$ "Upon initial complaint of PONV, either in PACU or Day Surgery, all subjects were instructed to inhale deeply through their nose to the count of 3 , hold their breath to the count of 3 , and exhale to the count of 3 . A single treatment was composed of 3 repetitions of this deep breathing. PONV symptoms were reassessed 5 minutes after initial complaint, and if symptoms persisted a second treatment was administered. At 10 minutes following initial complaint, symptoms were reassessed." Participants randomized to aromatherapy also received peppermint spirit vapour from a vial held under their nose during controlled breathing, participants in the controlled breathing group received a similar vial without peppermint spirit.

"A 13-dram vial containing a cotton braid impregnated with 500 microlitres of pharmacy-grade peppermint spirits (Humco, Peppermint Spirits USP: ethyl alcohol 82\%, NF Grade peppermint leaf extract, peppermint oil, purified water) was placed under the nostrils at midseptum of subjects randomised to the AR group during the controlled breathing treatments. A sham vial without peppermint was used with $\mathrm{CB}$ subjects while they were receiving treatments."
\end{abstract}

Outcomes Nausea severity as measured by descriptive ordinal scale $(0=$ no nausea, $10=$ worst possible nausea) at initial complaint, $5 \mathrm{~min}$ and $10 \mathrm{~min}$. "Treatment effectiveness was equated with a DOS score of 0 postintervention. Efficacy was a measure of no postintervention antiemetic rescue desired by subjects regardless of their DOS score."

Notes Unequal group sizes, likely due to study design. Addtional information requested. No information on funding sources 
Sites 2014 (Continued)

Risk of bias

\begin{tabular}{|c|c|c|}
\hline Bias & Authors' judgement & Support for judgement \\
\hline \multirow[t]{2}{*}{$\begin{array}{l}\text { Random sequence genera- } \\
\text { tion (selection bias) }\end{array}$} & Low risk & $\begin{array}{l}\text { "A computer generated random number table was used to determine subject } \\
\text { assignment" }\end{array}$ \\
\hline & & Comment: likely done \\
\hline $\begin{array}{l}\text { Allocation concealment } \\
\text { (selection bias) }\end{array}$ & Unclear risk & $\begin{array}{l}\text { Probably not done: no documentation of allocation concealment in an other- } \\
\text { wise well-documented study }\end{array}$ \\
\hline $\begin{array}{l}\text { Blinding of participants } \\
\text { and personnel (perfor- } \\
\text { mance bias) } \\
\text { All outcomes }\end{array}$ & Unclear risk & $\begin{array}{l}\text { Comment: a sham aromatherapy vial without peppermint was used in the } \\
\text { controlled breathing group, however due to the odour of the peppermint, the } \\
\text { group allocation would have been immediately apparent to both the nurse } \\
\text { (who delivered the treatment and assessed the outcomes) and the participant. }\end{array}$ \\
\hline $\begin{array}{l}\text { Blinding of outcome as- } \\
\text { sessment (detection bias) } \\
\text { All outcomes }\end{array}$ & Unclear risk & $\begin{array}{l}\text { Comment: a sham aromatherapy vial without peppermint was used in the } \\
\text { controlled breathing group, however due to the odour of the peppermint, the } \\
\text { group allocation would have been immediately apparent to both the nurse } \\
\text { (who delivered the treatment and assessed the outcomes). }\end{array}$ \\
\hline $\begin{array}{l}\text { Incomplete outcome data } \\
\text { (attrition bias) } \\
\text { All outcomes }\end{array}$ & Low risk & $\begin{array}{l}\text { Comment: does not appear to have been an issue once participants had en- } \\
\text { tered into the study phase. Outcome data reported for all participants who re- } \\
\text { ceived the treatment. }\end{array}$ \\
\hline \multirow[t]{2}{*}{$\begin{array}{l}\text { Selective reporting (re- } \\
\text { porting bias) }\end{array}$} & High risk & $\begin{array}{l}\text { "The study evaluated a single episode of PONV whether it occurred in PACU or } \\
\text { Day Surgery." }\end{array}$ \\
\hline & & $\begin{array}{l}\text { Comment: participants who experienced multiple episodes of PONV did not } \\
\text { have those recorded. }\end{array}$ \\
\hline Other bias & Low risk & Comment: no other sources of bias apparent \\
\hline
\end{tabular}

\section{Tate 1997}

\begin{tabular}{|c|c|}
\hline Methods & $\begin{array}{l}\text { 3-arm CCT of peppermint oil inhalations, peppermint essence inhalations (placebo) and no treatment } \\
\text { (control) to treat PONV in women. } \\
\text { Setting: acute hospital, UK }\end{array}$ \\
\hline Participants & $\begin{array}{l}18 \text { women undergoing major gynaecological surgery. Mean weight group 1: } 152 \mathrm{lb} \text { [69 kg]; group 2: } \\
139.5 \mathrm{lb} \text { [63 kg]; group 3: } 144.2 \mathrm{lb} \text { [65 kg]. Mean height group 1: } 64.2 \text { inches [1.63 m]; group 2: } 62.5 \mathrm{inch}- \\
\text { es [1.58 m]; group 3: } 64.3 \text { inches [1.63 m]. Mean age group 1: } 54 \text { years; group 2: } 43.2 \text { years; group 3: } 45.5 \\
\text { years. Participants were assessed as having no significant differences in personal characteristics, past } \\
\text { medical history or preoperative anxiety levels. There were no statistically significant differences in pre- } \\
\text { operative fasting times, anaesthetic and recovery times or postoperative fasting times. } 5 \text { of the experi- } \\
\text { mental group had intra-abdominal surgery, compared with } 3 \text { in each of the other } 2 \text { groups. }\end{array}$ \\
\hline
\end{tabular}

Interventions Participants were given bottles of their assigned substance postoperatively and instructed to inhale the vapours from the bottle whenever they felt nauseous.

Outcomes Self-reported nausea as measured by VAS of 0-4 where $0=$ "not experiencing any nausea" and $4=$ "about to vomit" reported as the average score per person per day

Cost of treatment in GBP 
Tate 1997 (Continued)

Patient satisfaction with treatment, reported narratively

Notes

Participants may or may not have received standard antiemetics in PACU. Study author Sylvina Tate supplied some extra data on group allocation methods. No information reported on funding sources

\section{Risk of bias}

\begin{tabular}{lll}
\hline Bias & Authors' judgement & Support for judgement \\
\hline $\begin{array}{l}\text { Random sequence genera- } \\
\text { tion (selection bias) }\end{array}$ & Unclear risk & "The subjects were assigned to one of three groups." \\
& & $\begin{array}{l}\text { Comment: study author states that participants were "randomly assigned" to } \\
\text { ward areas }\end{array}$ \\
\end{tabular}

Allocation concealment $\quad$ Unclear risk $\quad$ Comment: no information reported regarding concealment
(selection bias)

\begin{tabular}{|c|c|c|}
\hline $\begin{array}{l}\text { Blinding of participants } \\
\text { and personnel (perfor- } \\
\text { mance bias) }\end{array}$ & Low risk & $\begin{array}{l}\text { Comment: use of peppermint essence as placebo blinded experimental and } \\
\text { placebo group patients to treatment allocation }\end{array}$ \\
\hline
\end{tabular}

mance bias)

All outcomes

\begin{tabular}{|c|c|c|}
\hline \multirow{2}{*}{$\begin{array}{l}\text { Blinding of outcome as- } \\
\text { sessment (detection bias) } \\
\text { All outcomes }\end{array}$} & Low risk & $\begin{array}{l}\text { "It was decided to use a standardized descriptive ordinal scale to collect the } \\
\text { subjective patient self-reported data." }\end{array}$ \\
\hline & & Comment: probably done \\
\hline
\end{tabular}

\begin{tabular}{|c|c|c|}
\hline $\begin{array}{l}\text { Incomplete outcome data } \\
\text { (attrition bias) } \\
\text { All outcomes }\end{array}$ & Unclear risk & $\begin{array}{l}\text { Comment: no mention of patients lost to follow-up, however group numbers } \\
\text { are not reported. (Group numbers clarified by author via email). }\end{array}$ \\
\hline
\end{tabular}

All outcomes Selective reporting (re- High risk
porting bias)

Other bias Unclear risk
Comment: triallists did not provide measure of statistical significance or measures of variance for daily average nausea scores, even though they state "statistically significant difference in the amount of self-reported nausea between the placebo and experimental groups".

\section{Wang 1999}

\begin{tabular}{l} 
Methods $\begin{array}{l}\text { Double-blind RCT of IPA as a treatment for PONV. "When any episode of vomiting or nausea occurred, } \\
\text { patients were randomised, using a random number table to receive a cotton ball soaked with ISO or } \\
\text { saline placed under the patient's nose by the nursing staff. The patient was instructed to sniff twice by } \\
\text { a nurse who was blind to group assignment. It should be emphasized that the nursing staffs were in- } \\
\text { structed not to smell the content of cotton ball and to hold it away from themselves when administer- } \\
\text { ing to patient. } \\
\text { If the severity of nausea or vomiting improved after a single treatment, a VAS assessment of nausea } \\
\text { was obtained every } 5 \text { minutes until the patient was discharged or PONV symptoms recurred. Improve- } \\
\text { ment of nausea was defined as a decrease of at least } 40 \% \text { in initial VAS score, and improvement of vom- } \\
\text { iting was defined as no further episodes of vomiting. If, after treatment, severity of nausea did not im- } \\
\text { prove or retching/vomiting persisted, a second treatment with the same agent was given. Treatment } \\
\text { sequences were repeated for a maximum of three times in a 15-minute period. When severity of either } \\
\text { nausea or vomiting failed to improve despite three treatments, intravenous (IV) ondansetron } 0.1 \mathrm{mg} / \mathrm{kg}\end{array}$ \\
\hline
\end{tabular}


Wang 1999 (Continued)

(maximum $4 \mathrm{mg}$ ) was administered. If symptoms persisted, a second dose of ondansetron was administered. For patients who failed to improved after two ondansetron doses (maximum dose: $8 \mathrm{mg}$ ), other IV antiemetic medications (i.e., $200 \mathrm{mg} / \mathrm{kg}$ of metoclopramide; $10 \mathrm{mg} / \mathrm{kg}$ droperidol) were given."

Setting: acute paediatric day surgery centre, USA

\begin{tabular}{ll}
\hline Participants & $\begin{array}{l}\text { 39 children aged 6-16 years having surgery under general anaesthesia. ASA physical status I and II. } \\
\text { Treatment } \mathrm{n}=20 . \text { Control } \mathrm{n}=19 . \text { No significant differences in demographic data across groups. } \\
\text { Exclusions: children with a history of chronic illness or developmental delay }\end{array}$ \\
\hline Interventions & $\begin{array}{l}\text { Inhalations of IPA or saline placebo. Intervention repeated up to } 3 \text { times. IV ondansetron was used as } \\
\text { 'rescue therapy' if PONV continued. }\end{array}$ \\
\hline Outcomes & $\begin{array}{l}\text { Severity of nausea and vomiting as measured by } 100 \mathrm{~mm} \text { VAS with a range of } 0=\text { no nausea to } 100= \\
\text { extreme nausea } \\
\text { - Use of rescue antiemetics as measured by drug and number of doses }\end{array}$
\end{tabular}

Notes

Study author, Dr Shu-Ming Wang contacted for any further data, however due to the age of the study there was none available. No information reported on funding sources

\section{Risk of bias}

\begin{tabular}{lll}
\hline Bias & Authors' judgement & Support for judgement \\
\hline $\begin{array}{ll}\text { Random sequence genera- } \\
\text { tion (selection bias) }\end{array}$ & Low risk & "If any episode of vomiting or nausea occurred, patients were randomised, us- \\
& $\begin{array}{l}\text { ing a random number table to receive a cotton ball soaked with ISO or saline } \\
\text { placed under the patient's nose by the nursing staff." } \\
\text { Comment: probably done }\end{array}$
\end{tabular}

\begin{tabular}{|c|c|c|}
\hline $\begin{array}{l}\text { Allocation concealment } \\
\text { (selection bias) }\end{array}$ & Unclear risk & $\begin{array}{l}\text { Comment: no data on who conducted the allocation and any degree of separa- } \\
\text { tion from the conduct of the study }\end{array}$ \\
\hline
\end{tabular}

\begin{tabular}{|c|c|c|}
\hline $\begin{array}{l}\text { Blinding of participants } \\
\text { and personnel (perfor- } \\
\text { mance bias) }\end{array}$ & Unclear risk & $\begin{array}{l}\text { "The patient was instructed to sniff twice by a nurse who was blind to group } \\
\text { assignment." }\end{array}$ \\
\hline All outcomes & & $\begin{array}{l}\text { Comment: personnel probably blinded, participants probably not blinded due } \\
\text { to odour of treatment substance }\end{array}$ \\
\hline
\end{tabular}

\begin{tabular}{|c|c|c|}
\hline $\begin{array}{l}\text { Blinding of outcome as- } \\
\text { sessment (detection bias) } \\
\text { All outcomes }\end{array}$ & Low risk & $\begin{array}{l}\text { "The patient was instructed to sniff twice by a nurse who was blind to group } \\
\text { assignment. It should be emphasized that the nursing staffs were instructed } \\
\text { not to smell the content of cotton ball and to hold it away from themselves } \\
\text { when administering to patient." }\end{array}$ \\
\hline & & Comment: probably done \\
\hline
\end{tabular}

\begin{tabular}{lll}
\hline $\begin{array}{l}\text { Incomplete outcome data } \\
\text { (attrition bias) } \\
\text { All outcomes }\end{array}$ & Low risk \\
\hline $\begin{array}{l}\text { Selective reporting (re- } \\
\text { porting bias) }\end{array}$ & Low risk & Comment: all stated outcomes reported \\
\hline Other bias & Low risk & Comment: no other sources of bias apparent
\end{tabular}


Winston 2003

\section{Methods}

RCT of IPA for treatment of PONV. Participants were randomized to receive either IPA inhalations, or 4 mg ondansetron.

Setting: same day surgery centre, USA

\section{Participants}

41 women aged 18-65 years who were scheduled for diagnostic laparoscopy, operative laparoscopy or laparoscopic bilateral tubal occlusion (ASA physical status I, II or III) in a day surgery unit. Treatment $\mathrm{n}$ $=29$, control $n=12$

Exclusions: inability or impaired ability to breathe through the nose, or history of sensitivity to IPA or ondansetron, had used an antiemetic within $24 \mathrm{~h}$ of surgery, pregnant or breastfeeding, reported existing nausea, history of significant PONV resistant to antiemetics, using disulfiram or had a history of alcoholism
Comparison of inhaled $70 \%$ IPA to ondansetron for treatment of PONV.

Ondansetron (control) group: at first request for treatment participants in this group received IV ondansetron $4 \mathrm{mg}$, repeated once in $15 \mathrm{~min}$ if required.

70\% IPA (experimental) group: a standard alcohol prep pad was held under the participant's nose and she was instructed to take 3 consecutive deep breaths through the nose.

Nausea score collected for baseline at preop, then immediately postop in PACU and at any time the participant complained of nausea. Additionally, participants who complained of nausea were assessed every $5 \mathrm{~min}$ following treatment for $30 \mathrm{~min}$ and then every $15 \mathrm{~min}$ until discharge from PACU.
Outcomes
- Nausea score as measured by VRNS (range 0-10 where $0=$ no nausea and $10=$ worst imaginable nau- sea)
- Number of emetic events, defined as episodes of nausea or vomiting more than 1 min apart
- Time to reduction of PONV in minutes
- Cost
- Patient satisfaction with anaesthesia care

\section{Notes}

This study was replicated by Cotton 2007 with the number and frequency of IPA inhalations increased. Study author J Pellegrini provided additional data via email. No funding sources reported

\section{Risk of bias}

Bias Authors' judgement Support for judgement
tion (selection bias)

\section{Random sequence genera- Low risk}

"subjects were randomly assigned to receive inhaled 70\% IPA (experimental group) or IV ondansetron (control group) for the treatment of PON" "despite the use of block randomisation"

Comment: study author states via email that randomization was conducted using a computer-generated random numbers table.

Allocation concealment Low risk
(selection bias)

"Block randomisation was used for all of the studies using a computer generated randomisation program done by an independent party (myself) who was not involved in the data collection."

Comment: probably done

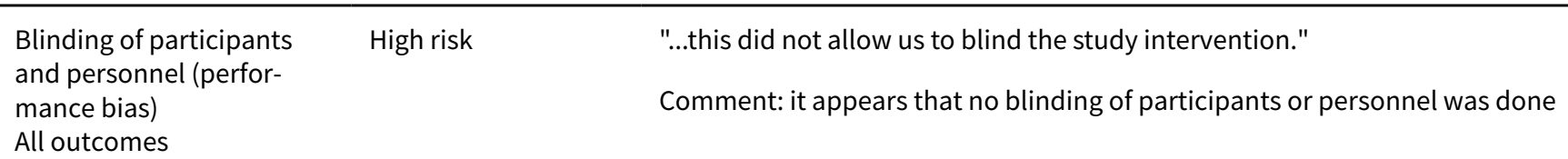

High risk

"...this did not allow us to blind the study intervention."

Blinding of outcome as-
sessment (detection bias) 
Winston 2003 (Continued)

All outcomes

\section{Incomplete outcome data Low risk} (attrition bias)

All outcomes

Selective reporting (re- Unclear risk
porting bias)
Comment: it appears that outcome assessors were not blinded

Comment: it appears that data were reported for all participants, no evidence of exclusions or attrition

Comment: original study protocol unavailable. Despite stating collection of data on patient satisfaction with anaesthetic experience, no results for this were reported, however these data were made available by a study author via email

AD: admitting department; ASA: American Society of Anesthesiologists; CB: controlled breathing; CCT: controlled clinical trial; C-section: cesarean section; DOS: descriptive ordinal scale; ENT: ear, nose, throat; GBP: Great Britain Pound; IPA: isopropyl alcohol; ITT: Intention-totreat; ISO: isopropyl alcohol; IV: intravenous; PACU: post-anaesthesia care unit; PON: postoperative nausea; PONV: postoperative nausea and vomiting; PP: per protocol; RCT: randomized controlled trial; RNs: registered nurses; SD: standard deviation; SDSU: same-day surgery unit; USD: United States Dollar; VAS: visual analogue scale; VNRS: verbal numeric rating scale

Characteristics of excluded studies [ordered by study ID]

\begin{tabular}{|c|c|}
\hline Study & Reason for exclusion \\
\hline Adib-Hajbaghery, 2015 & Prevention of PONV, not treatment \\
\hline Apariman 2006 & Prevention of PONV, not treatment \\
\hline Apfel 2001 & Not RCT/CCT. Not aromatherapy \\
\hline Arfeen 1995 & Prevention of PONV, not treatment \\
\hline Betz 2005 & Not RCT/CCT \\
\hline Bone 1990 & Prevention of PONV, not treatment \\
\hline Briggs, 2016 & Not RCT/CCT \\
\hline Buckle 1999 & Not RCT/CCT \\
\hline Chaiyakunapruk 2006 & Prevention of PONV, not treatment \\
\hline Chiravalle 2005 & Not RCT/CCT \\
\hline Chrubasik 2005 & Not RCT/CCT \\
\hline Couture 2006 & Prevention of PONV, not treatment \\
\hline Dabaghzadeh, 2014 & Prevention of PONV, not treatment \\
\hline de Pradier 2006 & Not RCT/CCT \\
\hline Eberhart 2003 & Prevention of PONV, not treatment \\
\hline Eberhart 2006 & Not RCT/CCT \\
\hline
\end{tabular}




\begin{tabular}{|c|c|}
\hline Study & Reason for exclusion \\
\hline Ekenberg 2007 & Not RCT/CCT \\
\hline Ernst 2000 & Not RCT/CCT \\
\hline Fujii 2008 & Not RCT/CCT \\
\hline Geiger 2005 & Not RCT/CCT \\
\hline Golembiewski 2005 & Not RCT/CCT \\
\hline Hosseini, 2015 & Prevention of PONV, not treatment \\
\hline Keifer 2007 & Not RCT/CCT \\
\hline Kim 2006 & Not PONV \\
\hline Kim 2007 & Not PONV \\
\hline King 2009 & Not RCT/CCT \\
\hline Koretz 2004 & Not RCT/CCT \\
\hline Lee, 2016 & Prevention of PONV, not treatment \\
\hline Mamaril 2006 & Not RCT/CCT \\
\hline Mcilvoy, 2015 & Not RCT/CCT \\
\hline Morin 2004 & Not RCT/CCT \\
\hline Nale 2007 & Prevention of PONV, not treatment \\
\hline Nanthakomon 2006 & Prevention of PONV, not treatment \\
\hline Phillips 1993 & Prevention of PONV, not treatment \\
\hline Pompeo 2007 & Not RCT/CCT \\
\hline Pongrojpaw 2003 & Prevention of PONV, not treatment \\
\hline Rosén 2006 & Not RCT/CCT \\
\hline Spencer 2004 & Not RCT/CCT \\
\hline Tavlan 2006 & Prevention of PONV, not treatment \\
\hline Tramer 2001 & Not RCT/CCT \\
\hline Visaylaputra 1998 & Prevention of PONV, not treatment \\
\hline Zeraati, 2016 & Prevention of PONV, not treatment \\
\hline
\end{tabular}

CCT: controlled clinical trial; PONV: postoperative nausea and vomiting; $\mathbf{R C T}$ : randomized controlled trial 
Characteristics of ongoing studies [ordered by study ID]

\section{NCT02189980}

\section{Trial name or title}

Methods

\section{Aromatherapy using a nasal clip after surgery}

Allocation: randomized

Intervention model: parallel assignment

Masking: double blind (subject, caregiver, investigator, outcomes assessor)

\begin{tabular}{ll}
\hline Participants & $\geq 18$ years (adult, senior) \\
\hline Interventions & Placebo comparator: saline and nasal clip \\
& Saline and nasal clip inhaled postoperatively \\
& Experimental: aromatherapy blend and nasal clip \\
& Aromatherapy blend and nasal clip inhaled postoperatively
\end{tabular}

Outcomes Primary outcome measures

Duration of effectiveness of the essential oil blend (time frame: immediately to 1-day postoperative)

Evidence of effectiveness of tested aromatherapy blend in reducing symptoms of postoperative nausea as measured by participant self-report using Likert-type scale measure

Secondary outcome measures

Participant comfort using the nasal clip delivery system (time frame: immediately postop to 1-day postop)

Comfort of participants using nasal clip delivery system for aromatherapy will be measured by selfreport using Likert-type scale

\begin{tabular}{ll}
\hline Starting date & June 2014 \\
\hline Contact information & Ronald Hunt, MD 704-604-5031 rhunt@balancedhealthplus.com \\
\hline Notes & Sponsor: Balanced Health Plus \\
\hline
\end{tabular}

\section{NCT02732379}

Trial name or title

Effect of aromatherapy on postoperative nausea, vomiting and quality of recovery

\begin{tabular}{ll}
\hline Methods & Study type: interventional \\
& Study design: allocation: randomized \\
& Intervention model: parallel assignment \\
& Masking: single blind (outcomes assessor) \\
\hline Participants & $18-65$ years (adult) \\
\hline Interventions & Experimental: lavender aromatherapy \\
& Aromatherapy with lavender essential oil. Procedure: lavender aromatherapy
\end{tabular}


NCT02732379 (Continued)

The 2 drops of lavender essential oil will be dropped into the gauze and the participant will inhale it for $5 \mathrm{~min}$

Other name: aromatherapy with lavender essential oil

Experimental: rose aromatherapy

Aromatherapy with rose essential oil. Procedure: rose aromatherapy

The 2 drops of rose essential oil will be dropped into the gauze and the participant will inhale it for $5 \mathrm{~min}$

Other name: aromatherapy with rose essential oil

Experimental: ginger aromatherapy

Aromatherapy with ginger essential oil. Procedure: ginger aromatherapy

The 2 drops of ginger essential oil will be dropped into the gauze and the participant will inhale it for $5 \mathrm{~min}$

Other name: aromatherapy with ginger essential oil

Placebo comparator: placebo aromatherapy

Aromatherapy with pure water. Procedure: placebo aromatherapy

The 2 drops of pure water will be dropped into the gauze and the participant will inhale it for $5 \mathrm{~min}$

Other name: aromatherapy with pure water

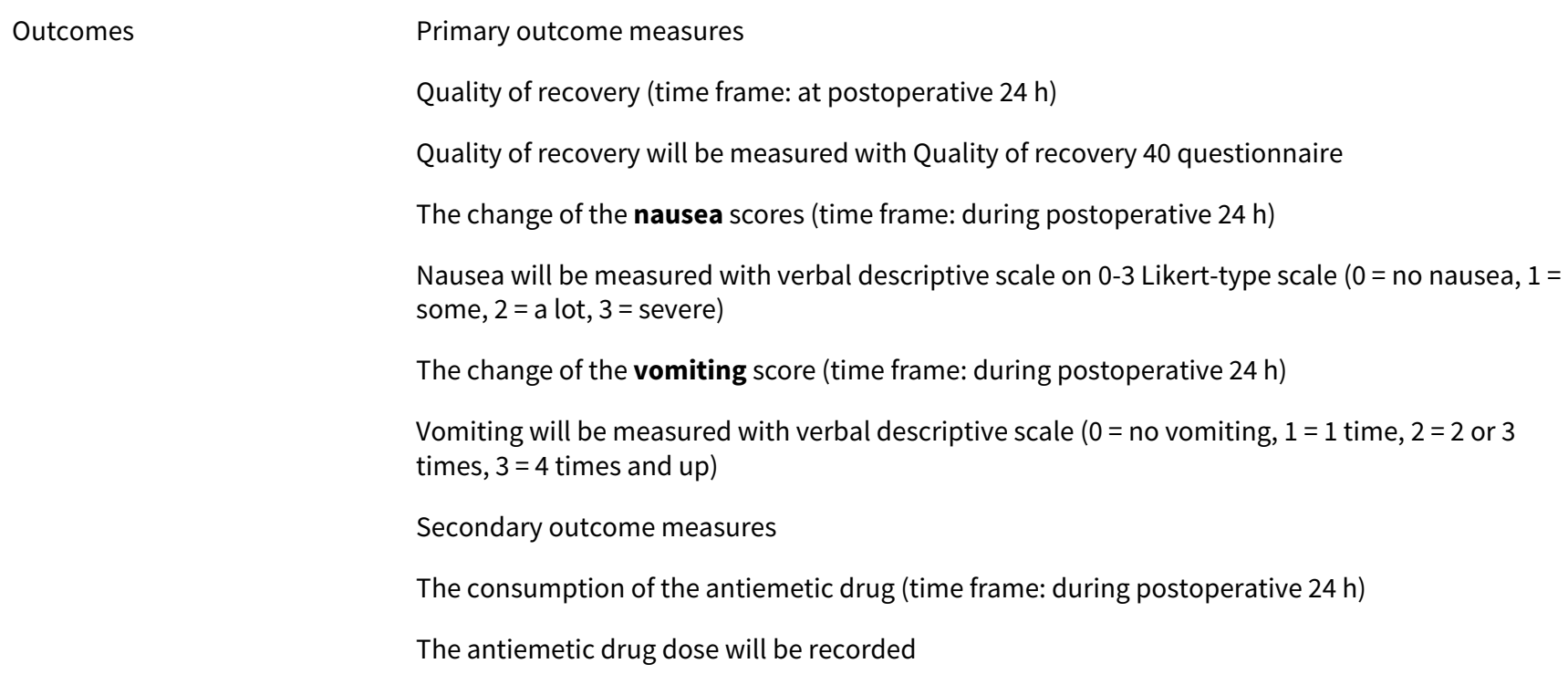


DATA AND ANALYSES

Comparison 1. Aromatherapy versus placebo

\begin{tabular}{lllll}
\hline Outcome or subgroup title & No. of studies & $\begin{array}{l}\text { No. of partici- } \\
\text { pants }\end{array}$ & Statistical method & Effect size \\
\hline $\begin{array}{llll}1 \text { Nausea severity at end of treatment } \\
\text { n }\end{array}$ & 6 & 241 & $\begin{array}{l}\text { Std. Mean Difference (IV, } \\
\text { Random, 95\% Cl) }\end{array}$ & $-0.22[-0.63,0.18]$ \\
\hline $\begin{array}{l}\text { 2 Duration of nausea measured as nau- } \\
\text { sea-free at the end of treatment }\end{array}$ & 4 & 193 & $\begin{array}{l}\text { Risk Ratio (M-H, Random, } \\
95 \% \text { Cl) }\end{array}$ & $3.25[0.31,34.33]$ \\
\hline $\begin{array}{l}\text { 3 Proportion requiring rescue antiemet- } \\
\text { ics }\end{array}$ & 7 & 609 & $\begin{array}{l}\text { Risk Ratio (M-H, Random, } \\
95 \% \text { Cl) }\end{array}$ & $0.60[0.37,0.97]$ \\
\hline
\end{tabular}

Analysis 1.1. Comparison 1 Aromatherapy versus placebo, Outcome 1 Nausea severity at end of treatment.

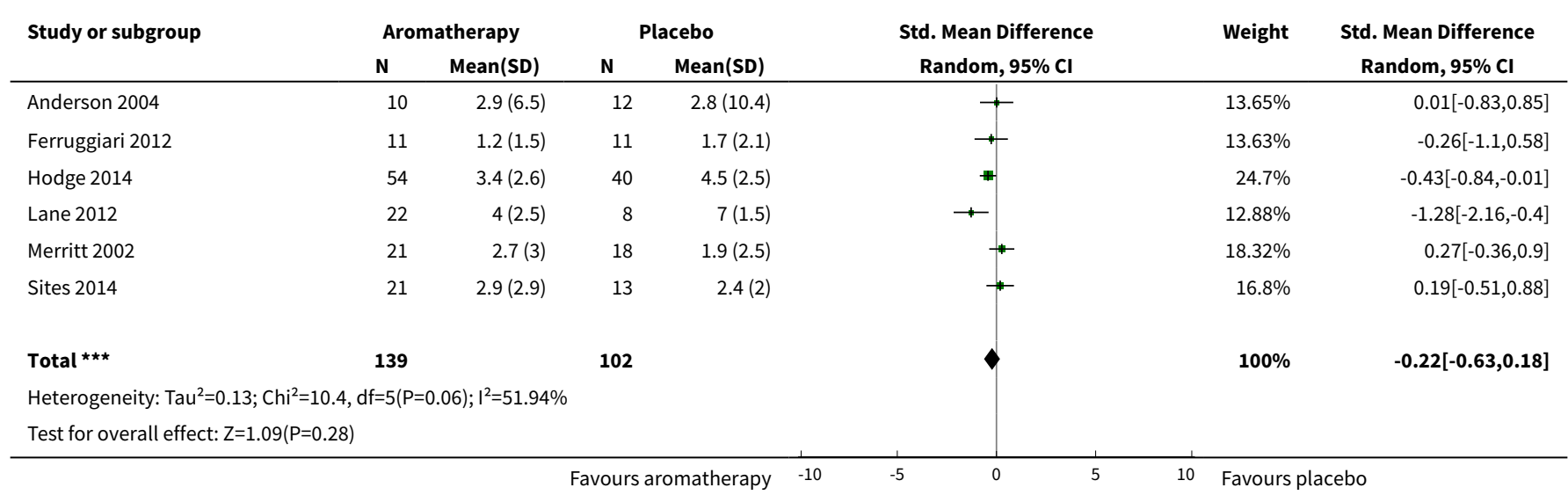

Analysis 1.2. Comparison 1 Aromatherapy versus placebo, Outcome 2

Duration of nausea measured as nausea-free at the end of treatment.

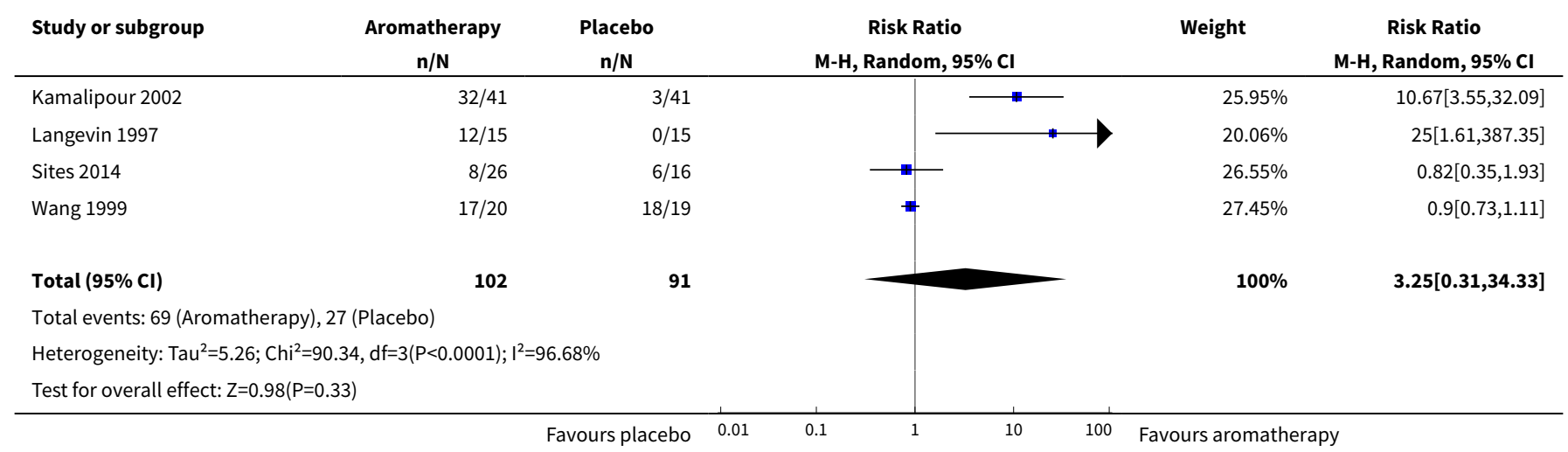


Analysis 1.3. Comparison 1 Aromatherapy versus placebo, Outcome 3 Proportion requiring rescue antiemetics.

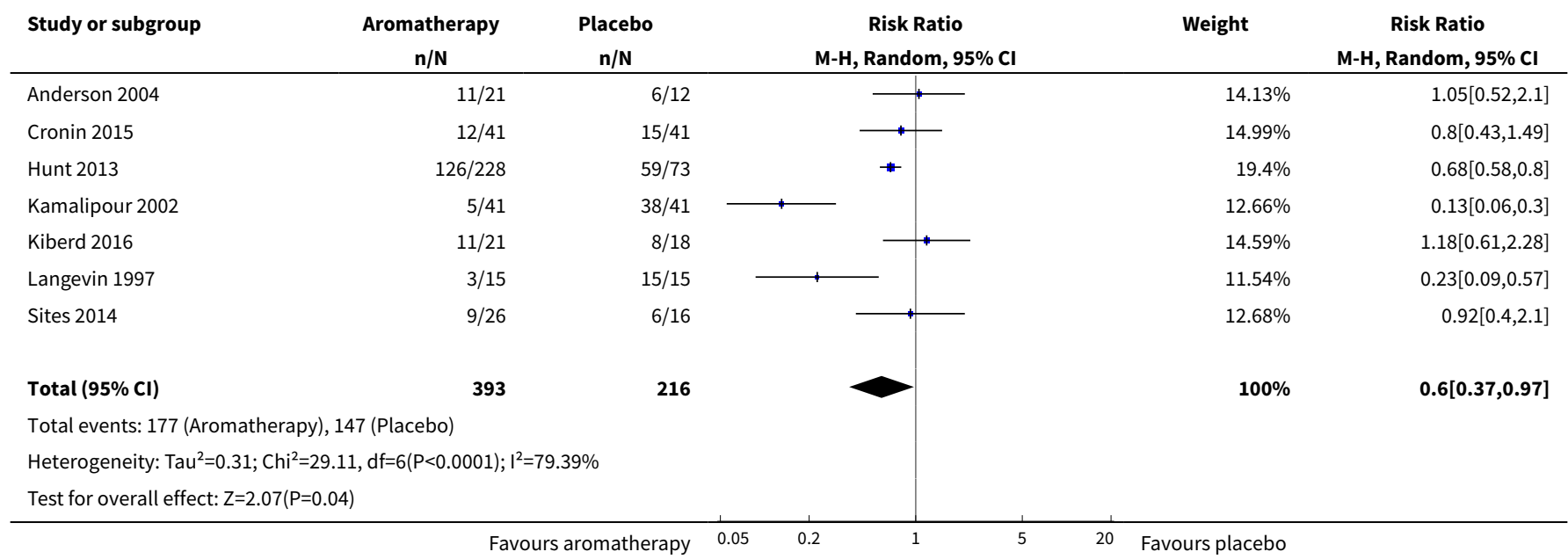

Comparison 2. Peppermint versus placebo

\begin{tabular}{lllll}
\hline Outcome or subgroup title & No. of studies & $\begin{array}{l}\text { No. of partici- } \\
\text { pants }\end{array}$ & Statistical method & Effect size \\
\hline $\begin{array}{l}1 \text { Nausea severity at } 5 \text { minutes post-ini- } \\
\text { tial treatment }\end{array}$ & 4 & 115 & $\begin{array}{l}\text { Std. Mean Difference (IV, Ran- } \\
\text { dom, 95\% Cl) }\end{array}$ & $-0.18[-0.86,0.49]$ \\
\hline
\end{tabular}

Analysis 2.1. Comparison 2 Peppermint versus placebo, Outcome 1 Nausea severity at 5 minutes post-initial treatment.

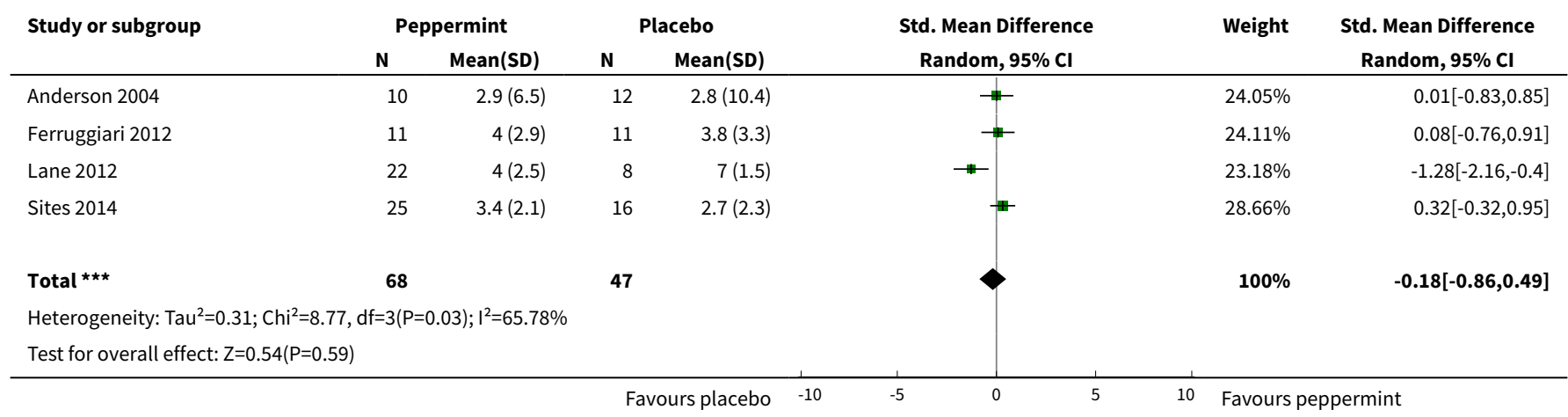

\section{Comparison 3. Isopropyl alcohol versus standard treatment for PONV}

\begin{tabular}{lllll}
\hline Outcome or subgroup title & No. of studies & $\begin{array}{l}\text { No. of partici- } \\
\text { pants }\end{array}$ & Statistical method & Effect size \\
\hline $\begin{array}{l}1 \text { Time (minutes) to 50\% reduction } \\
\text { in nausea score }\end{array}$ & 3 & 176 & $\begin{array}{l}\text { Std. Mean Difference (IV, Ran- } \\
\text { dom, 95\% Cl) }\end{array}$ & $-1.10[-1.43,-0.78]$ \\
\hline
\end{tabular}




\begin{tabular}{llllll}
\hline Outcome or subgroup title & No. of studies & $\begin{array}{l}\text { No. of partici- } \\
\text { pants }\end{array}$ & Statistical method & Effect size \\
\hline 2 Proportion requiring antiemetics & 4 & 215 & $\begin{array}{l}\text { Risk Ratio (M-H, Random, 95\% } \\
\mathrm{Cl})\end{array}$ & $0.67[0.46,0.98]$ \\
\hline 3 Patient satisfaction & 2 & 172 & $\begin{array}{l}\text { Risk Ratio (M-H, Random, 95\% } \\
\mathrm{Cl})\end{array}$ & $1.12[0.62,2.03]$ \\
\hline
\end{tabular}

Analysis 3.1. Comparison 3 Isopropyl alcohol versus standard treatment for PONV, Outcome 1 Time (minutes) to $50 \%$ reduction in nausea score.

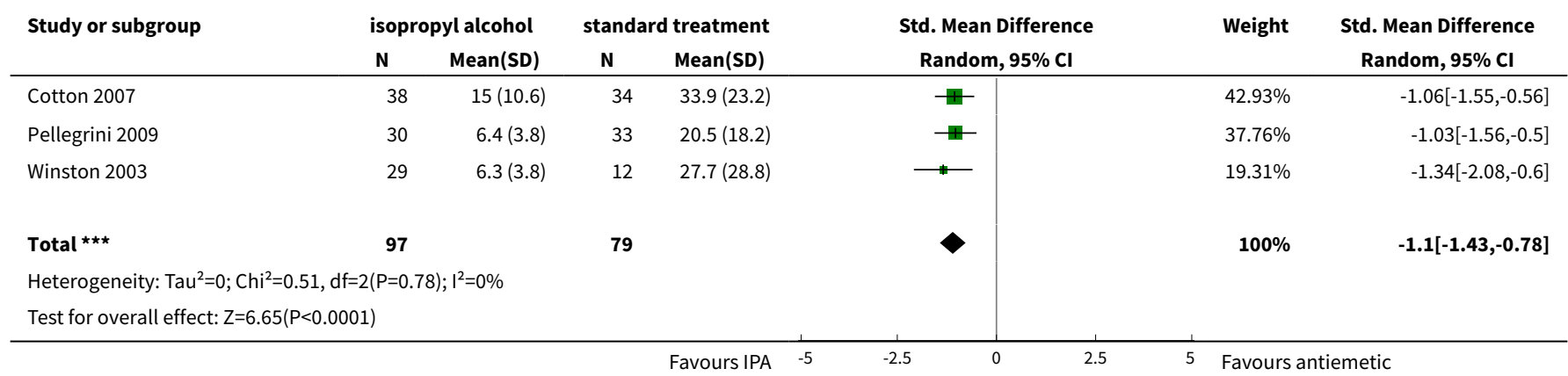

Analysis 3.2. Comparison 3 Isopropyl alcohol versus standard treatment for PONV, Outcome 2 Proportion requiring antiemetics.

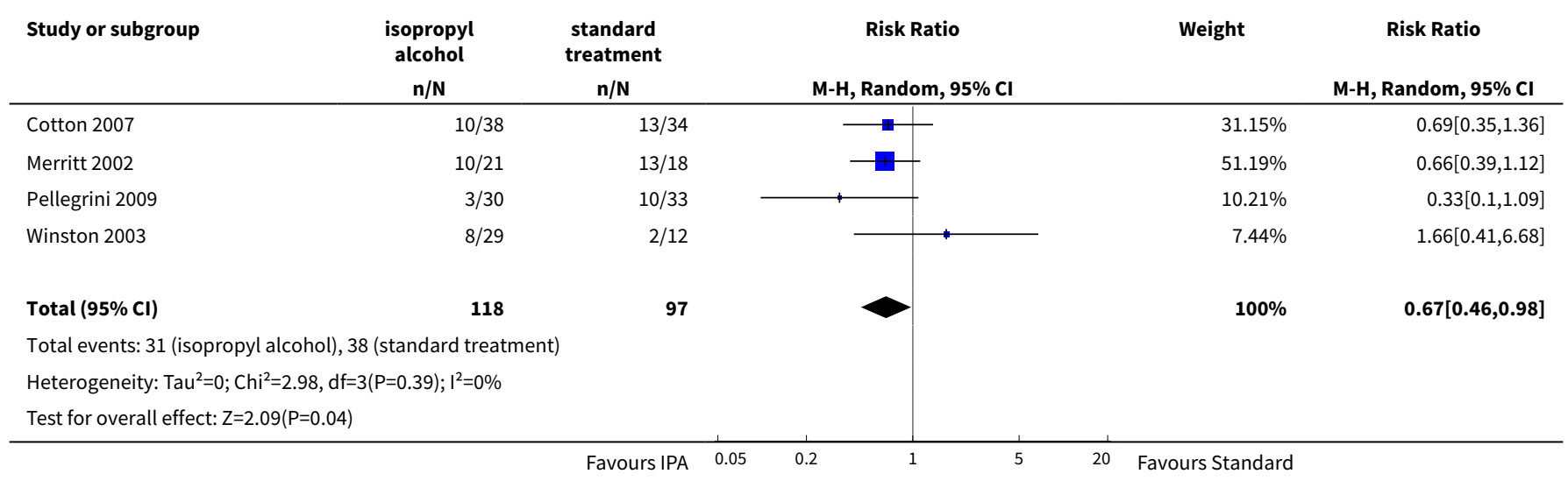

Analysis 3.3. Comparison 3 Isopropyl alcohol versus standard treatment for PONV, Outcome 3 Patient satisfaction.

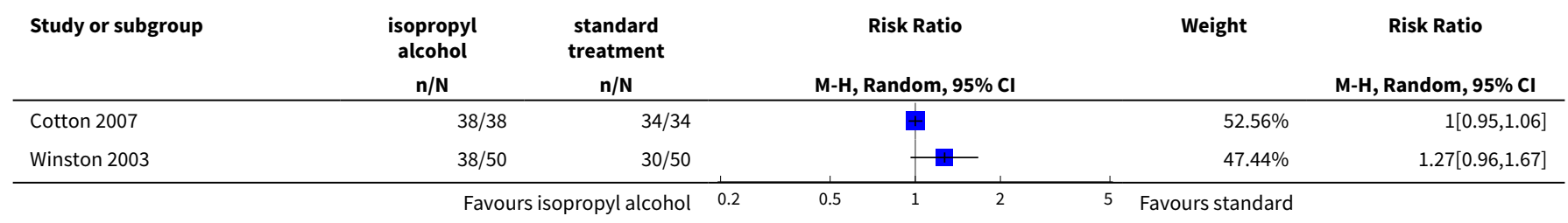




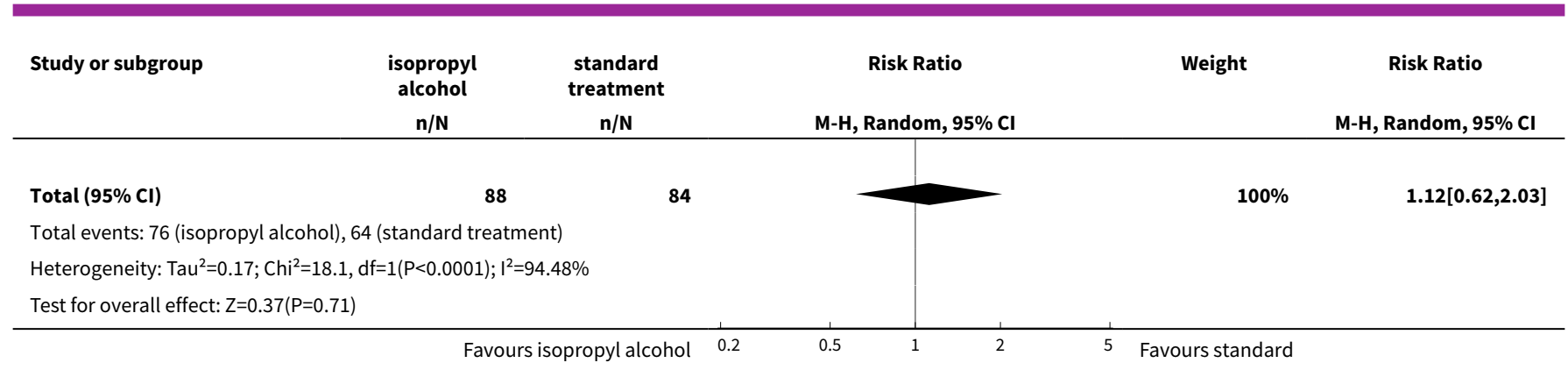

\section{Comparison 4. Isopropyl alcohol versus saline}

\begin{tabular}{lllll}
\hline Outcome or subgroup title & No. of studies & $\begin{array}{l}\text { No. of partici- } \\
\text { pants }\end{array}$ & Statistical method & Effect size \\
\hline $\begin{array}{l}1 \text { Proportion requiring rescue } \\
\text { antiemetics }\end{array}$ & 4 & 291 & $\begin{array}{l}\text { Risk Ratio (M-H, Random, } \\
95 \% \mathrm{Cl})\end{array}$ & $0.39[0.12,1.24]$ \\
\hline
\end{tabular}

Analysis 4.1. Comparison 4 Isopropyl alcohol versus saline, Outcome 1 Proportion requiring rescue antiemetics.

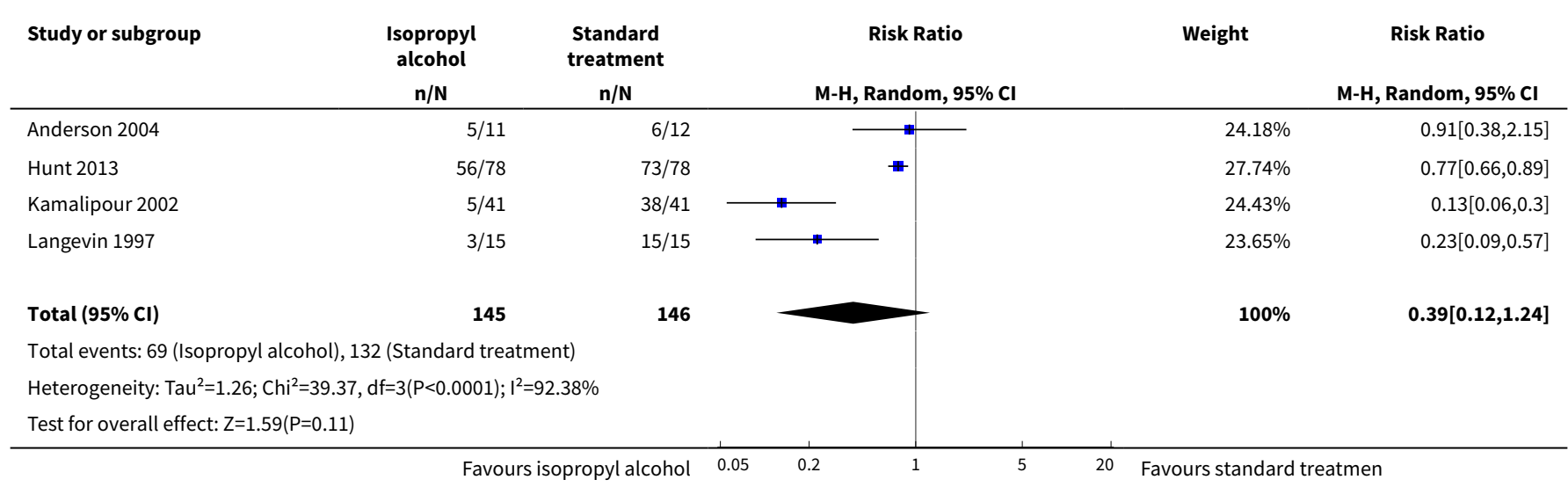

\section{ADDITIONAL TABLES}

Table 1. Patient satisfaction

\begin{tabular}{lllll}
\hline Study & Design & $\begin{array}{l}\text { Interven- } \\
\text { tion/compari- } \\
\text { son }\end{array}$ & Measure & Satisfied \\
\hline Anderson 2004 & RCT & $\begin{array}{l}\text { IPA/Saline/Pep- } \\
\text { permint }\end{array}$ & $\begin{array}{l}100 \text { mm VAS (0 mm extremely } \\
\text { dissatisfied; } 100 \text { mm fully satis- } \\
\text { fied) }\end{array}$ & IPA: 90.3 (SD: 14.9) \\
& & peppermint: 86.3 (SD: 32.3$)$ & saline: 83.7 (SD: 25.6$)$ \\
\hline Cotton 2007 & RCT & IPA/ondansetron & 4-point DOS & $\begin{array}{l}\text { Good or excellent: Intervention: } \\
\text { 38/38 }\end{array}$ \\
\hline
\end{tabular}


Table 1. Patient satisfaction

(poor, fair, good, excellent) Comparison: 34/34

\begin{tabular}{lllll}
\hline Pellegrini 2009 & RCT & $\begin{array}{l}\text { IPA/Promet- } \\
\text { hazine }\end{array}$ & $\begin{array}{l}\text { 5-point DOS } \\
(1=\text { totally unsatisfied, } 5=\text { to- } \\
\text { tally satisfied) }\end{array}$ & $\begin{array}{l}\text { Both groups reported median score } \\
4\end{array}$ \\
\hline Winston 2003 & RCT & IPA/ondansetron & 4-point DOS & Good or excellent: \\
& & (poor, fair, good, excellent) & Intervention: $38 / 50$ \\
& & & Comparison: $30 / 50$ \\
\hline
\end{tabular}

DOS: descriptive ordinal scale; IPA: isopropyl alcohol; RCT: randomized controlled trial; SD: standard deviation; VAS: visual analogue scale

\section{AP P E N DICES}

\section{Appendix 1. Peppermint oil}

Peppermint oil (Mentha piperita) is one of the oldest European herbs used for medicinal purposes. It is a hybrid species of spearmint (Mentha spicata) and water mint (Mentha aquatica) (Price 2007). The essential oil is derived by steam distillation of the fresh aerial parts of the flowering plant (Lis-Balchin 2006). Peppermint oil is listed in the European Pharmacopeia, British Pharmacopoeia, and United States Pharmacopeia. The active ingredients of the peppermint essential oil ( $0.4 \%$ to $5 \%$ ) are menthol ( $35 \%$ to $45 \%)$ and menthone (10\% to $30 \%)$ (Lis-Balchin 2006).

One possible mechanism of action of peppermint oil in the gastrointestinal system is inhibition of muscular contractions induced by serotonin and substance $P$ (Hills 1991). Early studies (1969) showed that direct administration of peppermint oil to the stomach (27 patients) caused relaxation of the lower oesophageal sphincter (Sigmund 1969). Subsequent studies have shown that administration (dose of $0.1 \mathrm{~mL}$ peppermint oil in $20 \mathrm{~mL}$ of saline) to the sigmoid colon in five participants produced increased intraluminal pressure, abdominal cramps, and the urge to defecate and urinate, suggesting widespread stimulation of smooth muscle (Rogers 1988). In another study, peppermint oil injected into the colon (20 participants) was shown to relieve colon spasms (Leicester 1982).

Peppermint oil has also been shown to accelerate the gastric emptying rate in dyspeptic patients as well as reduce the pain intensity (Dalvi 1991; May 1996). In a double-blind study, it was shown that the incidence of postoperative nausea in 18 gynaecological patients was significantly reduced in those that inhaled the peppermint oil (Tate 1997). In another randomized double blind study, a liquid herbal extract containing peppermint oil as the principal ingredient was found to relieve the symptoms of pain, nausea, belching, and heartburn (Westphal 1996).

\section{Appendix 2. Search strategies}

\section{Search strategy for CENTRAL, in the Cochrane Library}

\#1 MeSH descriptor Holistic Health explode all trees \#2 MeSH descriptor Aromatherapy explode all trees \#3 MeSH descriptor Medicine, Traditional explode all trees \#4 MeSH descriptor Naturopathy explode all trees \#5 MeSH descriptor Phytotherapy explode all trees \#6 MeSH descriptor Plants, Medicinal explode all trees \#7 MeSH descriptor Ginger explode all trees \#8 MeSH descriptor Mentha piperita explode all trees \#9 (Aromatherapy or "Holistic Health" or "Medicine, Traditional" or Naturopathy or Phytotherapy or "Plants, Medicinal" or Ginger or "Mentha piperita"):ti,ab \#10 (\#1 OR \#2 OR \#3 OR \#4 OR \#5 OR \#6 OR \#7 OR \#8 OR \#9)

$\# 11$ MeSH descriptor Postoperative Nausea and Vomiting explode all trees \#12 MeSH descriptor Postoperative Care explode all trees \#13 MeSH descriptor Recovery Room explode all trees \#14 MeSH descriptor Anesthesia Recovery Period explode all trees $\# 15$ (postoperative* or post surg* or surgical or recovery) and (vomit* or nausea* or sick ${ }^{\star}$ or PONV) \#16 (\#11 OR \#12 OR \#13 OR \#14 OR \#15) 


\section{Search Strategy for MEDLINE ( Ovid SP)}

1. exp Aromatherapy/ or exp Plants, Medicinal/ or exp Mentha piperita/ or exp Ginger/ or exp Complementary Therapies/ or exp Naturopathy/ or exp Phytotherapy/ or Holistic Health/ or (aromatherap* or ((plant* or traditional or complementary) adj3 medicin*) or ginger or peppermint or isopropyl alcohol or (holistic adj3 health) or naturopath^ or phytotherap* or (mentha adj3 piperita)).mp.

2. exp "Postoperative Nausea and Vomiting"/ or exp Anesthesia Recovery Period/ or (postoperative adj3 (care or nausea or vomit*)).mp. or (recovery adj3 (room or an?esthesia or period)).mp. or PONV

3. ((randomized controlled trial or controlled clinical trial).pt. or randomized.ab. or placebo.ab. or clinical trials as topic.sh. or randomly.ab. or trial.ti.) not (animals not (humans and animals)).sh.

4. 1 and 2 and 3

\section{Search strategy for Embase (Ovid SP)}

1. exp aromatherapy/or exp alternative medicine/ or exp medicinal plant/ or exp Mentha piperita/ or exp peppermint/ or exp ginger/ or exp phytotherapy/ or (aromatherap* or ((plant* or traditional or complementary) adj3 medicin ${ }^{\star}$ ) or ginger or peppermint or isopropyl alcohol or (holistic adj3 health) or naturopath* or phytotherap* or (mentha adj3 piperita)).mp.

2. exp "postoperative nausea and vomiting"/ or exp anesthetic recovery/ or postoperative care/ or (postoperative adj3 (care or nausea or vomit $\left.^{\star}\right)$ ).mp. or (recovery adj3 (room or an?esthesia or period)).mp. or PONV

3. (randomized-controlled-trial/or randomization/or controlled-study/ or multicenter-study/or phase-3-clinical-trial/ or phase-4-clinical-

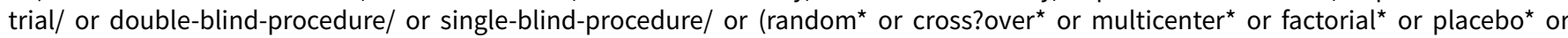
volunteer ${ }^{\star}$ ).mp. or ((singl* or doubl* or trebl $l^{\star}$ or tripl $\left.{ }^{\star}\right)$ adj3 (blind ${ }^{\star}$ or mask $\left.{ }^{\star}\right)$ ).ti,ab. or (latin adj square).mp.) not (animals not (humans and animals)).sh.

4. 1 and 2 and 3

\section{Search strategy for CINAHL (EBSCOhost)}

S1 (MH "Aromatherapy") or (MH "Holistic Health") or (MH "Medicine, Traditional+") or (MH "Medicine, Oriental Traditional+") or (MH "Medicine, Chinese Traditional+") or (MH "Medicine, Latin American Traditional") or (MH "Medicine, African Traditional") or (MH "Australian Traditional Medicine Society") or (MH "Medicine, Native American") or (MH "Traditional Healers") or (MH "Medicine, Arabic") or (MH "Naturopathy") or (MH "Medicine, Herbal+") or (MH "Plants, Medicinal+") or (MH "Medicine, Herbal+") or (MH "Ginger") or (MH "Peppermint") or ((aromatherap* or complementary or ginger or peppermint or isopropyl alcohol) and ((traditional or natural or alternat*) and (therap* or medicine or treatment $\left.\left.{ }^{\star}\right)\right)$ )

S2 (MH "Nausea and Vomiting+") or (MH "Nausea") or (MH "Postoperative Care+") or (MH "Post Anesthesia Care Units") or (MH "Anesthesia Recovery") or ((postoperative* or post surg* or surgical or recovery) and (vomit* or nausea* or sick* or PONV))

S3 (MH "Clinical Trials") or (random* or multicenter or prospective) or ((single or double or triple or treble) and (mask* or blind*)) S4 S1 AND S2 AND S3

5 Search strategy for CAM on PubMed (1966 to 2010)

\begin{tabular}{ll}
\hline 1 & Search aromatherapy Limits: Complementary Medicine \\
\hline 2 & Search peppermint Limits: Complementary Medicine \\
\hline 3 & Search ginger Limits: Complementary Medicine \\
\hline 4 & Search 1 OR 2 OR 3 Limits: Complementary Medicine \\
\hline 5 & Search postoperative nausea vomiting Limits: Complementary Medicine \\
\hline 7 & Search postoperative care Limits: Complementary Medicine \\
\hline 8 & Search 5 OR 6 Limits: Complementary Medicine \\
\hline
\end{tabular}


6 Search strategy for Meditext (Informit 1995 to 2010) (now Informit Health Collection from January 2010)

1. (aromatherapy OR natural medicine OR traditional medicine OR phytotherapy OR medicinal plant OR holistic health OR ginger OR peppermint)

2. ((postoperative nausea and vomiting) OR postoperative care OR recovery room OR post-anesthesia recovery period OR PONV)

3. 1 AND 2

\section{Search strategy for LILACS database}

(mentha piperita OR gengiber offinale OR peppermint OR ginger OR aromatherap\$ OR terap\$ herb\$ OR medic\$ herb\$ OR complement\$ medic\$ OR (essential AND oil))

\section{Search strategy for ISI Web of Science}

\#1. TS=((nausea or vomiting) SAME postoperativ*)

\#2. TS=(aromatherap* or complementary or ginger or peppermint or isopropyl alcohol ) AND TS=((traditional or natural or alternat*) and (therap* or medicine or treatment $\left.{ }^{\star}\right)$ )

\#3. \#1 AND \#2

\section{Appendix 3. Verification of Study Eligibility Form}

Aromatherapy for PONV

VERIFICATION OF STUDY ELIGILIBILITY

\section{AUTHOR AND YEAR}

\section{JOURNAL}

\section{TITLE}

\section{NAME/CODE OF REVIEWER}


IF YOU HAVE NOT ANSWERED YES TO ALL OF THE ABOVE QUESTIONS, YOU SHOULD EXCLUDE THE STUDY. IF YOU ANSWERED YES TO ALL, PLEASE CONTINUE.

Language: Does the study require translation before it can be appraised? Yes No

If yes, please arrange for translation before proceeding

PLEASE RECORD ALL STUDY DETAILS AS PER THE DATA MANAGEMENT FLOW SHEET

Appendix 4. Data Extraction Form

\begin{tabular}{|c|c|c|c|c|c|}
\hline \multicolumn{6}{|l|}{ AUTHOR AND YEAR } \\
\hline \multicolumn{6}{|l|}{ JOURNAL/SOURCE } \\
\hline \multicolumn{6}{|l|}{ TITLE } \\
\hline \multicolumn{6}{|l|}{ INITIALS OF REVIEWER: } \\
\hline STUDY METHOD RCT ? & Quasi RCT ? & ССТ ? & & & \\
\hline PARTICIPANT & & Group & Group & Group & Group \\
\hline \multicolumn{6}{|l|}{ Number in each group } \\
\hline \multicolumn{6}{|l|}{ Mean age and range } \\
\hline \multicolumn{6}{|l|}{ Gender } \\
\hline \multicolumn{6}{|l|}{ Population } \\
\hline \multicolumn{6}{|l|}{ Setting } \\
\hline Procedure/s & & & & & \\
\hline
\end{tabular}

Participants excluded in selection criteria

Participants who left study and reasons why

\begin{tabular}{lllll}
\hline INTERVENTION & Group & Group & Group & Group \\
\hline \hline
\end{tabular}


(Continued)

Aromatherapy type

\section{Method of administration}

Dose (if stated)

Times administered

Cost (if stated)

Administered by?

Control

\begin{tabular}{|c|c|c|c|c|}
\hline OUTCOMES & Group & Group & Group & Group \\
\hline \multicolumn{5}{|l|}{ Nausea (severity score?) } \\
\hline \multicolumn{5}{|l|}{ Vomiting (severity score?) } \\
\hline \multicolumn{5}{|l|}{ Adverse reactions } \\
\hline \multicolumn{5}{|l|}{ Cost } \\
\hline Rescue antiemetics used & & & & \\
\hline
\end{tabular}

\section{Author's Conclusion}

\section{WHAT'S NEW}

\begin{tabular}{lll}
\hline Date & Event & Description \\
\hline 3 March 2017 & $\begin{array}{l}\text { New citation required and conclusions } \\
\text { have changed }\end{array}$ & $\begin{array}{l}\text { New studies have introduced interventions not previously re- } \\
\text { viewed and changed the estimate of effectiveness. }\end{array}$ \\
\hline 3 March 2017 & New search has been performed & $\begin{array}{l}\text { New searches conducted to 3 March 2017, seven new studies } \\
\text { found and added. }\end{array}$ \\
\hline
\end{tabular}

\section{H I S T ORY}

Protocol first published: Issue 1, 2009

Review first published: Issue 4, 2012 


\begin{tabular}{lll}
\hline Date & Event & Description \\
\hline 15 March 2010 & Amended & $\begin{array}{l}\text { Change in author's name: Kristen Gibbons was previously known } \\
\text { as Kristen Gilshenan. Previous citation read: Hines S, Steels E, } \\
\text { Chang A, Gilshenan K }\end{array}$ \\
\hline
\end{tabular}

\section{CONTRIBUTIONS OF AUTHORS}

Conceiving the review: Sonia Hines (SH)

Designing the review: $\mathrm{SH}$

Co-ordinating the review: $\mathrm{SH}$

Undertaking manual searches: $\mathrm{SH}$

Screening search results: SH, Elizabeth Steels (ES)

Organizing retrieval of papers: $\mathrm{SH}$

Screening retrieved papers against inclusion criteria: SH, ES, Anne Chang (AC)

Appraising quality of papers: $\mathrm{SH}, \mathrm{ES}, \mathrm{AC}$

Abstracting data from papers: SH, ES, Kirsten Gibbons (KG)

Writing to authors of papers for additional information: $\mathrm{SH}$

Providing additional data about papers: $\mathrm{SH}, \mathrm{AC}$

Obtaining and screening data from unpublished studies: SH, ES

Data management for the review: $\mathrm{SH}$

Entering data into Review Manager 5 (RevMan 2014): SH, KG

Analysis of data: $\mathrm{SH}, \mathrm{ES}, \mathrm{KG}$

Interpretation of data: $\mathrm{SH}, \mathrm{ES}, \mathrm{AC}, \mathrm{KG}$

Writing the review: $\mathrm{SH}, \mathrm{AC}, \mathrm{KG}$

Securing funding for the review: $\mathrm{SH}$

Performing previous work that was the foundation of the present study: $\mathrm{SH}$

Guarantor for the review (one author): SH

Statistical analysis: KG, AC, SH

\section{DECLARATIONS OF INTEREST}

Sonia Hines: Queensland Health Nursing and Midwifery Research Grant received by Sonia Hines in 2008 to assist with the conduct of the original review (AUD 5906) (Hines 2012). The granting body had no influence on the findings of this review.

Elizabeth Steels: no conflict of interest is known

Anne Chang: no conflict of interest is known

Kristen Gibbons: no conflict of interest is known

\section{SOURCES OF SUPPORT}

\section{Internal sources}

- Nursing Research Centre, Mater Health Services, Australia.

Time and facilities. 


\section{External sources}

- Queensland Health, Australia.

Nursing and Midwifery Research Grant $(\$ 5906)$ awarded to Sonia Hines

\section{DIFFERENCES BETWEEN PROTOCOLANDREVIEW}

The original protocol (Hines 2009) stated "We will judge the study quality using a validated critical appraisal checklist developed by the Joanna Briggs Institute and based on the work of The Cochrane Collaboration and the Centre for Reviews and Dissemination (Figure 2). This checklist assesses selection, allocation, treatment, and attrition biases". Due to changes in Cochrane requirements, we have used the Cochrane 'Risk of bias' assessment instead.

We had originally planned to search the website www.nhmrc.gov.au/nics/asp/index.asp, however this no longer exists and we searched www.anzctr.org.au/Default.aspx instead.

\section{INDEX TERMS}

\section{Medical Subject Headings (MeSH)}

2-Propanol [ ${ }^{*}$ administration \& dosage]; Administration, Inhalation; Antiemetics [*administration \& dosage]; Aromatherapy [*methods]; Controlled Clinical Trials as Topic; Plant Oils [ ${ }^{\star}$ administration \& dosage]; Postoperative Nausea and Vomiting [ ${ }^{\star}$ therapy]; Randomized Controlled Trials as Topic; Salvage Therapy [methods]

\section{MeSH check words}

Humans 